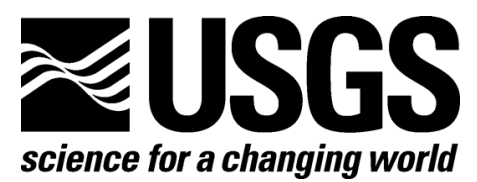

\title{
Seismic Hazard Maps for Seattle, Washington, Incorporating 3D Sedimentary Basin Effects, Nonlinear Site Response, and Rupture Directivity
}

By Arthur D. Frankel, William J. Stephenson, David L. Carver, Robert A. Williams, Jack K. Odum, and Susan Rhea

Open-File Report 2007-1175

U.S. Department of the Interior

U.S. Geological Survey 


\section{U.S. Department of the Interior \\ DIRK KEMPTHORNE, Secretary}

\section{U.S. Geological Survey \\ Mark D. Myers, Director}

U.S. Geological Survey, Reston, Virginia 2007

For product and ordering information:

World Wide Web: http://www.usgs.gov/pubprod

Telephone: 1-888-ASK-USGS

For more information on the USGS - the Federal source for science about the Earth, its natural and living resources, natural hazards, and the environment:

World Wide Web: http://www.usgs.gov

Telephone: 1-888-ASK-USGS

Suggested citation:

Frankel, A.D., Stephenson, W.J., Carver, D.L., Williams, R.A., Odum, J.K, and Rhea, S., 2007, U.S. Geological Survey Open-File Report 2007-1175, 77 p. , 3 pls.

Any use of trade, product, or firm names is for descriptive purposes only and does not imply endorsement by the U.S. Government.

Although this report is in the public domain, permission must be secured from the individual copyright owners to reproduce any copyrighted material contained within this report. 


\section{Contents}

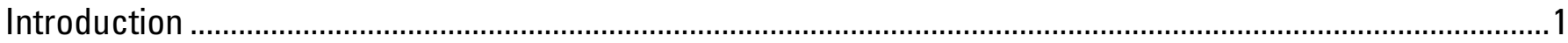

Seismic Sources and Logic Tree ................................................................................................................

Methodology of Including 3D Basin Effects, Nonlinear Site Response, and Rupture Directivity in Probabilistic Seismic Hazard Assessment (PSHA) .....................................................................................

PSHA with Site and Source Dependent Amplific ation .................................................................................

PSHA Procedure for Spatially-Smoothed Seismicity and Cascadia subduction zone ...................................

Nonlinear Site Response and PSHA .................................................................................................

PSHA Procedure for Seattle and South Whidbey Island Faults ....................................................................

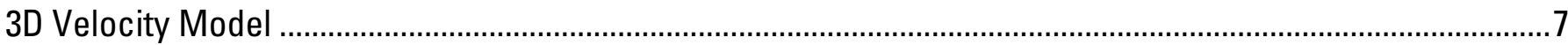

Validation of 3D Velocity Model.................................................................................................................

3D Simulations for Seattle Fault Earthquakes ..............................................................................................11

Validation of Finite-Fault Procedure Using the Northridge Earthquake..........................................................14

3D Simulations for Gridded Seismicity ..................................................................................................... 14

3D Simulations for Cascadia Subduction Zone Earthquakes ......................................................................15

3D Simulations for South Whidbey Island Fault...........................................................................................16

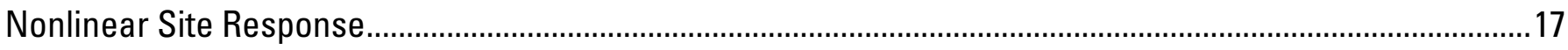

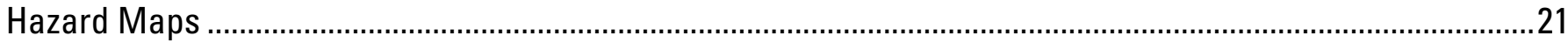

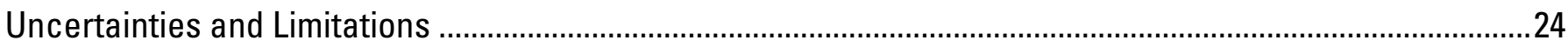

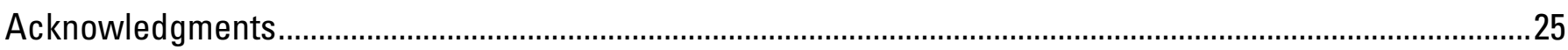

References

\section{Figures}

1. Earthquake epicenters used in study ……….....................................................................................

2. Map of Seattle with surficial geology, place names, and locations of stations ...........................................31

3. Amplification as function of back azimuth to earthquake .......................................................................32

4. Logic tree used to characterize uncertainties in earthquake source …….................................................33

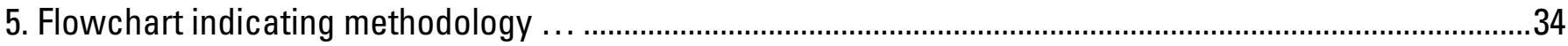

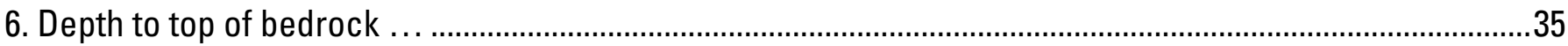

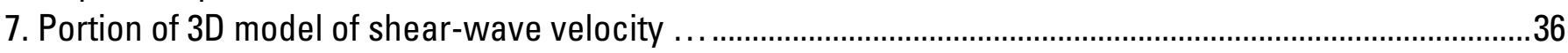

8. Synthetic and observed waveforms for the $2001 \mathrm{M} 6.8$ Nisqually earthquake ...........................................

9. Comparison between predicted and observed peak velocities for the Nisqually earthquake ......................38

10. Puget Sound region showing peak values of ground velocity from 3D simulation of

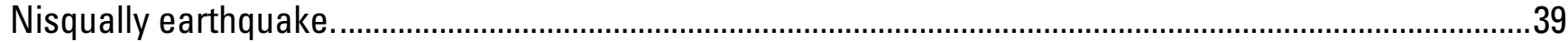

11. Predicted spectral ratios from 3D simulations plotted against observed ratios. ........................................40

12. Standard deviations of the spectral amplific ation for four modeled earthquakes.........................................41

13. Synthetic and observed velocity seismograms at station LAP ................................................................42

14. Map showing floating rupture zones along the Seattle fault.....................................................................4

15. Slip distributions and maps of amplifications for two 3D simulations of Seattle fault earthquakes.

16. Comparison of amplification maps for two rupture velocities for Seattle fault earthquakes. 
17. Comparison of amplification maps for simulations with different dips of the Seattle fault .45

18. Geometrical average and standard deviation of the amplifications derived from simulations of Seattle fault earthquakes.

19. Predicted and observed spectral amplitude ratios for the Northridge, California earthquake

20. Epicenters of earthquakes used in 3D simulations for background seismicity..

21. Amplification maps from 3D simulations for earthquakes at four azimuths.

22. Amplification maps from 3D simulations for earthquakes at different depths. .50

23. Seismograms from 3D simulation showing effects of Seattle basin. .51

24. Locations of point sources along the Cascadia subduction zone used in 3D simulations. 52

25. Amplification maps for five Cascadia point sources. .53

26. Thickness of fill and Holocene alluvium. .54

27. Average shear-wave velocity with depth for fill/alluvium sites. .55

28. Examples of shear-wave velocity profiles used for SHAKE. .56

29. Response spectral amplification predicted for station HAR from SHAKE. 57

30. Predicted and observed amplific ations at soft-soil sites. .58

31. Seismic hazard map for Seattle from this study compared to 2002 national seismic hazard map for rock sites.

32. Seismic hazard maps for Seattle for $1 \mathrm{~Hz}$ spectral acceleration with $2 \%$ probability of exceedance in 50 years.

33. Seismic hazard maps for Seattle for $1 \mathrm{~Hz}$ spectral acceleration with $10 \%$ probability of exceedance in 50 years.

\section{Tables}

1. Earthquakes modeled using $3 \mathrm{D}$ simulations 61

2. Locations of stations used in study. 62

3. Rock-site attenuation relations used for various earthquake sources, with weights in parentheses (based on 2002 national seismic hazard maps).

4. Amplification factors used for site at $47.581^{\circ} \mathrm{N}, 122.357^{\circ} \mathrm{W}$, near station $H A R$, with respect to the top of the $3 \mathrm{D}$ velocity model 63

Appendix 64

\section{Over-Sized Plates}

1. Seismic hazard map of Seattle, Washington, $1 \mathrm{~Hz}$ Spectral Acceleration with $2 \%$ Probability of Exceedance in 50 Years

2. Seismic hazard map for Seattle, Washington, $1 \mathrm{~Hz}$ Spectral Acceleration with 5\% Probability of Exceedance in 50 Years 
3. Seismic hazard map for Seattle, Washington, $1 \mathrm{~Hz}$ Spectral Acceleration with $10 \%$ Probability of Exceedance in 50 Years 


\section{Seismic Hazard Maps for Seattle, Washington, Incorporating 3D Sedimentary Basin Effects, Nonlinear Site Response, and Rupture Directivity}

By Arthur D. Frankel, William J. Stephenson, David L. Carver, Robert A. Williams, Jack K. Odum, and Susan Rhea

\section{Introduction}

It is clear from recent seismological research that sedimentary basins strongly affect the amplitude and duration of earthquake ground motions and are responsible for certain damage patterns caused by earthquakes (Graves and others 1998; Stephenson and others, 2006). Furthermore, it has been recognized for many decades that shallow geological units such as artificial fill amplify ground shaking and that the direction of rupture propagation on a fault (directivity; see Wald and others, 1996) is an important cause of large-velocity ground-motion pulses that can damage buildings. As seismologists develop a predictive understanding of these phenomena, they can be quantitatively incorporated into probabilistic assessments of seismic hazard.

In this paper we include these effects in seismic hazard maps for Seattle, Washington, which we call urban seismic hazard maps. Urban seismic hazard maps provide more spatiallydetailed information about seismic hazard than the national seismic hazard maps, which use a firmrock site condition and ground-motion relations that don't explicitly include rupture directivity (Frankel and others, 2002a). However, our urban seismic hazard maps are not site-specific maps. They are based on models of sub-surface structure that are often interpolated from sub-surface data several hundreds of meters from a given site, as opposed to a site-specific study where a shearwave velocity profile is measured at that particular location. The limitations of these maps are described in detail in the last section of this report.

The Seattle maps presented in this document use the same set of faults and distributedearthquake sources as in the 2002 national seismic hazard maps (Frankel and others, 2002a). The new maps include the effects of the Seattle basin, the young alluvium, artificial fill, and rupture directivity on the Seattle fault. A summary of the methodology and preliminary maps were presented in Frankel and others (2006).

This is the first set of probabilistic seismic hazard maps that we are aware of that directly incorporate the results of 3D wave-propagation simulations. Several studies have shown that ground motions for sites in Seattle are strongly influenced by the 3D structure of the Seattle basin (Frankel and Stephenson, 2000; Pitarka and others, 2004; Pratt and Brocher, 2006). Two major sedimentary basin effects are: (1) the production of basin surface waves by the conversion of incident shear waves (S-waves) at the edge of the basin and (2) the focusing of S-waves by the edges of the basin. Frankel and others (2002b) documented the strong basin surface waves recorded for sites in the Seattle basin from the 2001 Nisqually earthquake. These surface waves were generated at the southern edge of the Seattle basin and they dominated the velocity waveforms at frequencies of about $1 \mathrm{Hertz}(\mathrm{Hz})$, for stiff soil sites in the Seattle basin. Stephenson and others 
(2006) showed how the focusing of S-waves at the southern edge of the Seattle basin likely caused the enhanced damage to chimneys in West Seattle during the Nisqually earthquake.

Another indicator of the importance of 3D basin effects for Seattle is the dependence of amplification in the basin on the azimuth to the earthquake. We determined the amplification for 19 earthquakes in the Puget Sound region (fig. 1, table 1) using spectral ratios. The data come primarily from the Seattle Urban Seismic Array that we operate (fig. 2) while some of the data are from the Pacific Northwest Seismic Network operated by the University of Washington, which is part of the Advanced National Seismic System. Station locations are given in table 2. These amplifications were determined from Fourier spectra derived from the root-mean-square average of the horizontal seismograms at each station and were calculated by dividing the spectral amplitudes, after correction for distance, by those at station ALK, which is a hard-rock site. Although ALK has anomalously low spectral amplitudes at $5 \mathrm{~Hz}$, it has similar amplitudes as other rock sites at $1 \mathrm{~Hz}$ (see Frankel and others, 2002b). The spectral amplitudes were adjusted to a common sourcereceiver distance assuming a geometrical spreading of 1/distance and the regional Q values reported by Atkinson (1995), which are $\mathrm{Q}=380 \mathrm{f}^{0.39}$, where $\mathrm{f}$ is frequency. Figure 3 shows the results for stiff-soil sites. This figure demonstrates that for sites in the Seattle basin, earthquakes from the south and southwest produce higher amplifications, on average, than earthquakes from other azimuths. This pattern cannot be explained by velocity models with horizontal layers. This is yet another indication that it is important to include 3D sedimentary basin effects when assessing the seismic hazard of Seattle.

Previous studies for Seattle have also demonstrated the importance of amplification from shallow, soft-soil deposits of artificial fill and Holocene alluvium (Frankel and others, 1999; Hartzell and others, 2000). During the Nisqually earthquake, these soft soil deposits amplified 1 $\mathrm{Hz}$ ground motions by factors of 5-7, relative to the rock site SEW (Frankel and others 2002b). Hartzell and others (2002) made maps of ground motions for a magnitude 6.5 earthquake on the Seattle fault, combining the results of 3D simulations with nonlinear site response for shallow deposits.

In probabilistic seismic hazard assessment (PSHA), a seismic hazard curve (or set of curves) is calculated for each site that describes the probabilities of exceeding various values of ground motions. PSHA considers all potential sources of earthquakes that can affect a site. The inputs to PSHA consist of information on the recurrence times for each type of source (for example, a fault, an areal source zone, a grid of seismicity rates) affecting a site, as well as a description of the ground motions expected at that site when an earthquake occurs. This process is described in more detail below. The ground motions with any specified probability of exceedance can be determined from the hazard curve for that site.

The probabilistic seismic hazard maps presented here are for $1 \mathrm{~Hz}$ response spectral accelerations (S.A.) with 5\% of critical damping. These maps include 3D basin effects, rupture directivity, and nonlinear amplification for soft-soil deposits. The 3D velocity model developed for this study is not detailed enough for accurate 3D simulations much above $1 \mathrm{~Hz}$. Furthermore, the computing time would be excessive for 3D simulations using the larger grids needed for simulations above $1 \mathrm{~Hz}$. We determined the seismic hazard for 7236 sites with a spacing of $280 \mathrm{~m}$. Approximately 500 3D simulations were conducted. For each site, we calculated a set of hazard curves. The final products are maps depicting $1 \mathrm{~Hz}$ S.A. with $10 \%, 5 \%$, and $2 \%$ probabilities of exceedance in 50 years (pl. 1, pl. 2, pl. 3). 


\section{Seismic Sources and Logic Tree}

The set of seismic sources used here is almost the same as those used in the national seismic hazard maps: 1) spatially smoothed shallow seismicity (depth, $\mathrm{d}<35 \mathrm{~km}$ ), 2) spatially smoothed deep seismicity (d $>35 \mathrm{~km}), 3$ ) earthquakes on the Seattle fault zone, 4) earthquakes on the Cascadia subduction zone, and 5) earthquakes on the South Whidbey Island fault. The one difference is that we did not use a Puget Sound areal source zone with a seismicity rate based on the north-south convergence rate determined by GPS measurements. This model was given half weight in the 2002 maps, with half weight assigned to the shallow gridded seismicity. Note that these two approaches yielded very similar hazard results for Seattle (Frankel and others, 2002).

We use a revised version of the logic tree applied in the national maps (see Frankel and others, 2002a). Logic trees are commonly used in PSHA studies to incorporate alternative models of seismic sources and ground-motion models. Figure 4 shows the logic tree that characterizes the epistemic (modeling) uncertainty of the earthquake sources. Nodes of the logic tree include the recurrence relation on individual crustal faults (characteristic versus truncated Gutenberg Richter), the eastern location of the Cascadia subduction zone (CSZ) and the magnitude of great earthquakes on the CSZ. Compared to the 2002 national seismic hazard maps, we added a node allowing for two dips $\left(45^{\circ}\right.$ and $\left.30^{\circ}\right)$ of the frontal portion of the Seattle fault and two depths (10 and $\left.15 \mathrm{~km}\right)$ for the shallow gridded seismicity (see below).

We also developed a logic tree for the ground-motion estimation. This includes three different approaches for determining the nonlinear response at soft soils (see below) and multiple ground-motion attenuation relations for rock sites. Note that we used the same set of rock-site attenuation relations as in the national maps (table 3; see Frankel and others, 2002a). These attenuation relations differ between crustal sources, the Cascadia subduction zone, and deep earthquakes on the Benioff zone.

We had to make some compromises to reduce the number of earthquake scenarios so that the 3D simulations could be completed in a reasonable amount of time, while still capturing the salient features of the hazard. These compromises will be described in the following sections.

The resulting maps are similar to the 2002 national seismic hazard maps for the geometrical average of the three rock sites of our array (ALK, SEW, and BRI), since all of the amplification maps are divided by the average value at these sites. The average value at these three sites is not quite identical to that from the national maps, since some of the floating earthquake scenarios were not used in the urban hazard maps.

\section{Methodology of Including 3D Basin Effects, Nonlinear Site Response, and Rupture Directivity in Probabilistic Seismic Hazard Assessment (PSHA)}

\section{PSHA with Site and Source Dependent Amplification}

Probabilistic seismic hazard assessment (PSHA) involves the calculation of the probabilities of exceeding specified values of ground motions or spectral accelerations for a set of earthquake sources. PSHA requires estimates of the recurrence time as a function of magnitude for each source that affects a site. It also requires a set of attenuation relations that gives the median ground 
motions expected for a given distance and magnitude, as well as its uncertainty. For the national seismic hazard maps, we used attenuation relations developed from regressions of strong-motion data recorded at rock-sites for crustal earthquakes primarily in California. In making the Seattle urban maps, we applied factors to these rock-site attenuation relations that quantified sedimentary basin response, nonlinear soil response, and rupture directivity. These factors are derived from 3D simulations and from a nonlinear site response calculation.

Figure 5 shows a flowchart illustrating the general procedure, which is described in more detail below. Median ground motions are calculated for each site by modifying the median values from rock-site attenuation relations using amplification maps derived from the 3D simulation for that particular earthquake scenario. A scenario is defined here as a particular hypocenter, magnitude, source time function, and focal mechanism for the case of a point source and as a particular rupture zone, slip distribution, rupture history, and hypocenter (rupture initiation point) for a finite source. The recurrence rate for each scenario is the other key input into the probabilistic seismic hazard calculation. This calculation produces seismic hazard curves, which describe the frequencies of exceeding a set of ground-motion values. In turn, these hazard curves can be used to produce a map of probabilistic ground motions with any specified probability of exceedance.

A key issue in PSHA is the random variability of ground motions for a given magnitudedistance combination. This aleatory uncertainty in ground motions is important in the determination of the probability of exceeding a given ground motion at a site. Ideally, this uncertainty would be calculated from an exhaustive set of 3D simulations that involved multiple velocity models that reflected our uncertainty of the basin structure and the shallow velocity under each site. In addition, a far larger set of rupture models would be required to formally determine the aleatory uncertainty. Our approach here is to use the published values of uncertainty from the generic rock-site attenuation relations. These are the values used in the national seismic hazard maps. One advantage of this approach is that the probabilistic ground motions averaged over the three rock sites will be approximately equal to those in the national seismic hazard maps. Thus, we are modifying the median values from rock-site attenuation relations to account for basin effects, nonlinear site response, and rupture directivity, but are using the uncertainty derived from the standard deviation of rock-site strong-motion data relative to the prediction of the rock-site attenuation relations.

\section{PSHA Procedure for Spatially-Smoothed Seismicity and Cascadia subduction zone}

The fundamental equation of PSHA determines the annual frequency $\lambda\left(u \geq u_{0}\right)$ of exceeding ground motion $u_{0}$ at a site from multiple faults or source locations by summing over source location and magnitude:

$$
\lambda\left(u \geq u_{0}\right)=\sum_{M} \sum_{\text {source }_{j}} \operatorname{rate}\left(M, \text { source }_{j}\right) P\left(u \geq u_{0} \mid \text { site }_{i}, \text { source }_{j}, M\right)
$$

where $\operatorname{rate}\left(M\right.$, source $\left._{j}\right)$ is the annual rate of occurrence for an earthquake with magnitude $M$ at source location $j$. This annual rate can be determined from either a time independent or time dependent calculation. Here we use time-independent earthquake probabilities (Poissonian distribution of inter-event times), so that the probability of exceeding ground motion $u_{0}$ in time $t$ equals $1-\mathrm{e}^{-\lambda t}$.

The second factor $(P)$ on the right hand side of equation 1 is the probability of having ground motions $u$ greater or equal to $u_{0}$ at site $i$, if an earthquake occurs at source location $j$ with magnitude $M$. In a typical PSHA calculation, this factor is determined using a set of standard attenuation (ground-motion prediction) relations where the ground motion amplitudes depend only 
on the magnitude and the distance from the site to the fault. Here we modify this term so that the ground motion amplitudes $u$ are also dependent on the site and earthquake locations.

We used 3D finite-difference simulations in the calculation of $u$ (1 Hz S.A.) for the 7236 sites and a large set of scenario earthquakes. We start with the ground motion predicted at each site $u_{\text {rock }}(M, D)$ from generic rock-site attenuation relations (for example, Abrahamson and Silva, 1997). Then we calculate the site- and source-specific amplification using the 3D simulations, so that

$$
u=u_{\text {rock }}(M, D) \mathrm{A}_{3 \mathrm{D}}\left(\text { site }_{i}, \text { source }_{j}\right)
$$

Here $\mathrm{A}_{3 \mathrm{D}}\left(\right.$ site $_{i}$, source $)$ is the amplification of the pseudo spectral acceleration (5\% damping) derived from each 3D simulation by taking the geometrical average of the two horizontal synthetic seismograms at each site. These values are averaged over a frequency range of 0.8 to $1.2 \mathrm{~Hz}$.

For the cases of the smoothed seismicity and the Cascadia subduction zone we corrected the amplitudes from the 3D simulations for geometrical spreading and Q. For each scenario earthquake, we determined a $1 \mathrm{~Hz}$ amplification map for Seattle from the 3D simulation, by adjusting the spectral amplification to a common source-receiver distance for geometrical spreading (1/distance) and attenuation using an average $\mathrm{Q}$ at $1 \mathrm{~Hz}$ for the upper crust of 380 . This is a representative value of the $\mathrm{Q}$ in the upper crust used in the 3D simulations (see below) and is also the same as the Q at $1 \mathrm{~Hz}$ found from earthquake data in the region by Atkinson (1995). We divided the amplification at each location by the geometrical average of the amplitude at the three rock sites (ALK, SEW, and BRI) of our Seattle Urban Seismic Array. It is necessary to correct for geometrical spreading and Q, because these amplification maps will also be applied to the hazard calculation for sources at different distances (but similar azimiths) than those used in the simulations. In the hazard calculation itself, at each site the rock-site ground motion is calculated using the generic attenuation relations, and then the site and source specific amplification is applied from the $3 \mathrm{D}$ simulations.

\section{Nonlinear Site Response and PSHA}

The velocity model used in the 3D simulations does not contain the relatively thin layers of artificial fill and Holocene alluvium that are present in parts of Seattle. These sites are denoted as soft soil sites. We modified the amplifications determined from the 3D simulations with the nonlinear amplifications calculated for these soft soil sites. Thus the ground motion for these sites is found from:

$$
u_{0}=u_{\text {rock }}(M, D) \mathrm{A}_{3 \mathrm{D}}\left(\text { site }_{i}, \text { source }_{j}\right) \mathrm{A}_{\text {soft }}\left(\text { site }_{i}, \mathrm{PGA}_{\text {rock }}\right) .
$$

Here $\mathrm{A}_{\text {soft }}\left(\right.$ site $\left._{i}, \mathrm{PGA}_{\text {rock }}\right)$ is the nonlinear amplification for vertically-propagating shear waves.

We calculate these nonlinear amplification factors in three ways. The first method used is SHAKE (Schnabel and others, 1972; Idriss and Sun, 1992), a widely-used program that is based on the equivalent linear procedure. This program assumes vertically propagating shear waves. The amplification at each soft-soil site is derived from a shear-wave velocity (Vs) profile developed for each site using a model of the thickness of the fill/alluvium and an average shear-wave velocity profile found from seismic refraction studies (see below). This amplification (equation 3) is a function of the rock site peak ground acceleration, because of the nonlinearity of the shallow soil response. 
We multiplied the amplification derived from SHAKE by the amplification from the 3D simulations. This is not a perfect solution, since the seismograms from the $3 \mathrm{D}$ simulations contain surface waves as well as S-waves and SHAKE only considers amplification from vertically propagating S-waves. The best solution would be to have a 3D nonlinear simulation code. To our knowledge, such a code does not exist.

Our second method applied NEHRP (National Earthquake Hazards Reduction Program) amplification factors (see below) at the soft-soil sites that depend on the shear-wave velocity averaged over the top $30 \mathrm{~m}$ (Vs30). The NEHRP factors for $1 \mathrm{~Hz} \mathrm{S.A.} \mathrm{are} \mathrm{a} \mathrm{function} \mathrm{of} \mathrm{the} 1 \mathrm{~Hz}$ S.A. for a rock site, rather than the peak ground acceleration (PGA).

The third method we tried was based on the site amplification factors developed by Choi and Stewart (2005) using observations from strong-motion data. These factors depend on the Vs30 of the site and the PGA for a rock site.

We did not consider nonlinear amplification for stiff soil or rock sites. The stiff soil sites in Seattle generally have Vs30 values of greater than $300 \mathrm{~m} / \mathrm{s}$. We would expect minimal nonlinearity for these sites at $1 \mathrm{~Hz}$ S.A. based on the observations reported in Choi and Stewart (2005) and the modeling results described in Hartzell and others (2004).

\section{PSHA Procedure for Seattle and South Whidbey Island Faults}

One of the major features of the Seattle hazard maps is that they include the results of hundreds of 3D simulations for possible earthquakes on the Seattle fault. These simulations contain the effects of rupture directivity and the Seattle basin. The basic PSHA equation used for the Seattle fault is

$$
\lambda\left(u \geq u_{0}\right)=\sum_{M} \sum_{\text {rupture }_{j}} \frac{\operatorname{rate}(\mathrm{M})}{\mathrm{N}_{\mathrm{r}}(\mathrm{M})} P\left(u \geq u_{0} \mid \text { site }_{i}, \text { rupture }_{j}, M\right)
$$

where rate $(M)$ is the annual rate for earthquakes with magnitude $M$ on the Seattle fault and $N_{r}(M)$ is the number of scenarios for that magnitude. We need to divide by $\mathrm{N}_{\mathrm{r}}(\mathrm{M})$, since we require the rate of each scenario when doing the summation of the frequency of exceedance from each scenario. Here $u$ is derived from equations 2 and 3, but now $\mathrm{A}_{3 \mathrm{D}}$ also depends on the rupture scenario. For each scenario earthquake rupture, we considered different hypocenters (where the earthquake nucleates) and slip distributions (see below).

We determined a map of $1 \mathrm{~Hz}$ spectral amplification from each 3D simulation, by averaging pseudo-spectral acceleration values between 0.8 and $1.2 \mathrm{~Hz}$ and dividing by the average value at three rock sites. Again, the geometrical average of the two horizontal components was used. In contrast to the cases of the smoothed seismicity and the CSZ, we did not adjust the amplitudes from the Seattle fault 3D simulations for geometrical spreading and regional Q. For the Seattle fault scenarios we used the relative amplitudes from the simulations directly in the hazard calculations. The S.A. value at each site from each 3D simulation is divided by the average values in the 3D simulation for the three rock sites. In the hazard code, the ground motion at each site for each scenario is calculated by equation (2), with $\mathrm{A}_{3 \mathrm{D}}$ ( site $_{i}$, , $_{\text {ource }}$ ) being the normalized ground motions from each simulation. Now $u_{\text {rock }}(M, D)$ is the geometrical average of the values from the rock-site attenuation relations for that rupture scenario for the three rock sites. For soft-soil sites, these values are then multiplied by the nonlinear amplifications and inserted into the PSHA calculation (equation 4). 
For the South Whidbey Island fault we used the same formulation (no correction for geometrical spreading and Q), although many fewer scenarios were considered (see below), since this fault contributes less to the seismic hazard of Seattle.

\section{D Velocity Model}

A three-dimensional model for the $\mathrm{P}$ and S-wave velocities (Vp and Vs, respectively) and density was constructed for the Puget Sound region and for the Pacific Northwest (west of the Cascades front) using seismological, geological, and geophysical information. More details of the construction of the model are provided in Stephenson (in preparation). We started with the P-wave tomography results for the Puget Sound region of Ramachandran and others (2006). They used travel times of P-waves from various active source experiments (SHIPS) done in the region, as well as from local earthquakes. In general, the model for the Puget lowland was developed assuming three distinct geologic units: crystalline basement rocks, Tertiary sedimentary rock, and Quaternary deposits. For the crystalline basement rocks, we calculated $\mathrm{S}$-wave velocities from the P-wave velocities using the $\mathrm{Vp} / \mathrm{Vs}$ relations of Brocher (2005). The Vp/Vs of the Tertiary sedimentary rock in the Seattle basin was set to 2, consistent with findings from seismic refraction work. For the shallow portion of the Quaternary deposits, the $\mathrm{Vp} / \mathrm{Vs}$ ratios were derived from the average ratios found in shallow seismic refraction work in Seattle (Williams and others.1999 and unpublished data). The density was derived from Vp using the relationship of Brocher (2005).

Since the tomography results have relatively low resolution (large block size), we added a distinct velocity contrast across the frontal strand of the Seattle fault zone. We used the surface trace of the frontal strand defined by Blakely and others (2002) from aeromagnetic anomalies. A dip of 45 degrees to the south was assumed for the velocity contrast across the fault, which is the center of the range of dips of the velocity contrast indicated by various seismic imaging studies (e.g., Pratt and others, 1997; Johnson and others, 1999; Brocher and others 2004; ten Brink and others 2002).

We also included an explicit Vp and Vs contrast at the bottom of the Seattle basin at the $\mathrm{Vp}=4500 \mathrm{~m} / \mathrm{s}$ contour, consistent with the depth of the basin determined from gravity data by Richard Blakely (written comm., 2005). The Vp contrast is from the tomography results of Ramachandran and others, 2006). Vs below the base of the Seattle basin is derived from the Vp value using Brocher (2005). Vs above the base is set to $\mathrm{Vp} / 2$. The greatest depth of the bottom of the basin is about $8 \mathrm{~km}$.

A velocity contrast across the Moho at about $25 \mathrm{~km}$ depth was also specified in the model. The Vp values in the upper mantle were based on the tomography results of Stanley and others (1999) and the Moho depth was derived from Chulick and Mooney (2002). Vs values for the upper mantle were determined from Vp, using the relations of Brocher (2005).

To define the thickness of the Quaternary deposits, we used the depth to bedrock map derived by Johnson and others (1999), which is based on compilations of borehole and seismic reflection data by Jones (1996) and Yount and others (1985) and by new marine seismic reflection results. Figure 6 contains the depth to bedrock map (depth to base of Quaternary deposits) based on Johnson and others (1999). Note that the shallowest bedrock is located under portions of south Seattle, to the south of the northern strand of the Seattle fault. The deepest depth to bedrock is in the Seattle basin to the north of the Seattle fault zone.

We actually developed two mutually compatible velocity models. The first velocity model was for the Puget Sound region and was applied for all simulations except for the Cascadia 
subduction zone events. The second model encompassed the larger region of Washington and Oregon west of the Cascades front. This model was used for the Cascadia point source simulations. This velocity model also contained the subducted slab based on the geometry in Flueck and others (1997). Oceanic crust and mantle were included in the slab model. This larger model used additional velocity information from seismic reflection studies in the region, which necessitated a slightly different smoothing from the smaller model. We did tests to ensure that the slight difference in smoothing between the two velocity models did not significantly affect the waveforms from the 3D simulations.

Figure 7 shows a portion of the Puget Sound region velocity model with a vertical slice taken through the approximate longitude of Seattle. The velocity offset across the Seattle fault is visible in the cross section. The Seattle fault forms the southern edge of the Seattle basin. At the surface, we see that Vs is relatively low in the Puget lowland, with higher velocities to the west at the Olympic Mountains and to the east at the Cascade mountain belt.

We used the 3D finite-difference program written by Pengcheng Liu for the simulations (see Liu and Archuleta, 2006). This program allows for two different depth regions with different horizontal grid spacing. For shallow depths, the horizontal grid spacing is set to $1 / 3$ of that used for the deeper portion of the model. The program also allows for depth-variable grid spacing in the vertical direction.

For these hazard maps we are interested in frequencies up to about $1 \mathrm{~Hz}$. For the upper portion of the model above about $1.5 \mathrm{~km}$ depth, we used a horizontal grid spacing of $70 \mathrm{~m}$. The lower portion of the model has a horizontal grid spacing of $210 \mathrm{~m}$. The vertical grid spacing ranged from $70 \mathrm{~m}$ to $500 \mathrm{~m}$ in the deeper part of the grid. The minimum number of grid points per wavelength at $1 \mathrm{~Hz}$ was six. Minimum Vs was $600 \mathrm{~m} / \mathrm{s}$, similar to the Vs30 found for many stiff soil sites in Seattle. These stiff soils are of Pleistocene age.

We used a frequency-independent Q model where Qs $=0.1643$ x Vs -14 for $\mathrm{Vs}<1000 \mathrm{~m} / \mathrm{s}$. For Vs $\geq 1000 \mathrm{~m} / \mathrm{s}$, Qs was set to 0.15 x Vs. Qp was taken to be 2Qs. This Q model produced synthetic seismograms that had basin surface waves with amplitudes similar to the observations (see below). We found that changing the Q value in the Quaternary deposits within reasonable limits had little effect on the amplification factors calculated across Seattle. For example, we tried lowering Qs to 48 for Vs=600 m/s from the original value of 85. Amplification maps for Seattle looked virtually identical for one of the Cascadia point-source runs, with the differences in amplification values being only about $5 \%$ for the two cases.

Our 3D simulations do not include topography on the free surface. Seattle has hills approximately $100 \mathrm{~m}$ high. This is a small fraction of the wavelength of $1 \mathrm{~Hz}$ waves with a shearwave velocity of $500 \mathrm{~m} / \mathrm{s}$, which is typical for near-surface stiff soils in Seattle, so we might expect there to be minimal effect at $1 \mathrm{~Hz}$. We would expect that this topography would have a larger effect on higher-frequency seismic waves. We also did not consider the effect of propagation through water. For areas underwater, the free surface was taken to be the top of the sediments. Futhermore, our simulations did not include small-scale (hundreds of meters or less), lateral variations in seismic velocities that could scatter seismic waves. Such small-sale variations have not been systematically mapped, so a deterministic treatment is not possible at this time. These variations might best be treated in the future as random heterogeneities superimposed on the velocity model we have developed. 


\section{Validation of 3D Velocity Model}

The 3D velocity model was validated by comparing properties of observed and simulated seismograms. First we compared the synthetic and observed waveform amplitudes for the Nisqually earthquake. Next we compared synthetic and observed waveforms and spectral amplifications for four smaller (M3.4-4.8) earthquakes in the Puget Sound region.

We used the 3D simulation to calculate synthetic seismograms for the Nisqually earthquake for stations in the Seattle area. We applied the focal mechanism, seismic moment, and rise time found by Pitarka and others (2004) from modeling strong-motion records in the region. Pitarka and others (2004) considered two sub-events separated by $1.5 \mathrm{~s}$. We also used two sub-events, but chose a slightly larger separation in time of $1.7 \mathrm{~s}$. We calculated this separation time from the inverse of the frequency of a spectral peak observed on station SEW for this event. We used the same source location for the two sub-events, corresponding to the hypocenter of the earthquake, which is at a depth of $52 \mathrm{~km}$. Each sub-event was taken to be a point source. The seismic moment for each sub-event was $7.0 \times 10^{18}$ Newton $\mathrm{m}$. We chose a rise time (duration of rupture) of $4.0 \mathrm{~s}$ for each sub-event.

Figure 8 shows the synthetic and observed velocity waveforms for the Nisqually earthquake at representative stations in Seattle. The synthetic and observed waveforms are all bandpass filtered between 0.5 and $1.0 \mathrm{~Hz}$. We do not expect these high-frequency waveforms to compare "wiggle for wiggle." Instead we are interested in the timing of the initial S-waves, the peak amplitudes, the relative amplification of spectral response, and the timing of basin surface waves. The synthetics capture the basic observations that seismograms on the rock site ALK and the site near the basin edge (WEK) have relatively simple, short duration $\mathrm{S}$-waves, whereas stations in the Seattle basin have more complex, longer duration waveforms, with phases following the S-waves. The simulated waveforms contain the basin surface waves observed in the data, as seen in the EW component for station LAP. The timing of this surface wave in the synthetic is similar to that observed. More synthetic and observed waveforms are plotted in the appendix.

In general, the peak amplitudes are similar between the synthetics and observed waveforms. Figure 9 depicts a comparison between the observed and predicted peak ground velocities (PGV) for our Seattle array sites on stiff soil or rock site conditions. The observed and synthetic seismograms were filtered between 0.5 and $1.0 \mathrm{~Hz}$. In most cases the predicted PGV is within a factor of 1.5 of the observed PGV. More importantly, the synthetics capture the trend of the data; stations with observed high PGV are generally found to have higher PGV in the synthetics. It's notable that the synthetics underestimate the PGV at rock site SEW and station BHD. Another discrepancy is for station ALK where the synthetic seismogram for the east-west component is about 50\% larger than that observed (see also fig. 8). The synthetic for the northsouth component at LAP is significantly smaller than the observed, because this synthetic does not capture the observed arrivals after the S-wave (Figure 8).

On a broader scale, figure 10 displays a map of the peak values of the root mean square of the two horizontal velocity components for the Nisqually simulation for the Puget Sound region. Here we are using seismograms calculated over a grid with a spacing of $280 \mathrm{~m}$. For each site we calculated the root mean square amplitude of the two horizontal velocity components at each time step. Then we plotted the peak value of the root mean square velocity time series for that site. Of course the highest velocities are located near the epicenter of the event. There are localized areas of high velocities in the northern part of the grid. 
Most notable is the band of high ground motions along the southern margin of the Seattle basin. This band passes through the northern end of West Seattle (fig. 10). This is the same area that had anomalously high chimney damage from the Nisqually earthquake (Booth and others, 2004). Stephenson and others, (2006) used seismic reflection data to identify a step or downwarp in the top of the bedrock just to the south of the anomalous damage. This step may represent a portion of the Seattle fault zone. They showed how the high damage area corresponded to higher ground motions recorded by station WEK, which was very close to the damage area. Stephenson and others (2006) modeled this amplified motion using 2D SH (horizontally polarized S-waves) simulations up to frequencies of $5 \mathrm{~Hz}$ and demonstrated that focusing from the step in bedrock can explain the elevated ground motions and enhanced damage. The results of the lower-frequency 3D simulation presented here corroborate their findings that the southern edge of the Seattle basin focuses the incident $\mathrm{S}$-wave at a location similar to where the anomalous damage occurred.

It is interesting that the simulation predicts an area of relatively low peak velocities near Tacoma. This is caused by a node in the radiation pattern of the earthquake. Ground motion recordings from this area showed relatively low peak velocities for the Nisqually earthquake (see SHAKEMAP web page). This correspondence between the observed low velocities and the node of the radiation pattern was first suggested by K. Creager (personal comm., 2001)

The four smaller earthquakes that were modeled are labeled in figure 1 (and table 1) and encompass a range of azimuths from Seattle. For each earthquake we used the hypocenter, magnitude, and focal mechanism determined by the Pacific Northwest Seismic Network. In this comparison, we used Fourier spectral amplitudes of the root-mean-square average of the two horizontal components averaged over frequencies of 0.8-1.2 Hz. Spectral ratios were calculated with respect to the geometrical average at stations ALK, BRI, and SEW, except for event 4 (Oct. 15, 2000), where we used ALK and SEW, because BRI did not record this event. These sites are either rock sites (ALK) or have a thin layer of soil over rock (BRI and SEW).

Figure 11 compares the predicted spectral ratios from the 3D simulations with the observed spectral ratios for stiff-soil sites in the Seattle basin. There is good agreement between the predicted and observed ratios, in general, although the simulations underestimate the observed spectral ratios for station BHD for two events and station WEK for one event. Note that these stations are located close to the inferred southern edge of the Seattle basin, and that small changes in the location of this boundary will change their amplitudes in the simulations.

The simulations reproduce the azimuthally-dependent amplification that is observed in the data (fig. 11). The simulations show the largest spectral ratios (amplification) for the earthquakes to the southwest and south. They produce the lowest amplification for the event to the northwest. This agrees with the observations shown in figure 3. The fit to the observed amplification can be quantified by looking at the reduction in the standard deviation of the amplification. Figure 12 shows the observed standard deviation of the natural log of the amplification for the four earthquakes. We then divided the observed amplification with that predicted for that site and earthquake by the simulations, and calculate the standard deviation of the log of the result. Essentially this represents the reduction in the root mean square of the residuals by using the simulation results. We see that using the simulations reduces the standard deviation of the $\ln$ (natural logarithm) amplification by about a factor of 2, for the three events which showed substantial amplification. The event to the northwest displayed little amplification in the data and in the simulation. This comparison demonstrates that the 3D simulations reproduce a large portion of the observed amplifications. This gives us confidence in using the 3D simulations with our velocity model to predict ground motions for future large earthquakes. 
Figure 13 displays the synthetic and observed waveforms at station LAP (east-west component) in the Seattle basin, for the four earthquakes. Note that the absolute amplitudes of the synthetics agree well with the data, except for the smallest event (March 1, 2001). For this event, the rise time used in the simulation was too long. Here, we were primarily interested in the relative amplitudes between sites (see above) and the modeling of the basin surface waves. While, there are significant differences between the synthetic and observed waveforms, the simulations typically contain the basin surface waves that are observed in the data (see appendix). The timing of these surface waves on the synthetics is in good agreement with the data. In some cases (Oct. 15, 2000) the synthetics do not contain the complexity of the observed records.

It appears that the azimuthal dependence of the amplification is partly the result of larger basin surface waves being generated at the south and southwest edge of the Seattle basin compared to those produced along the northern edge of the basin. The relatively large surface waves generated along the southern edge of the basin are the result of the velocity contrast across the Seattle fault.

\section{D Simulations for Seattle Fault Earthquakes}

A large set of scenario earthquakes on the Seattle fault zone was simulated for this study. In the hazard calculations for the national seismic hazard maps, two recurrence models were used: a characteristic model that ruptures the entire length of the fault and a truncated Gutenberg-Richter (GR) relation where earthquake rupture zones for various magnitudes were floated along the fault strike. We used the geometry for the three traces of the Seattle fault from Blakely and others (2002)., which was also applied in the 2002 national seismic hazard maps (fig. 1). The characteristic model was only used for the northern, frontal strand of the fault, with a magnitude of 7.2, as in the national maps. The truncated GR model was applied to the three traces of the fault. The overall recurrence parameters were the same as used in the national seismic hazard maps, which were constrained by paleoseismic and slip rate data. The recurrence time for characteristic earthquakes was taken to be 5,000 yr. The recurrence time for the truncated GR model for $\mathrm{M} \geq 6.5$ was $1000 \mathrm{yr}$. For the $45^{\circ}$ dip models, we used a minimum rupture depth of $5 \mathrm{~km}$ in the simulations, consistent with the minimum depth for slip for the Northridge earthquake (Wald and others, 1996).

Figure 14 schematically illustrates the procedure for floating rupture zones along the Seattle fault. In this example, we only show the northern strand, although a similar floating procedure was done on the other two strands. To limit the number of 3D simulations we used a distance of $10 \mathrm{~km}$ between the western edges of the floating ruptures. We used a magnitude increment of 0.2 magnitude units (m.u.), going from M6.6 to M7.0. For each magnitude the ruptures are floated along the fault. Typically, there were 3-4 rupture zone locations along each fault strand, for any given magnitude. In the calculations for the national maps, a $1 \mathrm{~km}$ floating increment was used along with a magnitude increment of 0.1 m.u. All told we did 450 simulations for Seattle fault earthquake scenarios.

There were 35 different rupture zones considered for Seattle fault zone earthquakes (for $45^{\circ}$ dip), in addition to characteristic rupture on the entire frontal strand. For each rupture zone, a total of nine 3D simulations were conducted. These consisted of three different slip distributions and three hypocenters. The slip distributions were calculated using a Gaussian random variable filtered so that its wavenumber spectrum was proportional to $k^{-2}$, above a corner wavenumber inversely proportional to the dominant asperity size. Here, $k$ is the wavenumber. We used a dominant asperity size that varied with magnitude according to Somerville and others (1999). This falloff of the wavenumber spectrum ensures that the stress drop is independent of the scale of the heterogeneity 
(Frankel, 1991; Herrero and Bernard, 1994; Somerville and others, 1999). The three hypocenters were located at the bottom of the fault plane at three locations along strike: $1 / 4,1 / 2$, and $3 / 4$ times the length of that rupture segment. The fault width was taken to be $21 \mathrm{~km}$, identical to that used in the national seismic hazard maps. The fault dips to the south. In our first set of runs we assumed the dip was $45^{\circ}$, but we also tried other possibilities (see below).

The slip was input into the 3D simulations on a grid with $500 \mathrm{~m}$ spacing. The rise time was magnitude dependent, using the relations of Somerville and others (1999). However, we found that the spatial pattern of $1 \mathrm{~Hz}$ amplification, for the magnitudes considered here, was insensitive to the rise time. We used a rupture velocity of $2,800 \mathrm{~m} / \mathrm{s}$, similar to that found for the 1994 Northridge earthquake from an inversion of strong-motion data (Wald and others, 1996) and similar to the average rupture velocity found from inversions of strong-motion data (Somerville and others, 1999). This is about $0.9 \mathrm{Vs}$ for the bedrock at the depth of the midpoint of the fault. The effect of using a different rupture velocity is shown below. For each source grid point we added a random delay to the timing of the rupture initiation equal to 10 per cent of the time calculated from the distance to the hypocenter divided by the rupture velocity. All the events were thrust earthquakes, with an average rake of 90 degrees from the fault strike. At each source grid point we varied the rake by $\pm 20^{\circ}$. We found that without this randomizing of the rake, the amplitude differences over the study area became unreasonably large. The randomization of the rupture time and the rake are similar to the variations found in inversions of strong motion data (Wald and others, 1996). We confirmed the use of this randomization by modeling the observed amplitudes from the Northridge earthquake (see below).

Note that each trace of the Seattle fault has some local variation in strike along the length of the fault. We assumed that the variation of strike at the surface continues at depth. Thus the fault surface used in each simulation is not a plane; it is corrugated according to the curvature of that particular surface trace. At each source grid point, the local strike of the fault surface is used when specifying the focal mechanism of the source at that point.

Figure 15 contains examples of two different slip distributions and their corresponding amplitude patterns for the study area. In both cases, the hypocenter was at the bottom of the fault, halfway along the length. The amplitudes are from the $1 \mathrm{~Hz}$ Fourier spectra of the horizontal synthetic seismograms and are referenced to the geometrical average at the rock sites ALK, BRI, and SEW. Although there are substantial differences between the two amplitude patterns of the two simulations, there are common themes. Note that the highest amplitudes are located just north of the southern edge of the Seattle basin, with elevated, but lower, ground motions extending into the Seattle basin. The high values along the southern edge of the basin are caused by updip directivity of shear waves from the rupture and focusing by the southern edge of the Seattle basin. The velocity gradient in the Seattle basin turns the incident $S$-waves so that they are propagating more vertically. This gradient combined with the geometry of the edge of the basin tends to concentrate $\mathrm{S}$-wave energy at the southern edge of the basin. The locations of the highest ground motions are generally updip of the locations of the highest slip along the fault. The lowest ground motions are generally found in the areas where the top of the bedrock is shallowest (compare amplitude maps in fig. 15 with fig. 6). These are located in the portion of Seattle south of the frontal strand of the Seattle fault.

Obviously, we have chosen only a subset of the possible range of rupture parameters. We chose what we think is a reasonable average rupture velocity, based on inversion results from past earthquakes. To test the sensitivity of the results to the rupture velocity we did 3D simulations with two different rupture velocities: $2,800 \mathrm{~m} / \mathrm{sec}$ and 2,200 m/s. The results are depicted in Figure 16 and demonstrate that rupture velocity has a significant effect on the amplitude pattern. The example 
with the slower rupture velocity has a smaller peak amplitude above the fault. However, the slower rupture velocity produces a broader area of elevated ground motions.

We were concerned that the $45^{\circ}$ dip would cause an underestimation of the severity of ground motions on the hanging wall of the frontal strand of the Seattle fault if the fault actually had a shallower dip. Therefore, we also tried simulations with a range of dips for the frontal strand. Figure 17 highlights the differences between using $30^{\circ}, 45^{\circ}$, and $60^{\circ}$ dips. These cases all used a minimum rupture depth of $5 \mathrm{~km}$. As the dip gets shallower, ground motions are increased on the hanging wall, relative to values to the north of the fault. The dip of $30^{\circ}$ also produces higher amplitudes in the Seattle basin than the other cases, because $\mathrm{S}$-waves from the case with a shallower dip tend to produce larger basin surface waves at the southern edge of the Seattle basin. We decided to use runs with $30^{\circ}$ and $45^{\circ}$ dips for the frontal strand and give these possibilities equal weight in the final hazard calculation. For the $30^{\circ}$ dip runs we used a minimum depth of $3 \mathrm{~km}$. Using a deeper depth for this shallow dip offsets the surface projection of the rupture towards the southern end of the mapped area. The $30^{\circ}$ dip case added an additional 14 floating rupture zones and one characteristic rupture, each with nine different simulations, so that 135 additional simulations were done for the $30^{\circ}$ dip case.

Figures 18A and B show the geometrical average and standard deviation of the natural logarithm, respectively, of the amplifications found from the 315 simulations with a fault dip of $45^{\circ}$. We see that the highest ground motions are located just north of the frontal trace of the Seattle fault, with a peak amplification of about a factor of 4, relative to the reference rock sites. Again, this was produced by a combination of focusing by the edge of the basin and up-dip directivity. For most of Seattle the variability in the amplification is about 0.4 in natural log units. This is comparable to the variability in ground-motion amplitudes for a given magnitude and distance that is commonly found in regressions of strong-motion data for rock or soil sites. It is interesting that there is large variability of ground-motion amplitude along the western edge of the grid of sites, reaching values of 0.8 in natural log. This is not an edge effect, since the $3 \mathrm{D}$ model extends well to the west of the edge of the site grid. This area is up-dip from the location of an offset in the surface trace of the Seattle fault determined from seismic reflection (Johnson and others, 1999) and aeromagnetic data (Blakely and others, 2002). In the simulations the variable rake across this change of local strike apparently caused a large variation in the up-dip amplitude.

Figures $18 \mathrm{C}$ and D contain the geometrical average and standard deviation from the 135 simulations using a dip of $30^{\circ}$ on the northern strand. Now the area of highest ground motions is offset to the north compared to the $45^{\circ}$ case. This high is produced by large basin surface waves, which are more efficiently generated from incident $\mathrm{S}$-waves relative to the $45^{\circ}$ case because of the shallow dip of the fault and the shallower minimum depth of the rupture. A lobe of high ground motions to the south of the peak amplitude area is caused by forward directivity and is offset to the north compared to the $45^{\circ}$ case.

In the hazard calculations we float the earthquakes along the fault in the same manner as the simulations. For each rupture location we calculated the ground motions at stations ALK, BRI and SEW using the generic rock-site attenuation relations used in the national maps. We then calculated the geometrical average for these three sites from the horizontal components. The ground motion at each site is then determined from each of the nine amplification maps determined from the 3D simulations for that rupture location (three slip distributions times three hypocenters), multiplied by the average of the rock site values. In other words, each of the nine simulations done for each rupture location is given a 1/9 weight in the hazard calculation. This is also done for the characteristic ruptures on each fault strand. When two alternative dips are used, the results of each simulation are assigned a 1/18 weight. 


\section{Validation of Finite-Fault Procedure Using the Northridge Earthquake}

To validate the details of the finite-fault simulations, we modeled the 1994 Northridge earthquake, an event that is similar to what might be expected on the Seattle fault. We used the geometry of the fault and the slip model from Wald and others (1996). The slip model was from their combined inversion of strong motion, teleseismic, and geodetic data. We specified a constant rise time of $1 \mathrm{~s}$ across the fault plane, and randomized the rake and timing of rupture initiation at source grid points as we did in the Seattle fault simulations described above. The 3D velocity model (version 4.0) of the Southern California Earthquake Center (SCEC) was used. Because of the Vs values in this model, the finite difference synthetics were accurate up to $0.85 \mathrm{~Hz}$, using the criterion of six gridpoints per wavelength.

We calculated the spectral ratios at $1.2 \mathrm{sec}(0.833 \mathrm{~Hz})$ using the response spectral amplitudes for the horizontal synthetics, for stations within $10 \mathrm{~km}$ of the surface projection of the fault plane. We compared these ratios with the observed ratios derived from the $1.2 \mathrm{sec}$ spectral accelerations (from the NGA database, PEER). In both cases, the geometrical average of the two horizontal components is used. We chose the Arleta station as the reference site for the ratios. Figure 19 demonstrates that the synthetics capture the trend of the observed ratios, with the exception of underestimating the ratio at one station in the Santa Monica mountains south of Ventura (14145 Mulholland Dr., Beverly Hills). The ground motions from this station were not modeled by Wald and others (1996). This station was located in area south of Sherman Oaks which had an anomalously high number of red-tagged buildings in the southern San Fernando Valley and the hills to the south, which may be caused by focusing from a sub-basin (Meremonte and others, 1996; Stephenson and others, 2000). This Sherman Oaks sub-basin is not contained in the SCEC velocity model.

The high ratios occurred at stations above the northern portion of the fault plane or to the north of the fault and were produced by up-dip directivity. Using the formulas in Abrahamson and others (1990), we determined the bias between the synthetic and observed $1.2 \mathrm{sec}$ ratios to be -0.044 in natural $\log$ units, and the standard deviation to be 0.54 in natural log units (factor of 1.7). This standard deviation is similar to, or smaller than, those reported for the Northridge earthquake in Hartzell and others (1999) for a variety of simulation methods. This indicates that our finite-fault simulation methodology does an acceptable job of matching the rupture directivity and San Fernando basin effects in the Northridge data and is therefore appropriate for application to the Seattle fault.

\section{D Simulations for Gridded Seismicity}

An important aspect of the new hazard maps is including the azimuthal differences of amplification caused by random background earthquakes. The hazard from these earthquakes is quantified in the national seismic hazard maps by using seismicity-rate grids determined from the earthquake catalog, after spatial smoothing. In the national maps, the earthquake catalog was separated into shallow $(<35 \mathrm{~km})$ and deep $(>35 \mathrm{~km})$ hypocenters. Different b-values, maximum magnitudes and rock-site attenuation relations are used for the two depth ranges.

To quantify the azimuthal variations in amplification, we considered eight different azimuths from the center of the Seattle site grid. We used sectors of $45^{\circ}$. It was impractical to do 3D simulations for every possible point on the seismicity-rate grid. Instead we did 3D simulations 
at three epicentral distances. The central distance was the hypocentral distance of $16 \mathrm{~km}$ corresponding to the modal distance of the deaggregation for $1 \mathrm{~Hz} \mathrm{~S}$.A. for a probability of exceedance of $2 \%$ in 50 years (from website: http://eqhazmaps.usgs.gov). This corresponds to an epicentral distance of $15 \mathrm{~km}$. We then chose epicentral distances of 10 and $25 \mathrm{~km}$ to sample closer and farther distances. Figure 20 shows the epicenters used in the 3D simulations. We assumed the focal mechanism was an east-west thrust with a dip of $45^{\circ}$. This is a common type of focal mechanism found for shallow earthquakes in the area. We investigated the effect of varying the focal mechanism. For close-in shallow events, the focal mechanism can have a significant effect on the amplification pattern. Using a different focal mechanism will change the details of the final results, although the overall patterns will remain. We used two different depths; $10 \mathrm{~km}$ and $15 \mathrm{~km}$.

For deep earthquakes $(>35 \mathrm{~km}$ ) the mode of the deaggregation was at $64 \mathrm{~km}$ hypocentral distance, which corresponded to $45 \mathrm{~km}$ epicentral distance. We used this distance and a closer distance of $20 \mathrm{~km}$ for the simulations. For the deep earthquakes we used the focal mechanism of the Nisqually earthquake and a depth of $50 \mathrm{~km}$. We found that the amplification results for deep events were not sensitive to small changes in the focal mechanism. The epicenters of the deep earthquakes considered are shown in figure 20.

Figure 21 contains the amplification maps for the $15 \mathrm{~km}$ deep sources for four azimiths. We can see the highest amplification occurs in the Seattle basin for the earthquake to the south. For most source azimuths, the lowest ground motions are found in the area of shallow bedrock in the southern part of Seattle.

The amplification as a function of source depth is illustrated in figure 22 , for sources to the southwest (azimuth $=135^{\circ}$ ). We can see the highest amplification in the Seattle basin occurs for the shallower sources. For the $15 \mathrm{~km}$ deep source, there is a patch of elevated ground motions just to the north of the Seattle fault and another high patch to the north within the Seattle basin. In figure 23, we show the north-south synthetic seismograms for three locations. The most southerly site (site 1) is located over the shallow bedrock outside the basin and displays a simple S-wave pulse. The site located in the area just to the north of the southern edge of the Seattle basin exhibits a very large S-wave (site 2), caused by focusing by the edge of the basin. The seismogram from the high area within the basin shows a large basin surface wave and a relatively small direct $\mathrm{S}$-wave (site 3). Given the significant differences between the amplification maps for depths of 10 and 15 $\mathrm{km}$, we decided to use the simulations at both depths when calculating the hazard from the shallow gridded seismicity.

In the hazard calculation we divided the shallow and deep seismicity-rate grids into sectors of 45 degrees, with the center azimuth of each sector corresponding to that of each simulation. These sectors extend out from the center of the site grid at varying azimuths. So, the hazard calculation for each azimuth only considered the seismicity-rate grid for the sector centered on that azimuth. When calculating the hazard at each site from each seismicity grid point, we first determined the ground motions at that site from that source using the generic rock-site attenuation relations. Then we multiplied this by the value at that site from the amplification map for the appropriate source azimuth, after the amplification map was corrected for geometrical spreading and referenced by the geometrical average from sites ALK, BRI, and SEW.

\section{D Simulations for Cascadia Subduction Zone Earthquakes}


It was not possible to do 3D simulations up to $1 \mathrm{~Hz}$ for the entire $1,000 \mathrm{~km}$ length of the Cascadia subduciton zone (CSZ), at least with the computers available to us. Since we are interested in the amplification patterns across the Seattle area, we decided it was adequate to determine the amplification patterns using point sources along a portion of the Cascadia subduction zone. We first chose five locations along the subduction zone, all at a depth of $20 \mathrm{~km}$, as inferred from the fault geometry of Flueck and others (1997) (fig. 24). We assumed the sources consisted of east-west slip (pure thrust) on a north-south striking nodal plane with a dip to the east of $20^{\circ}$. The location of the southern sources were close to the midpoint of the bases of the elastic and transition zones specified by Flueck and others (1997) that were used in the national seismic hazard maps. The two northern sources are located between the midpoint model and the base of the transition zone. Note that our procedure of using the point sources does not include the effects of rupture directivity for Cascadia earthquake sources. However, since the Cascadia subduction zone is at least $60 \mathrm{~km}$ from Seattle, we expect that the effects of rupture directivity for Cascadia earthquakes would be similar across Seattle and would not produce a significant gradient of hazard across Seattle.

Figure 25 displays the amplification maps for these five point sources on the Cascadia subduction zone. The amplification maps are corrected for geometrical spreading and Q. In all cases we see significant amplification for sites in the Seattle basin and the lowest ground motions for the areas in southern Seattle over the shallow bedrock. The event to the southwest produces a band of elevated ground motions along the southern edge of the Seattle basin. Some of the point sources produce high amplitudes in the portion of the Seattle basin along the western portion of the site grid.

For the base of the transition zone model, we used the results from five other point sources (fig. 24) to the east of the original five sources. These easterly sources were placed at a depth of $26.5 \mathrm{~km}$ corresponding to the depth of the base of the transition zone. In general, we found that the amplification patterns for these 5 sources were very similar to those for the corresponding event to the west, with the exception of the southernmost source. For the source east of source 1, we found that this did not produce the strong amplification along the northeast edge of the shallow bedrock as did source 1.

The hazard calculation for Cascadia subduction zone earthquakes consists of two estimates of the characteristic magnitude: 9.0 and 8.3. The M8.3 rupture zones are floated along the strike of the CSZ. The 9.0 rupture zone encompasses the entire length of the CSZ. The four different geometries of the eastern edge of the CSZ used in the 2002 national seismic hazard maps were also applied here. For the M9.0 scenarios we used the amplification maps from the five point sources with equal weight. We found that this procedure gives essentially the same hazard map as doing a single hazard run using the average amplification at each site from the five amplification maps. For the floating M8.3 scenarios we used the amplification map for the point source that was closest (in the north-south direction) to the center of the rupture zone. The amplification maps were applied to the rock-site ground motions derived from the rock-site attenuation relations used in the 2002 national seismic hazard maps (see table 4).

\section{D Simulations for South Whidbey Island Fault}

A set of nine 3D simulations was used to approximate the amplification expected in Seattle for earthquakes on the South Whidbey Island fault. For each simulation, we assumed rupture of the entire fault. We used three slip distributions, using the same random slip procedure as for the Seattle fault. For each slip distribution we specified three hypocenters at the base of the fault, at 
distances $1 / 4,1 / 2$, and $3 / 4$ times the total length of the fault. We assume that the fault dips $60^{\circ}$ to the north, in accordance with the parameters used in the national seismic hazard maps. We did not do 3D simulations for floating ruptures along the fault. We applied the amplification patterns from the characteristic rupture model to the hazard calculation of the characteristic and truncated GR models.

\section{Nonlinear Site Response}

Using borehole data of depth to glacially-overridden material supplied by K. Troost and D. Booth of the University of Washington (Pacific Northwest Center for Geologic Mapping Studies, 2005; referred to here as GeomapNW, 2005) and limited results of a site response inversion, we calculated a model for the thickness of fill and young alluvium. We also used the locations of the surface contact between the fill/alluvium and the Pleistocene sediments as data points of zero thickness. The borehole data dominates the subsurface results by far, due to the hundreds of sites with borehole data. We supplemented this borehole data with the inferred thickness of fill/alluvium at four soft-soil locations where we have observed clear resonances in weak-motion earthquake recordings. These stations and their resonant frequencies are BOE $(1.1 \mathrm{~Hz}), \mathrm{KDK}(2.1 \mathrm{~Hz}), \mathrm{GEO}$ $(1.4 \mathrm{~Hz})$, and PIE $(1.4 \mathrm{~Hz})$. The resonant frequencies were determined from an inversion of Fourier spectra for the 19 earthquakes shown in figure 1 . The resonant frequencies were converted to thickness of fill using travel times for the average velocity profile (see below).

We determined the thickness of fill/alluvium in areas that were mapped as Holocene deposits in GeomapNW (2005) and that had multiple measurements of fill/alluvium thickness greater than about 10 feet $(3 \mathrm{~m})$. We did not include small localized areas of very thin Holocene deposits in this model. The areas we considered were: the Duwamish Valley including Harbor Island, the interbay region between Magnolia and Queen Anne and extending along the north side of the Ship Canal, and the area east of the University District and extending south of the Ship Canal. We had also considered the beach deposits along the west and north coast of West Seattle, and the Holocene deposits on the northwest coast of Magnolia. However, an earthquake recording from a recently installed station on the beach deposits in West Seattle did not show high response at $1 \mathrm{~Hz}$ relative to a West Seattle site on stiff soil, and seismic refraction results indicate that the beach deposits in West Seattle have significantly higher shear-wave velocity than fill deposits.

We applied an algorithm that fits a smooth surface to the thickness values within these areas. This surface was then sampled at the same grid as used in the 3D simulations (grid spacing $280 \mathrm{~m}$ ). For a few grid points in the extreme southeast corner of the fill/alluvium model, we assigned a default thickness of 30 feet $(9 \mathrm{~m})$, since there was no information on the thickness that was available for that corner of the model. The value of 30 feet was chosen to be consistent with other points with measured thicknesses at a similar distance from outcrops of rock and the edge of the fill area. A map of the thickness of fill from this model is displayed in figure 26. On land, the thickest fill/alluvium is in the Duwamish Valley, including Harbor Island. The greatest thickness of fill/alluvium in the model is about $80 \mathrm{~m}$.

We developed an average S-wave velocity (Vs) profile for soft soil sites (fill and Holocene alluvium) using seismic refraction and borehole information. The Vs profile at each soft-soil site consisted of this average velocity profile for the fill/alluvium and a step increase in Vs at the base of the fill/alluvium. We developed an average Vs profile in the top $30 \mathrm{~m}$ for fill/alluvium sites from several seismic refraction/reflection profiles in Seattle (Williams and others, 1999). We also used the measured Vs for a borehole near our station SDS (Washington State Department of Natural Resources, 2004) to provide data points at 30 and $45 \mathrm{~m}$. In addition, we included a representative 
value of Vs at 50m depth determined from borehole measurements at fill/alluvial sites south of downtown Seattle (Wong and others, 2003). These average velocities with depth are depicted in Figure 27 . We fit the points comprising the average velocity profile to a bilinear function as a function of depth, with the best fit yielding $\mathrm{Vs}=107+3.322 \mathrm{x}$ depth for depths less than $15.6 \mathrm{~m}$ and $\mathrm{Vs}=128+1.997 \mathrm{x}$ depth for depths greater than $15.6 \mathrm{~m}$. Here $\mathrm{Vs}$ is in $\mathrm{m} / \mathrm{s}$ and the depth is given in meters. We then use this bilinear function for constructing the velocity profile input into SHAKE and in calculations of Vs30. We set the Vs to be $350 \mathrm{~m} / \mathrm{s}$ for the top of the stiff soils that underlie the fill/alluvium, based on borehole measurements near SDS (Washington State Department of Natural Resources, 2004).

The amplification of the fill/alluvium sites is calculated relative to the top of the $3 \mathrm{D}$ velocity model. A key parameter is the shear wave velocity near the top of the 3D velocity model, since this affects the amplification from the Holocene material. We needed to account for the velocity contrast between the top of the 3D velocity model and the soft soils. Areas of soft soils where the 3D model has rock nearer the surface will have more amplification than areas of soft soils that are in the Seattle basin and overlie stiff soils. We calculated the velocity at the top of the 3D model for each site, averaged over a quarter wavelength for $1 \mathrm{~Hz}$ seismic waves. Thus, this average velocity (Vtop) is the depth corresponding to a $0.25 \mathrm{~s} \mathrm{~S}$-wave travel time from the surface divided by 0.25 sec. Over areas of shallow bedrock just south of the frontal trace of the Seattle fault, the $1 / 4$ wavelength velocity is between 1,200 and $1,700 \mathrm{~m} / \mathrm{s}$ whereas the $1 / 4$ wavelength velocity is about $630 \mathrm{~m} / \mathrm{sec}$ in the Seattle basin where the bedrock is deeper. For the SHAKE runs, $\mathrm{V}_{\text {top }}$ is used as the velocity of the half space below the velocity profile associated with the fill/alluvium. For the amplification factors from NEHRP and Choi and Stewart (2005), the values of $\mathrm{V}_{\text {top }}$ are used to adjust the amplification factors, as described in detail below.

Our initial approach to estimating the amplification of the Holocene material was to utilize the SHAKE 91 program (Schnabel and others, 1972; Idriss and Sun, 1992). This program calculates the response of shear waves vertically propagating through a stack of layers, using an equivalent linear formulation where the shear modulus and damping vary with strain. The depthdependent modulus reduction and damping curves for sand from EPRI (Electric Power Research Institute, 1993) were used in the calculations. In developing the Vs profiles for SHAKE, it is necessary to link up the Vs from the fill/stiff soil interface to the $\mathrm{V}_{\text {top }}$ used in the top layers of the velocity model used for the 3D simulations. We applied two approaches to this problem that gave similar results. First we used a velocity gradient where the velocity increased from $350 \mathrm{~m} / \mathrm{s}$ below the fill/alluvium interface to $\mathrm{V}_{\text {top }}$ over a distance equal to the fill/alluvium thickness. In the second approach we assumed that the velocity just below the fill/alluvium-stiff soil interface equaled Vtop. Figure 28 shows examples of the Vs profiles for these two approaches. We found that these two approaches gave very similar amplifications at any given site, usually within 5 percent. We averaged the amplifications between these approaches for the hazard calculation.

SHAKE requires an input time history. We used three time histories: Diamond Heights (East-West component) in San Francisco from the 1989 Loma Prieta earthquake and the Sylmar (North-South component) and Northridge (North-South component) records from the Northridge earthquake. The amplifications from each input time series were also averaged for each input PGA value. There were only minor differences in the amplifications derived from the three time histories. We did not use the synthetic seismograms from the $3 \mathrm{D}$ simulations as inputs to SHAKE since they were limited to frequencies of about $1 \mathrm{~Hz}$ and below.

The amplification at each site was determined for a set of input PGAs of 0.01. 0.1, 0.2, 0.3, $0.4,0.5,0.6,0.7,0.8 .0 .9$, and $1.0 \mathrm{~g}$. As is typical practice for using SHAKE, we scaled the input seismograms to these peak values (Idriss and Sun, 1992). The pseudo-spectral acceleration values 
at the surface outcrop and for the input motions were averaged over 0.8 to $1.2 \mathrm{~Hz}$ and then the ratio of the surface to the input values were determined for each input PGA.

Figure 29 shows the amplification (response spectra) for a site at Harbor Island (HAR), as determined from SHAKE. Note the shift of the resonant period to longer periods as the input accelerations increase. For small input accelerations, the $1 \mathrm{~Hz}$ amplification is about a factor of 2. For larger input accelerations $(0.5 \mathrm{~g})$ the site does not amplify at $1 \mathrm{~Hz}$. For even stronger input motions the site deamplifies at $1 \mathrm{~Hz}$ because of the decrease of shear wave velocity and the increase in damping with increasing strain.

Our second approach was to use the NEHRP amplification factors (Building Seismic Safety Council, BSSC, 2001) along with an estimate of Vs30 for each soft-soil site. We utilized the NEHRP factors $(\mathrm{Sv})$ which are a function of the values of $1 \mathrm{~Hz}$ S.A. from $0.1-0.5 \mathrm{~g}$ for a rock site. We assume that input $1 \mathrm{~Hz}$ S.A.'s higher than $0.5 \mathrm{~g}$ produce the same amplification as with the $0.5 \mathrm{~g}$ input, since $0.5 \mathrm{~g}$ is the highest $1 \mathrm{~Hz}$ S.A. given in the NEHRP amplification factor table (BSSC, 2001). The Vs30 for each soft-soil site was estimated from the average Vs profile by dividing $30 \mathrm{~m}$ by the travel time to a depth of $30 \mathrm{~m}$. If the thickness of the fill/alluvium was less than $30 \mathrm{~m}$, then the Vs30 was calculated by dividing $30 \mathrm{~m}$ by the sum of the travel time from the average Vs profile in the fill/alluvium to the base of the fill/alluvium and the travel time of the $350 \mathrm{~m} / \mathrm{s} \mathrm{stiff-soil}$ substrate for the remaining portion to $30 \mathrm{~m}$ depth.

This alternative approach was motivated by the deamplification at $1 \mathrm{~Hz}$ found for the SHAKE runs at high input accelerations, and the concern that the SHAKE results would underestimate the amplification. Observational work by Choi and Stewart (2005) and modeling results by Hartzell and others (2004) indicate that we would not expect significant deamplification at $1 \mathrm{~Hz}$ at class E soft-soil sites, even for peak accelerations up to about $0.8 \mathrm{~g}$. In contrast, the NEHRP amplification factors have an amplification of 1.71 (with respect to C-class sites) at $1 \mathrm{~Hz}$ for sites with $\mathrm{Vs} 30=180 \mathrm{~m} / \mathrm{s}$ for a $1 \mathrm{~Hz}$ S.A. of $0.5 \mathrm{~g}$ for rock sites.

A key issue with utilizing amplification factors based on Vs30 is determining the appropriate velocity value associated with the top of the $3 \mathrm{D}$ velocity model, since this is the reference for the amplification and the denominator in the calculation of amplification. For areas within the Seattle basin, $V_{\text {top }}$ (based on $1 / 4$ wavelength average for $1 \mathrm{~Hz}$ ) is about $630 \mathrm{~m} / \mathrm{s}$, and the velocity for the top grid cell ( $70 \mathrm{~m}$ in size) was $600 \mathrm{~m} / \mathrm{s}$. However, for sites above shallow bedrock outside of the basin, the velocity in the model increases rapidly with depth. $\mathrm{V}_{\text {top }}$ (based on $1 / 4$ wavelength average) is much larger than the Vs of the top grid cell. The amplitude of $1 \mathrm{~Hz}$ waves at the top of the 3D velocity model will be insensitive to the velocity of the top grid cell, but are dependent on the $1 / 4$ wavelength average velocity $\left(\mathrm{V}_{\text {top }}\right)$.

Our approach is to use a Vs30 of $600 \mathrm{~m} / \mathrm{s}$ for the reference site condition for the top of the 3D model for sites in the Seattle basin. A larger amplification factor is needed for soft-soil sites above shallow bedrock south of the basin. We needed to adjust for the higher $\mathrm{V}_{\text {top }}$ at these sites compared to basin sites. We use the square root of the impedance (Vs times $\rho$, where $\rho$ is density), based on the $1 / 4$ wavelength averages at $1 \mathrm{~Hz}$ from the $3 \mathrm{D}$ velocity model, for this adjustment. Here we are following the same procedure Boore and Joyner (1997) applied for determining site amplification of Fourier spectral amplitudes from the square root of the impedance. We are using this factor to estimate the amplification of response spectral values. We verified that the square root of the impedances accurately predicts the amplitude differences for response spectra by comparing the response spectra at the free surface derived from SHAKE runs 
that varied the Vs at the base of the velocity profile from $600 \mathrm{~m} / \mathrm{s}$ to $1,200 \mathrm{~m} / \mathrm{s}$ and used the same velocity profile in the fill/alluvium.

Therefore, we calculate the soft-soil amplification factor $\mathrm{A}_{\text {soft }}\left(\right.$ site $\left._{i}, U_{\text {rock }}\right)$ between the free surface of a soft-soil site $i$ and the top of the 3D velocity model from

$$
\mathrm{A}_{\text {soft }}\left(\text { site }_{i}, U_{\text {rock }}\right)=\frac{A\left(V_{\mathrm{s} 30, \mathrm{i}}, U_{\text {rock }}\right)}{A\left(V_{\mathrm{s} 30, \text { basin }}, U_{\text {rock }}\right)} \frac{C\left(V_{\text {top }, \mathrm{basin}}, \rho_{\text {top }, \mathrm{basin}}\right)}{C\left(V_{\text {top }, \mathrm{i}}, \rho_{\text {top }, \mathrm{i}}\right)} \text {, }
$$

where $A\left(V_{\mathrm{s} 30, \mathrm{i}}, U_{\text {rock }}\right)$ is the amplification factor derived from the Vs30 of site $i$ and $A\left(V_{\mathrm{s} 30 \text {, basin }}, U_{\text {rock }}\right)$ is the amplification factor from the Vs30 of a site in the Seattle basin, assumed here to be $600 \mathrm{~m} / \mathrm{s}$. These nonlinear factors are also functions of a particular ground-motion parameter $U_{\text {rock }}$ for a firm-rock site condition. Both of these factors are derived from the table of NEHRP amplification factors, which are a function of Vs30 and the rock-site value of $1 \mathrm{~Hz}$ spectral acceleration. $C\left(V_{\text {top,basin }}, \rho_{\text {top,basin }}\right) / C\left(V_{\text {top, },}, \rho_{\text {top, }}\right)$ is the amplitude ratio at the top of the $3 \mathrm{D}$ model for a site in the Seattle basin relative to that at site $i$. This amplitude ratio is a function of the impedances at the top of the 3D model for these sites, such that

$$
\frac{C\left(V_{\text {top,basin }}, \rho_{\text {top, basin }}\right)}{C\left(V_{\text {top }, \mathrm{i}}, \rho_{\text {top }, \mathrm{i}}\right)}=\sqrt{\frac{V_{\text {top }, \mathrm{i}} \rho_{\text {top }, \mathrm{i}}}{V_{\text {top }, \text { basin }} \rho_{\text {top }, \text { basin }}}} .
$$

Again, these velocities $\mathrm{V}_{\text {top }}$ and $\rho_{\text {top }}$ are averaged over a quarter wavelength for $1 \mathrm{~Hz}$ waves. $V_{\text {top,basin }}$ is $630 \mathrm{~m} / \mathrm{s}$ and $\rho_{\text {top,basin }}$ is $2.0 \mathrm{~g} / \mathrm{cm}^{3}$. $C\left(V_{\text {top,basin }}, \rho_{\text {top,basin }}\right) / C\left(V_{\text {top }, \mathrm{i}}, \rho_{\text {top, } \mathrm{i}}\right)$ equals one for a fill/alluvium site in the Seattle basin.

The third and preferred approach we tried utilized the amplification factors determined by Choi and Stewart (2005). They used a large set of strong-motion data to determine amplifications as a function of Vs30 and input PGA at rock sites. We used their A1, A2, and A3 formulas to determine amplification for the rock-site attenuation relations of Abrahamson and Silva, (1997), Sadigh and others (1997), and Campbell and Bozorgnia (2003), respectively. Since Choi and Stewart (2005) do not provide a formula for use with Boore and others (1997), we geometricallyaveraged the results for A1, A2, and A3 for this relation. We also used this average for the other attenuation relations not considered in Choi and Stewart (2005): the attenuation relations for great subduction zone earthquakes and deep events (Youngs and others, 1997; Atkinson and Boore, 2003). The relative amplification factors between vs 30 of $150 \mathrm{~m} / \mathrm{s}$ and $600 \mathrm{~m} / \mathrm{s}$ vary in the A1, A2, and A3 formulas by less than $10 \%$. We used input (rock-site) PGAs of 0.05, 0.1, 0.2, 0.3, 0.4, 0.5, $0.6,0.7$, and $0.8 \mathrm{~g}$, assuming that the amplification above $0.8 \mathrm{~g}$ was equal to that at $0.5 \mathrm{~g}$. Choi and Stewart (2005) point out that their data are limited to rock-site PGAs less than $0.8 \mathrm{~g}$. Furthermore, for rock-site PGA's less than $0.05 \mathrm{~g}$, we used their amplification factors for $0.05 \mathrm{~g}$, since Choi and Stewart (2005) had very limited data at soft-soil sites where the ground motions corresponded to less than $0.05 \mathrm{~g}$ rock PGA.

As in the second (NEHRP factors) approach, the soft-soil amplification at each site was calculated from equations five and six. Now $A\left(V_{\mathrm{s} 30, \mathrm{i}}, U_{\text {rock }}\right)$ and $A\left(V_{\mathrm{s} 30 \text {, basin }}, U_{\text {rock }}\right)$ in equation five are derived from the Choi and Stewart (2005) equations. $U_{\text {rock }}$ now stands for the PGA for a firmrock site condition. 
As an example, table 4 shows the nonlinear amplification factors used for a site near station HAR on Harbor Island. These factors do not include the results from the 3D simulations. For this location we estimated a Vs30 of $149 \mathrm{~m} / \mathrm{s}$ and a thickness of fill/alluvium of $38 \mathrm{~m}$. This thickness is poorly constrained because of the lack of deep borehole information near the site, although there is a suggestion of a reflector with Vs of $320 \mathrm{~m} / \mathrm{s}$ at about $33 \mathrm{~m}$ depth from a seismic refraction survey near HAR (Williams and others, 1999). This site lies within the Seattle basin. The amplification factors in Table 4 are applied to the results of the 3D simulations and take into account the $700 \mathrm{~m} / \mathrm{sec}$ Vtop of the basin sediments below the fill/alluvium. The values in table 4 are given as a function of the input peak ground acceleration (PGA) for a rock site, except for the NEHRP amplification factors, which are a function of the $1 \mathrm{~Hz}$ spectral acceleration for a rock site condition.

Some general trends can be gleaned from table 4. The amplification factors derived from SHAKE using the two shear-wave velocity profiles shown in figure 28 are very similar, for all input accelerations. For low input accelerations of $0.2 \mathrm{~g}$ or less the NEHRP amplification factors are similar to the ones derived from SHAKE. However, we should note again that the factors from SHAKE are based on rock-site PGA, and the ones from NEHRP are based on rock-site $1 \mathrm{~Hz}$ S.A. For rock sites, PGA and $1 \mathrm{~Hz}$ S.A. are roughly similar in value. However, at high rock-site accelerations of $0.5 \mathrm{~g}$ or larger the factors from SHAKE are much lower than the NEHRP factors. The Choi and Stewart (2005) factors are somewhat higher than the SHAKE and NEHRP factors for low values of rock-site PGA (0.1g and lower). At higher rock-site accelerations greater than $0.4 \mathrm{~g}$, the Choi and Stewart (2005) amplification factors are intermediate between the SHAKE and NEHRP factors.

In figure 30, we compared the observed and predicted $1 \mathrm{~Hz}$ spectral amplifications at softsoil sites, for the four earthquakes whose modeling was described above. Here we have multiplied the amplification from the 3D simulation for that earthquake with the soft-soil amplification derived from the three methods described above. Since these are small earthquakes with weak motions we used the SHAKE results for an input acceleration of $0.01 \mathrm{~g}$. We used the Choi and Stewart (2005) factors defined for an input acceleration of $0.05 \mathrm{~g}$ (see above). The Choi and Stewart (2005) factors provide a better fit to the data. The root mean square of the residuals between the natural logarithms of the observed and predicted amplification values is 0.46 for the Choi and Stewart (2005) factors, 0.56 for the factors from SHAKE, and 0.57 for the NEHRP factors.

The observations for the site at Boeing Field (BOE) are often underestimated from SHAKE and the NEHRP factors. This site has a very strong resonance at about $1 \mathrm{~Hz}$. The smoothing algorithm for producing the thickness of fill map causes the thickness of the fill to be slightly underestimated at BOE, which can cause an underestimation of the $1 \mathrm{~Hz}$ amplification. Also, the 3D simulation for the earthquake to the west (April 25, 2003) predicted strong deamplification for BOE (relative to the rock sites), which is outside the Seattle basin. This predicted deamplification, combined with the amplification predicted from SHAKE for this site yielded a predicted amplification of only 2.2 compared to the observed amplification of 6.4. Using the Choi and Stewart (2005) factors and the 3D results predicts an amplification of 4.0, much closer to the observed value.

\section{Hazard Maps}

Figure 31 displays three probabilistic seismic hazard maps for Seattle, each for $1 \mathrm{~Hz}$ S.A. with a $2 \%$ probability of exceedance (P.E.) in $50 \mathrm{yr}$. The map on the left is from the 2002 national 
seismic hazard maps and is for a firm-rock site condition throughout the city. The map in the middle is derived from the 3D simulations and does not include the effects of amplification by the fill and young alluvium. The map on the right is based on the 3D simulations and the effects of the nonlinear response of the soft soils (fill and alluvium). This is one of the urban seismic hazard maps developed in this study (pl. 1).

Note that the hazard for sites with shallow bedrock in the middle and right panels of fig. 31 is approximately the same as that in the 2002 national seismic hazard maps, since we have referenced the amplifications derived in the 3D simulations to the average at three rock sites. The urban seismic hazard map shown in figure 31 (right) used the Choi and Stewart (2005) amplification factors for the soft-soil sites. As we explain below, we prefer the hazard maps derived with these factors over maps derived from SHAKE and the NEHRP factors.

The map based on the 3D simulations without the soft-soil amplification (figure 31, middle) displays the higher hazard in the Seattle basin compared to sites south of the frontal strand of the Seattle fault where the bedrock is relatively shallow. The hazard decreases for sites in the northern part of the city farther from the Seattle fault. Soil sites outside of the basin to the south of the frontal strand of the Seattle fault show higher hazard than the areas of shallow bedrock, but lower hazard than sites in the Seattle basin.

The urban seismic hazard map shown in figure 31 (right), based on the 3D simulations and including the amplification of the soft soils, provides a clear ranking of the relative hazard within the city of Seattle, for $1 \mathrm{~Hz}$ spectral acceleration. The most hazardous locations are soft soil sites (fill and alluvium) within the Seattle basin and along the inferred trace of the frontal fault of the Seattle fault zone. The next highest hazard is found for soft-soil sites in the Duwamish Valley south of the Seattle basin. Stiff-soil sites in the Seattle basin generally have somewhat lower hazard than the soft-soil sites south of the basin, although we will describe below an exception to this for the $10 \%$ P.E. in $50 \mathrm{yr}$ map. Lower hazard is found for stiff-soil sites outside the basin and stiff-soil sites in the northeastern portion of Seattle. Sites outside the Seattle basin with shallow bedrock have the lowest estimated hazard for this frequency band (around $1 \mathrm{~Hz}$ ). There is an especially large increase of hazard as one proceeds from areas of shallow bedrock to areas of fill and alluvium in the Duwamish Valley.

For sites in the Seattle basin, the probabilistic ground motions are generally higher over areas where the thickness of the Quaternary deposits is greatest, according to the model we used. Thus areas where the thickness of the Quaternary deposits is believed to be less (see figure 6), such as northeastern Seattle, westernmost Bellevue, and Mercer Island, have lower hazard estimates than sites in, for example, Magnolia, Queen Anne, Capital Hill and downtown. The predicted ground motions are higher for sites on thicker Quaternary deposits. This is largely caused by the increased amplitude of $1 \mathrm{~Hz}$ surface waves in the thicker deposits. Obviously, it is critical to have an accurate map of the thickness of the Quaternary (depth to bedrock) to accurately predict the relative hazard. The hazard also increases for sites just north of the southern edge of the Seattle basin, reflecting the effects of directivity for Seattle fault earthquakes and focusing from the southern edge of the basin.

The relative values of the probabilistic ground motions found in the $2 \%$ P.E. in $50 \mathrm{yr}$ map are consistent with observations from recorded seismograms in the area. For example, the probabilistic ground motions are about a factor of 2.5 higher for stiff-soil sites in the basin compared to shallow-bedrock sites to the south of the basin. This is similar to the average amplification at stiff-soil sites in the Seattle basin observed at $1 \mathrm{~Hz}$ from the Nisqually earthquake (Frankel and others, 2002b). The probabilistic ground motions at the fill/alluvium sites in the 
hazard maps are about 3 to 5 times that at the shallow-bedrock sites. Again, this is similar to the average amplifications observed at fill/alluvium sites from recordings of the Nisqually earthquake (Frankel and others, 2002b).

Figure 32 compares hazard maps at 2\% P.E. in 50 years using different procedures for estimating the amplification at soft-soil sites: the NEHRP factors, the Choi and Stewart (2005) factors, and factors derived from SHAKE. Of course, these maps are identical for the areas outside of the soft-soil deposits. The maps using the NEHRP amplification factors are generally similar to those based on the Choi and Stewart (2005) factors, although the hazard values for the NEHRP factor map are somewhat higher in portions of the Duwamish Valley. Choi and Stewart (2005) noted that the NEHRP factors can overestimate the observed amplification for soft-soil sites for high input ground motions.

The seismic hazard map produced with the SHAKE amplification factors exhibits markedly lower probabilistic ground motions for fill/alluvium sites than the maps based on the NEHRP and Choi and Stewart (2005) factors (figure 33). The map using SHAKE predicts that soft-soil sites outside of the Seattle basin in the Duwamish Valley have lower hazard than stiff-soil sites in the Seattle basin. As shown in figure 29, the SHAKE runs predict no amplification for input ground motions of $0.5 \mathrm{~g}$, whereas Choi and Stewart (2005) find significant amplification at soft-soil sites (factors of 1.4 relative to a stiff-rock site) for this input ground motion, based on their analysis of strong-motion recordings. The NEHRP amplification factors were derived from a combination of analysis of recorded data at low and moderate ground motions and modeling for high ground motions. Obviously, more data were available for Choi and Stewart (2005) than were available for the NEHRP amplification factors, which were developed in the mid 1990s.

We think the maps produced from the Choi and Stewart (2005) amplification factors are a better representation of the relative hazard across Seattle, compared to the maps determined from the two other procedures. We have two reasons for this preference. First, the Choi and Stewart (2005) factors are based on analysis of data. Second, the map with the Choi and Stewart factors is in better agreement with observations from the Nisqually earthquake, the strongest earthquake to date that was well-recorded in Seattle. The $1 \mathrm{~Hz}$ ground motions were observed to be larger on softsoil sites outside the Seattle basin than stiff soil sites within the basin. Plates 1 and 2 show the preferred hazard maps for $2 \%$ and $10 \%$ probabilities of exceedance, respectively.

Figure 33 contains hazard maps for $10 \%$ P.E. in 50 years, for the three methods of estimating amplification for soft-soil sites. The relative seismic hazard is generally the same as described above for the $2 \%$ P.E. in 50 year maps. The map made with the SHAKE amplification factors again displays seismic hazard values in the soft soils south of the Seattle basin that are comparable to those for the stiff soils in the Seattle basin. The maps from the NEHRP and Choi and Stewart (2005) factors show higher hazard for most soft-soil sites outside of the basin relative to stiff soil sites in the basin. The map derived from the Choi and Stewart (2005) factors is somewhat higher for fill sites in the Seattle basin than the map from the NEHRP factors. This is caused by the higher amplification at low input accelerations for the Choi and Stewart (2005) factors, compared to the NEHRP factors (see Table 4).

It is notable that there is an area of somewhat elevated hazard in Magnolia and Queen Anne that is apparent on the $10 \%$ P.E. in 50 year maps. This is largely caused by the predicted ground motions for Cascadia subduction zone earthquakes. These earthquakes have a higher contribution to the overall hazard in the $10 \%$ P.E. in $50 \mathrm{yr}$ maps than they do for the $2 \%$ P.E. in $50 \mathrm{yr}$ maps, since their recurrence time (500 years) is shorter than that of Seattle fault earthquakes. Note that this area of Seattle (Magnolia and Queen Anne) have higher predicted ground motions in figure 25 
for the point sources (numbers 2-5) on the Cascadia subduction zone located to the west of Seattle. This elevated amplitude is caused by amplified surface waves that are propagating eastward along the thickest portion of the Quaternary section.

\section{Uncertainties and Limitations}

We view these maps as the first step in portraying the relative seismic hazard across Seattle. These maps are research products that are suitable for use in many applications. We can provide guidance to users about the appropriateness of the maps for a proposed application.

While the major divisions of relative hazard described above are robust, details of the hazard maps would change if we added additional 3D simulations. For example, although the hazard does decrease for the northeastern portions of Seattle, the exact location of the $100 \% \mathrm{~g}$ contour in the $2 \%$ P.E. in $50 \mathrm{yr}$ map would likely change if we added more simulations for the gridded seismicity. This contour moved about $1 \mathrm{~km}$ to the north when we went from using one epicentral distance for the smoothed seismicity simulations to using three distances. The user should be aware that small differences (about 10\%) in map values between neighboring areas are usually not significant.

Obviously, a key source of uncertainty in the hazard maps is the accuracy of the 3D velocity model and the shear-wave velocity profiles used for the soft-soil sites. These maps are not intended to be a substitute for site-specific studies where the Vs profile can be determined for that specific site. As we have shown, one critical parameter is the thickness of the Quaternary deposits in the Seattle basin. This is poorly known except in the limited locations where boreholes have reached bedrock, or where there have been seismic refraction/reflection surveys. This study points out the need for more seismic data to improve on the shallow portion of the 3D model.

This study mixes the results of the 3D simulations with nonlinear amplification for soft-soil deposits. The response of the soft soils will differ depending on whether the input is a shear wave or a basin surface wave. We used the ground motion at the base of the fill/alluvium determined from generic attenuation relations for rock sites. The effects of the 3D structure will likely alter the ground motions at the base of the soft-soil layers from the values in the rock-site attenuation relations. The best approach would be to apply a nonlinear code for three-dimensional wave propagation. To our knowledge, no such code has been developed to date.

Care should be taken in reading off values using the contouring in the page-sized maps for sites near the transition between the fill/alluvium and the upland areas of stiff soils. The $280 \mathrm{~m}$ grid spacing used to make the maps, combined with the smoothing that occurs in contouring of the page-sized maps, can sometimes blur where the transition in hazard actually is on the page-sized maps.

For the maps in the over-sized plates, we imposed a discontinuity in the probabilistic ground motions at the mapped boundary between the fill/alluvium and the stiff soils. On the fill/alluvium-side of this boundary, we used the ground motions calculated at the nearest fill/alluvium site. On the stiff-soil side of the boundary, we used the ground motions calculated at the nearest stiff-soil site.

It also should be stressed that these maps are for $1 \mathrm{~Hz}$ spectral acceleration so that maps for other frequencies may show a different pattern of relative hazard across Seattle. At $5 \mathrm{~Hz}$ we would 
expect that the amplification in the center of the Seattle basin would be less, since basin surface waves at $5 \mathrm{~Hz}$ will be quickly damped out. In addition, variations in Vs30 have less effect on the amplification of S-waves at $5 \mathrm{~Hz}$ than at $1 \mathrm{~Hz}$. We would still expect $5 \mathrm{~Hz}$ amplification along the southern edge of the basin from focusing (see Stephenson and others, 2006). Rupture directivity would also be less pronounced at $5 \mathrm{~Hz}$ compared to $1 \mathrm{~Hz}$. These differences would likely result in higher $5 \mathrm{~Hz}$ ground motions in the hanging wall of the Seattle fault compared to sites in the Seattle basin, a result that would look quite different from the $1 \mathrm{~Hz}$ hazard maps developed here. The user needs to decide whether these $1 \mathrm{~Hz}$ hazard maps are suitable for their particular application. The authors of this report are committed to assisting in this decision process.

\section{Acknowledgments}

We thank Kathy Troost and Derek Booth of the Pacific Northwest Center for Geologic Mapping Studies, University of Washington, for providing the borehole data of the depth to glacially-overridden material. Seismograms, hypocenters, and focal mechanisms from the Pacific Northwest Seismic Network were key inputs to this study. Pengcheng Liu kindly provided his 3D finite difference code that was essential to this project. We especially thank Craig Weaver for his support and encouragement of this effort. We acknowledge the help provided by Bob Norris, Dave Worley, and Oliver Boyd in various aspects of this study. John Michael provided some of the GIS databases. We appreciate the comments on seismic hazard issues provided by Tom Pratt, Steve Hartzell, Steve Harmsen, Steve Palmer, Bill Steele, Steve Malone, Sam Johnson, Brian Sherrod, and Brian Atwater. We thank Joan Gomberg for her valuable comments on the manuscript which helped us to make it more understandable. Robert Wesson and Steve Hartzell provided insightful reviews which led to substantial improvements in this report.

\section{References}

Abrahamson, N.A., Somerville, P.G., and Cornell, C.A., 1990, Uncertainty in numerical strong motion predictions, in Proc. of the Fourth U.S. National Conference on Earthquake Engineering, v. 1, p. 407-416.

Abrahamson, N.A. and Silva, W.J., 1997, Empirical response spectral attenuation relations for shallow crustal earthquakes, Seismological Research Letters, v. 68 (1), 94-127.

Atkinson, G.M., 1995, Attenuation and source parameters of earthquakes in the Cascadia region, Bulletin of the Seismological Society of America, v. 85, p.1327-1342.

Atkinson, G.M. and Boore, D.M., 2003, Empirical ground-motion relations for subduction-zone earthquakes and their application to Cascadia and other regions, Bulletin of the Seismological Society of America, v. 93, p.1703-1729.

Blakely, R.J., Wells, R.E., Weaver, C.S., and Johnson, S.Y., 2002, Location, structure, and seismicity of the Seattle fault zone, Washington: evidence from aeromagnetic anomalies, geologic mapping, and seismic-reflection data, Geological Society of America Bulletin, v.114, p. 169-177. 
Boore, D.M., and Joyner, W.B., 1997, Site amplification for generic rock sites, Bulletin of the Seismological Society of America, v. 87, p. 327-341.

Boore, D.M., Joyner, W.B. and Fumal, T.E., 1997, Equations for estimating horizontal response spectra and peak acceleration from western North American earthquakes: a summary of recent work, Seismological Research Letters, v. 68, p. 128-153.

Booth, D.B., Wells, R.E. and Givler, R.W., 2004, Chimney damage in the greater Seattle area from the Nisqually earthquake of 28 February, 2001, Bulletin of the Seismological Society of America, v. 94 , p. 1143-1158.

Brocher, T.M., 2005, Empirical relations between elastic wavespeeds and density in the Earth's crust, Bulletin of the Seismological Society of America v. 95, p. 2081-2092.

Brocher, T.M., Blakely, R.J. and Wells, R.E., 2004, Interpretation of the Seattle uplift, Washington, as a passive-roof duplex, Bulletin of the Seismological Society of America, v. 94, p. 1379-1401.

Building Seismic Safety Council (BSSC) (2001). NEHRP (National Earthquake Hazards Reduction Program) Recommended Provisions for Seismic Reulations for New Buildings and Other Structures, Part 1: Provisions and Part2: Commentary, Federal Emergency Management Agency, FEMA-368 and FEMA-369, Washington, DC.

Campbell, K.W. and Bozorgnia, Y., 2003, Updated near-source ground motion (attenuation) relations for the horizontal and vertical components of peak ground acceleration and acceleration response spectra, Bulletin of the Seismological Society of America, v. 93, p. 314-331.

Choi, Y. and Stewart, J.P., 2005, Nonlinear site amplification as function of 30m shear wave velocity, Earthquake Spectra, v. 21, p.1-30.

Chulick, G.S. and Mooney, W.D., 2002, Seismic structure of the crust and uppermost mantle of North America and adjacent basins: as synthesis, Bulletin of the Seismological Society of America, v. 92, p. 2478-2492.

Electric Power Research Institute (EPRI), 1993, Guidelines for determining design basis ground motions, Electric Power Research Institute Technical Report EPRI TR-102293.

Flueck, P., Hyndman, R.D., and Wang, K., 1997, Three-dimensional dislocation model for great earthquakes of the Cascadia subduction zone, Journal of Geophysical Research, v. 102, p. 20,539-20,550.

Frankel, A.,1991, High-frequency spectral falloff of earthquakes, fractal dimension of complex rupture, b value, and the scaling of strength on faults, Journal of Geophysical Research, v. 96, p. 6291-6302.

Frankel, A., Carver, D., Cranswick, E., Meremonte, M., Bice, T., and Overturf, D., 1999, Site response for Seattle and source parameters of earthquakes in the Puget Sound region, Bulletin of the Seismological Society of America, v. 89, p. 468-483. 
Frankel, A., Carver, D.L., and Williams, R.A., 2002b, Nonlinear and linear site response and basin effects in Seattle from the M 6.8 Nisqually, Washington, earthquake, Bulletin of the Seismological Society of America, v. 92, p. 2090-2109.

Frankel, A., Petersen, M., Mueller, C., Haller, K., Wheeler, R., Leyendecker, E., Wesson, R., Harmsen, S., Cramer, C., Perkins, D., and Rukstales, K., 2002a, Documentation for the 2002 update of the national seismic hazard maps, U.S. Geological Survey Open-File Report 02-420, 39 pages, http://eqhazmaps.usgs.gov.

Frankel, A.D. and Stephenson, W.J., 2000, Three-dimensional simulations of ground motions in the Seattle region for earthquakes in the Seattle fault zone, Bulletin of the Seismological Society of America, v. 90, p. 1251-1267.

Frankel, A.D., Stephenson, W.J., Carver, D.L., Williams, R.A., Odum, J.K., and Rhea, S., 2006, Seismic hazard maps for Seattle that include 3D sedimentary basin effects, rupture directivity, and site response, in proceedings for the $8^{\text {th }}$ U.S. National Conference on Earthquake Engineering, Earthquake Engineering Research Institute, Oakland, Calif., 10 p., 1 CD.

GeomapNW 2005. Pacific Northwest Center for Geologic Mapping Studies, University of Washington, online geodatabase. http://geomapnw.ess.washington.edu

Graves, R.W., Pitarka, A., and Somerville, P.G., 1998, Ground-motion amplification in the Santa Monica area: effects of shallow basin-edge structure, Bulletin of the Seismological Society of America v. 88, p. 1224-1242.

Hartzell, S., Bonilla, L.F. and Williams, R.A., 2004, Prediction of nonlinear soil effects, Bulletin of the Seismological Society of America, v. 94, p. 1609-1629.

Hartzell, S., Carver, D., Cranswick, E., and Frankel, A., 2000, Variability of site response in Seattle, Washington, Bulletin of the Seismological Society of America, v. 90, p. 1237-1250.

Hartzell, S., Harmsen, S., Frankel, A. and Larsen, S., 1999, Calculation of broadband time histories of ground motion: comparison of methods and validation using strong-ground motion from the 1994 Northridge Earthquake, Bulletin of the Seismological Society of America. v. 89, p. 14841504.

Hartzell, S., Harmsen, S., Williams, R., Carver, D., Frankel, A., Choy. G., Liu, P-C, Jachens, R., Brocher, T., and Wentworth, C., 2006, Modeling and validation of a 3D velocity structure for the Santa Clara Valley, California, for seismic-wave simulations, Bulletin of the Seismological Society of America, v. 96, p.1851-1881.

Hartzell, S., Leeds, A., Frankel, A., Williams, R., Odum, J., Stephenson, W., and Silva, W., 2002, Simulations of broadband ground motions including nonlinear soil effects for a magnitude 6.5 earthquake on the Seattle fault, Seattle, Washington, Bulletin of the Seismological Society of America, v. 92, p. 831-853.

Herrero, A. and Bernard, P., 1994, A kinematic self-similar rupture process for earthquakes, Bulletin of the Seismological Society of America, v. 84, p. 1216-1228. 
Idriss, I.M. and Sun, J.I., 1992, User's Manual for SHAKE 91, a computer program for conducting equivalent linear seismic response analyses of horizontally layered soil deposits. University of California, Davis, California, 37 p.

Johnson, S.Y., Dadisman, Childs, J.R., and Stanley, W.D., 1999, Active tectonics of the Seattle fault and central Puget Sound, Washington-Implications for earthquake hazards, Geological Society of America Bulletin, v. 111, p. 1042-1053.

Jones, M.A., 1996, Thickness of unconsolidated deposits in the Puget Sound Lowland, Washington and British Columbia, U.S. Geological Survey Water Resources Investigations Report 94-4133.

Liu, P-C and Archuleta, R.J., 2002, The effect of a low-velocity surface layer on simulated ground motion, Seismological Research Letters, v. 73, p. 267.

Meremonte, M., Frankel, A., Cranswick, E., Carver, D., and Worley, D., 1996, Urban seismology: Northridge aftershocks recorded by multiscale arrays of portable seismographs, Bulletin of the Seismological Society of America, v. 86, p. 1350-1363.

Pitarka, A., Graves, R., and Somerville, P., 2004, Validation of a 3D velocity model of the Puget Sound region based on modeling ground motion from the 28 February 2001 Nisqually earthquake, Bulletin of the Seismological Society of America, v. 94, p. 1670-1689.

Pratt, T.L., Johnson, S., Potter, C., Stephenson, W. and Finn, C., 1997, Seismic reflection images beneath Puget Sound, western Washington state: the Puget Lowland thrust sheet hypothesis, Journal of Geophysical Research, v. 102, p. 27,469-27,489.

Pratt, T.L. and Brocher, T.M., 2006, Site response and attenuation in the Puget Lowland, Washington, Bulletin of the Seismological Society of America, v. 96, p. 536-552.

Ramachandran, K., Hyndman, R.D., and Brocher, T.M., 2006, Regional P wave velocity structure of the northern Cascadia subduction zone, Journal of Geophysical Research, v. 111, B12301, doi:10.1029/2005JB004108.

Sadigh, K., Chang, C.-Y., Egan, J.A., Makdisi, F., and Youngs, R.R., 1997, Attenuation relations for shallow crustal earthquakes based on California strong motion data, Seismological Research Letters, v. 68, p. 180-189.

Schnabel, P.B., Lysmer, J. and Seed, H.B., 1972, SHAKE: A computer program for earthquake response analysis of horizontally layered sites, report UCB/EERC-72/12, Earthquake Engineering Research Center, University of California, Berkeley, 102 p.

Somerville, P., Irikura, K., Graves, R., Sawada, S., Wald, D., Abrahamson, N., Iwasaki, Y., Kagawa, T., Smith, N. and Kowada, A., 1999, Characterizing crustal earthquake slip models for the prediction of strong ground motions, Seismological Research Letters, v. 70, p. 59-80.

Stanley, D., Villasenor, A., and Benz, H., 1999, Subduction zoen and crustal dynamics of western Washington: A tectonic model for earthquake hazards evaluation, U.S. Geological Survey, OpenFile Report 99-311, http://pubs.usgs.gov/of/1999/ofr-99-0311. 
Stephenson, W.J., in Preparation, Velocity and density models incorporating the Cascadia Subduction Zone for 3D earthquake ground motion simulation, U.S. Geological Survey Open File Report.

Stephenson, W.J., Williams, R.A., Odum, J.K., and Worley, D.M., 2000, High-resolution reflection surveys and modeling across an area of high damage from the 1994 Northridge earthquake, Sherman Oaks, California, Bulletin of the Seismological Society of America, v. 90, p. 643-654.

Stephenson, W.J., Frankel, A.D., Odum, J.K., Williams, R.A., Pratt, T.L., 2006, Towards resolving an earthquake ground motion mystery in west Seattle, Washington state: shallow seismic focusing may cause anomalous chimney damage, Geophysical Research Letters, DOI 10.1029/2005GL025037.

ten Brink, U.S., Molzer, P.C., Fisher, M.A., Blakely, R.J., Bucknam, R.C., Parsons, T., Crosson, R.C., and Creager, K.C., 2002, Subsurface geometry and evolution of the Seattle fault zone and the Seattle basin, Washington, Bulletin of the Seismological Society of America, v. 92, p. 17371753.

Wald, D.J., Heaton, T.H., and Hudnut, K.W., 1996, The slip history of the 1994 Northridge, California, earthquake determined from strong-motion, teleseismic, GPS, and leveling data, Bulletin of the Seismological Society of America, v. 86, p. S49-S70.

Waldron, H.H., B.A. Liesch, D.R. Mullineaux, and D.R. Crandell, 1962. Preliminary geologic map of Seattle and vicinity, U.S. Geol. Surv. Map I-354.

Washington State Department of Natural Resources, 2005, Report on boring logs from Stanford Educational Center, Seattle, Washington State Department of Natural Resources, Olympia, Wash., 8 p.

Williams, R.A., Stephenson, W.J., Frankel, A.D., and Odum, J.K., 1999, Surface seismic measurements of near-surface P- and S-wave seismic velocities at earthquake recording stations, Seattle, Washington, Earthquake Spectra, v. 15, p. 565-584.

Wong, I., Sparks, A., Thomas, P., and Nemser, E., 2003, Evaluation of near-surface site amplification in the Seattle, Washington, metropolitan area, final technical report submitted to the U.S. Geological Survey, URS Corporation, Oakland, Calif., 37 p.

Youngs, R.R., Chiuo, S.-J., Silva, W.J. and Humphrey, J.R., 1997, Strong ground motion attenuation relationships for subduction zone earthquakes, Seismological Research Letters, v. 68, p. 58-73.

Yount, J.C., Dembroff, G.R., and Barats, G.M., 1985, Map showing depth to bedrock in the Seattle $30^{\prime}$ by $60^{\prime}$ quadrangle, Washington, U.S. Geological Survey Miscellaneous Field Studies Map MF-1692, scale 1:100,000. 


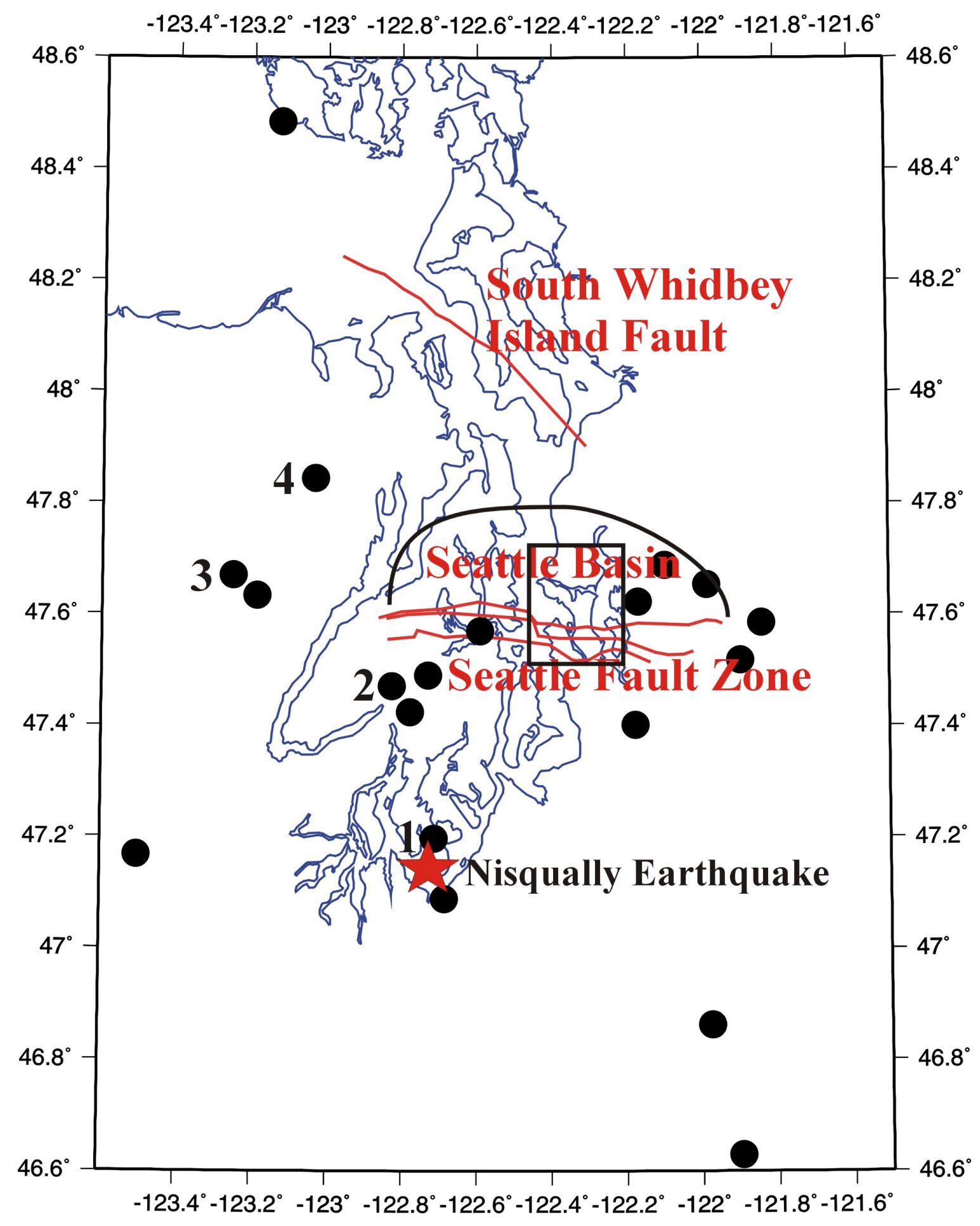

Figure 1. Epicenters of earthquakes (black dots) used in study of azimuthal dependence of amplification. Star is epicenter of 2001 Nisqually earthquake. The three inferred strands of the Seattle fault and the trace of the South Whidbey Islands fault are indicated. The box represents the area of the Seattle urban seismic hazard maps (borders are $47.48^{\circ} \mathrm{N}$ to $47.75^{\circ} \mathrm{N}, 122.2^{\circ} \mathrm{W}$ to $122.45^{\circ}$ W). The black line shows the approximate extent of the Seattle basin, whose southern border is the Seattle fault zone. Numbers refer to earthquakes modeled with 3D simulations (see table 1). 


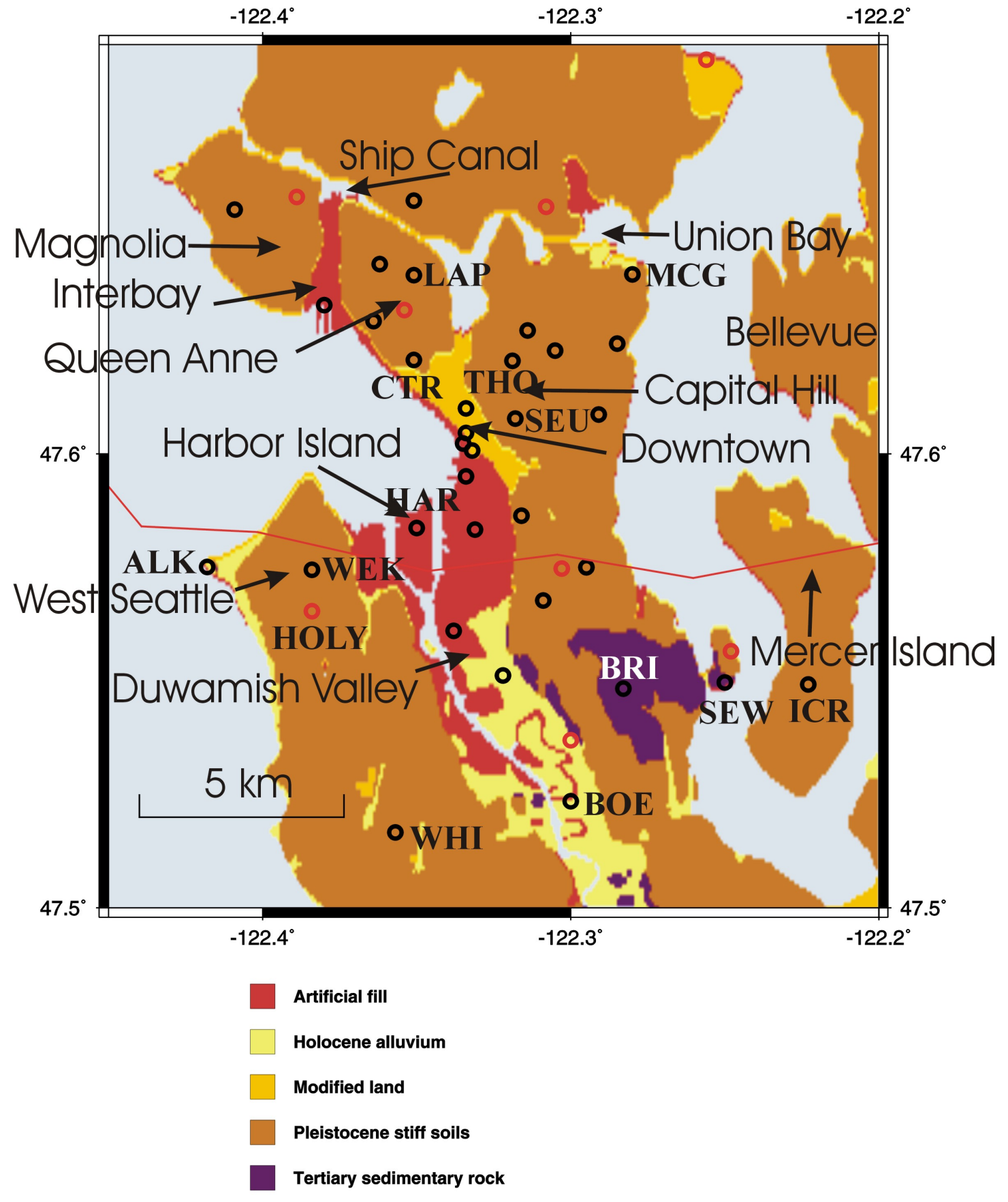

Figure 2. Map of Seattle area with surficial geology (Waldron and others, 1962), place names, and locations of stations of the Seattle Urban Seismic Network (black circles) and the Pacific Northwest Seismic Network (red circles). Some key stations are labeled. Red line indicates inferred location of frontal trace of Seattle fault zone. 


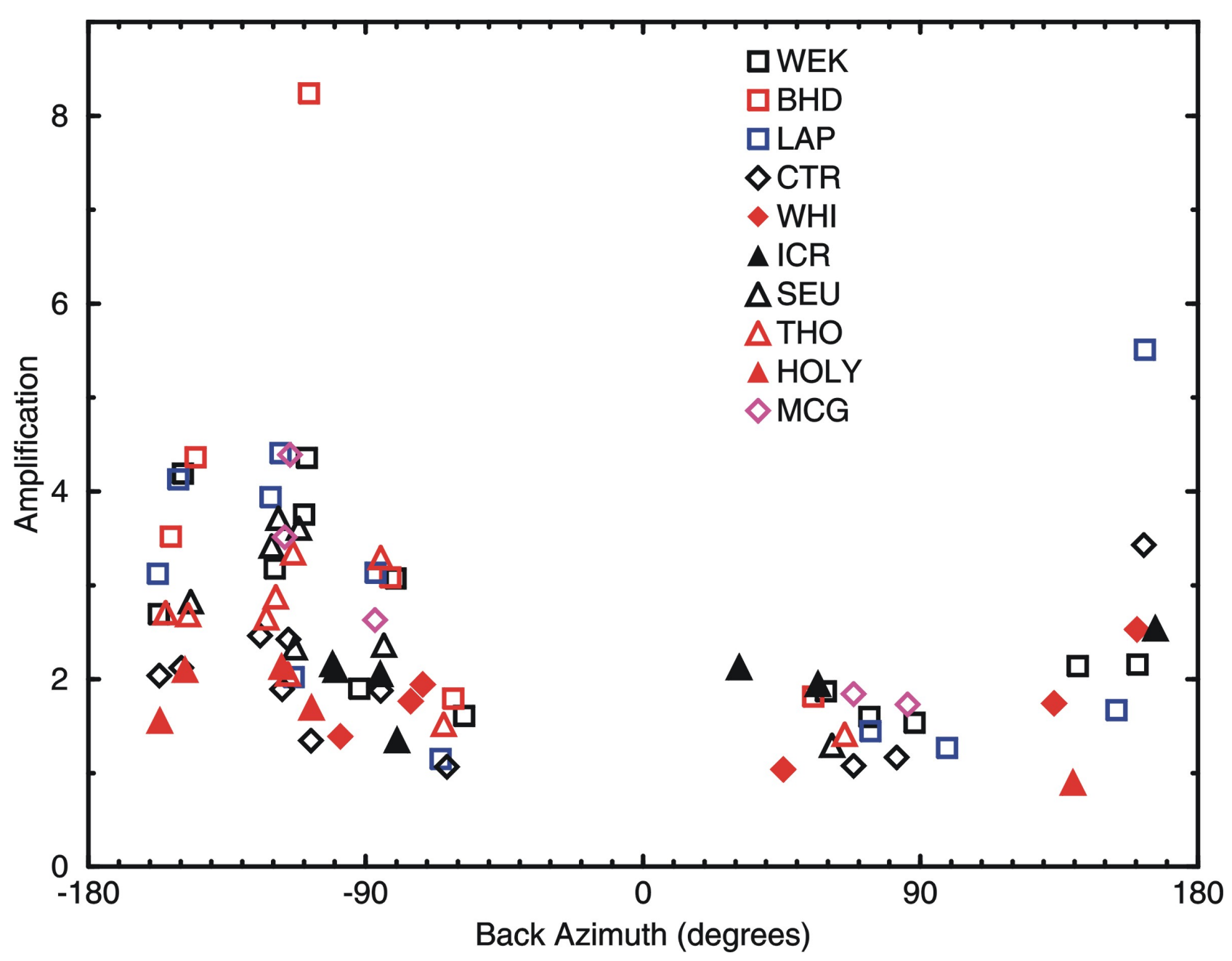

Figure 3. Amplification determined from Fourier spectral ratios at $1 \mathrm{~Hz}$, relative to rock site ALK. Open symbols are stations within the Seattle basin, the filled symbols denote stations outside the Seattle basin. The back azimuth is the angle from the station to the epicenter. Note the higher average amplification for earthquakes to the south and southwest (back azimuths from -160 to -70 ). 
Depth of gridded seismicity

$15 \mathrm{~km}$

$10 \mathrm{~km}$
Dip of frontal strand of Seattle fault

30 degrees

45 degrees
Recurrence relations on Seattle and S. Whidbey Island faults

Truncated GR

characteristic
Downdip edge of Cascadia Subduction Zone

Base of elastic zone

Midpoint between elastic and transition bases

Base of transition zone

Geometry used in 1996 maps
Magnitude and Recurrence Time for CSZ

M9.0, 500 yr recurrence time

M8.3, floating rupture; ruptures entire CSZ over 500 years

Figure 4. Logic tree used to characterize uncertainties in earthquake sources. CSZ stands for the Cascadia subduction zone. GR denotes a truncated Gutenberg-Richter model for earthquake recurrence on faults, with a minimum magnitude of 6.5 . $\mathrm{M}$ is moment magnitude. 


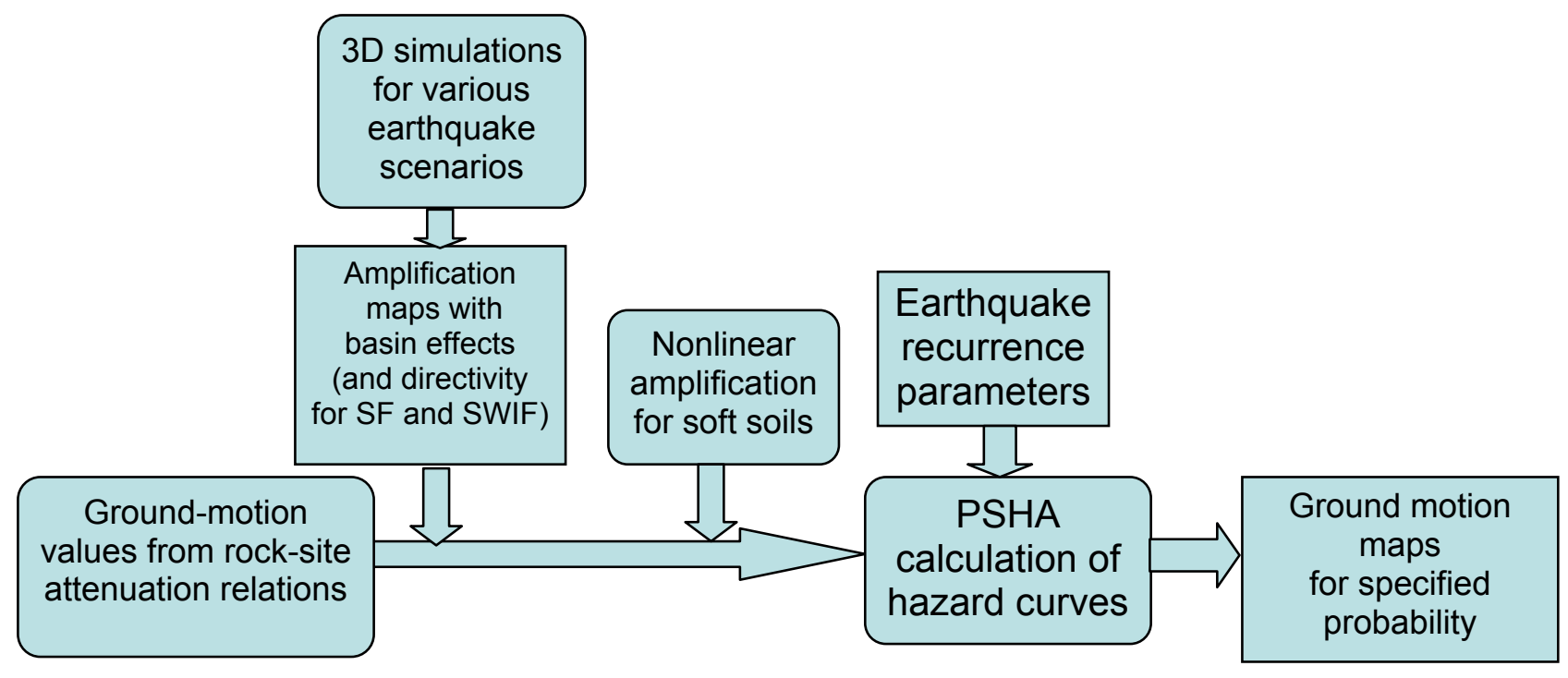

Figure 5. Flowchart indicating methodology for incorporating $3 \mathrm{D}$ simulations and nonlinear response into the probabilistic seismic hazard assessment (PSHA). The amplification map derived from each 3D simulation contains the effects of sedimentary basins, as well as rupture directivity for the cases of earthquakes on the Seattle fault (SF) and South Whidbey Island Fault (SWIF). PSHA; probabilistic seismic hazard assessment. 


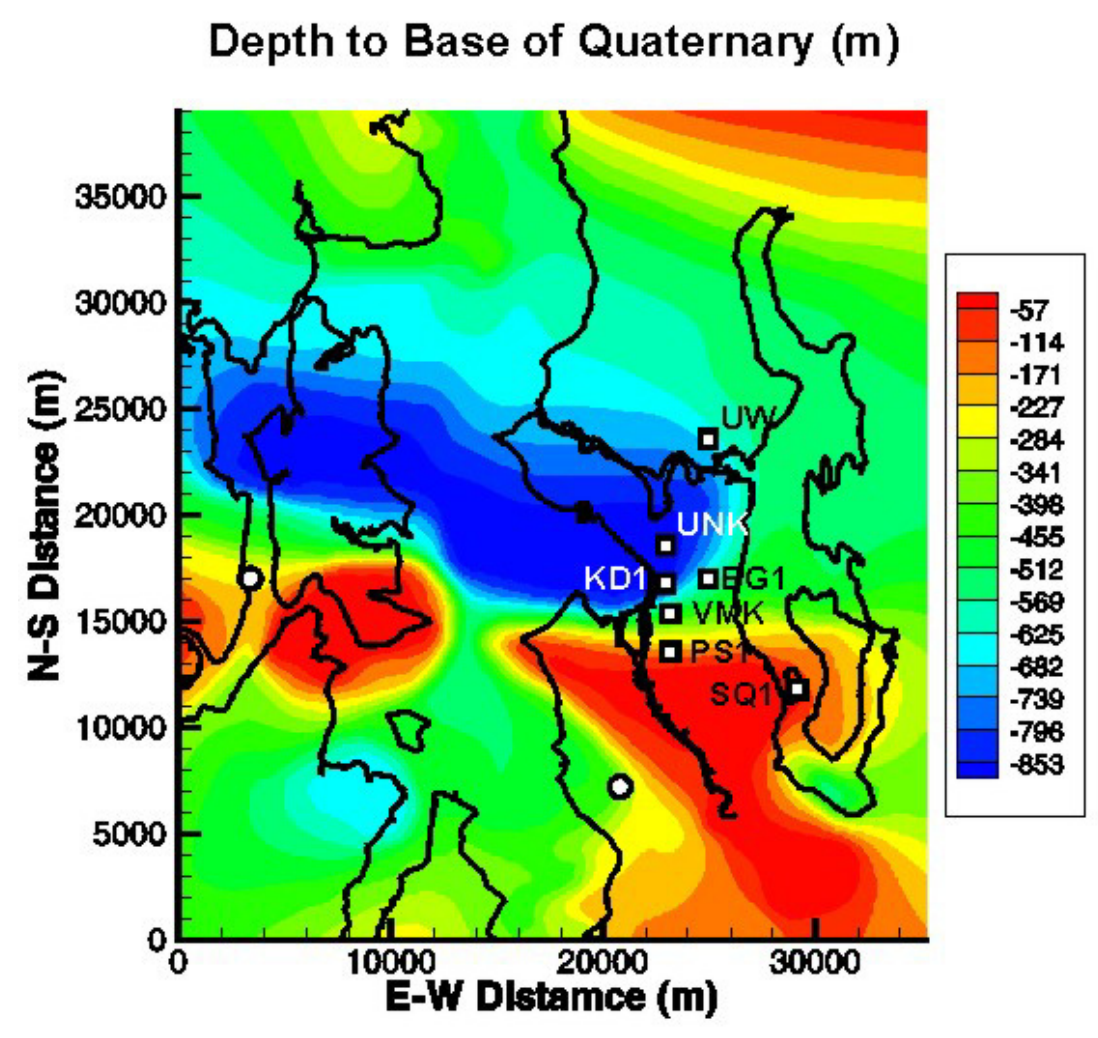

Figure 6. Depth to top of bedrock (base of Quaternary deposits) in meters below sea level, based on model developed by Johnson and others (1999) from borehole and seismic data. Squares are selected stations of the Seattle Urban Seismic Array. Circles are epicenters of the $M_{L} 4.9$ Bremerton earthquake (June 23, 1997) and the $M_{L} 3.5$ earthquake on Feb. 10, 1997. Figure is from Frankel and Stephenson (2000). 


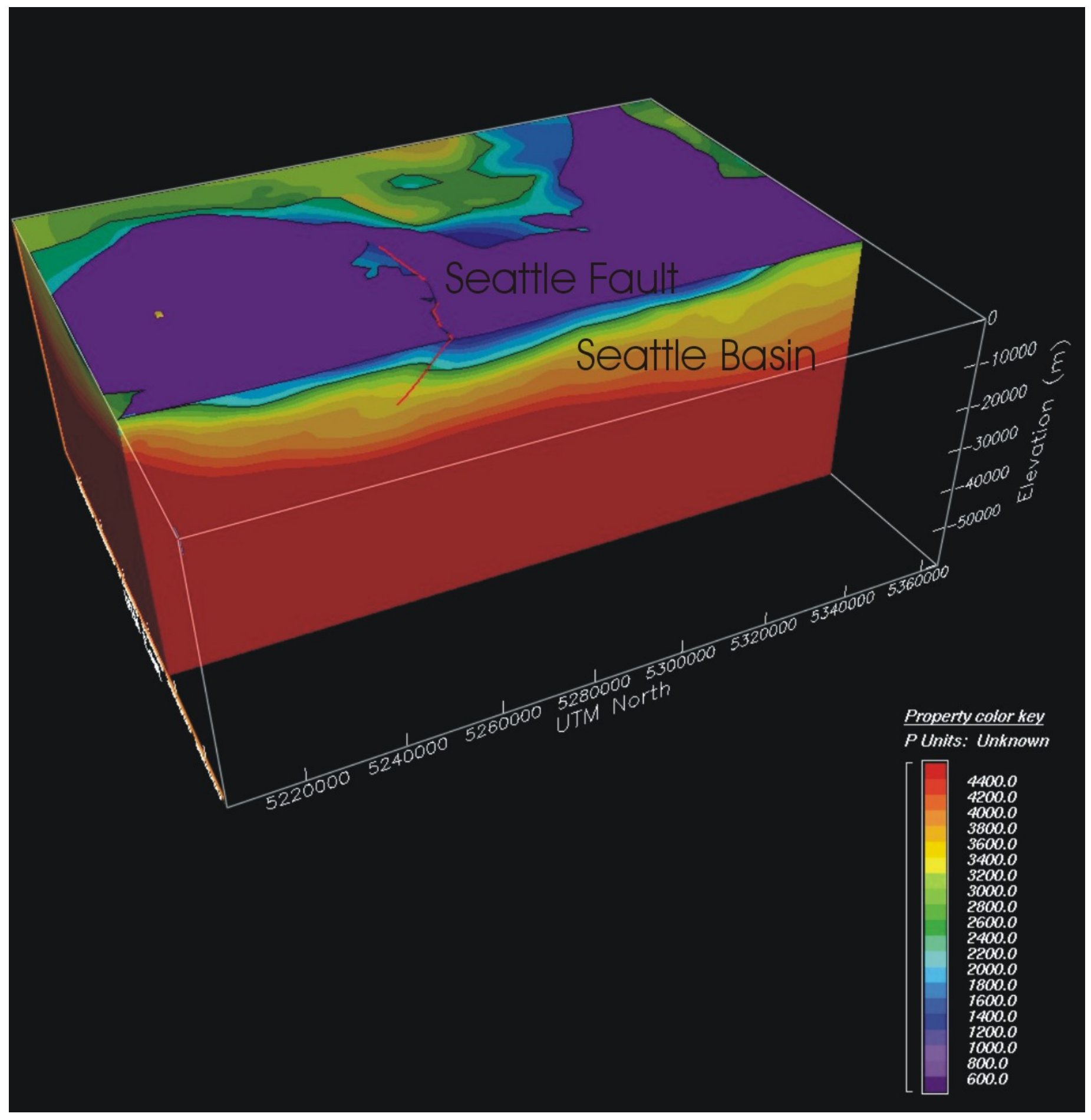

Figure 7. Portion of $3 \mathrm{D}$ model of the shear-wave velocity, used in the simulations. The cross section is at a longitude approximately corresponding to station ALK (see Figure 2). Note the offset of Swave velocities at the Seattle fault (red line), which comprises the southern edge of the Seattle basin. 
LAP (Queen Anne Hill)
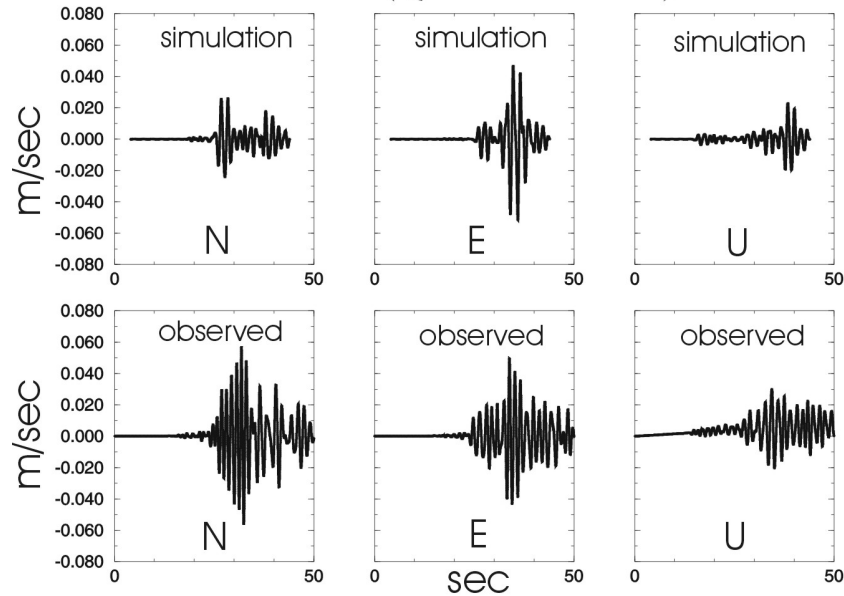

ALK (Alki Point, rock site)
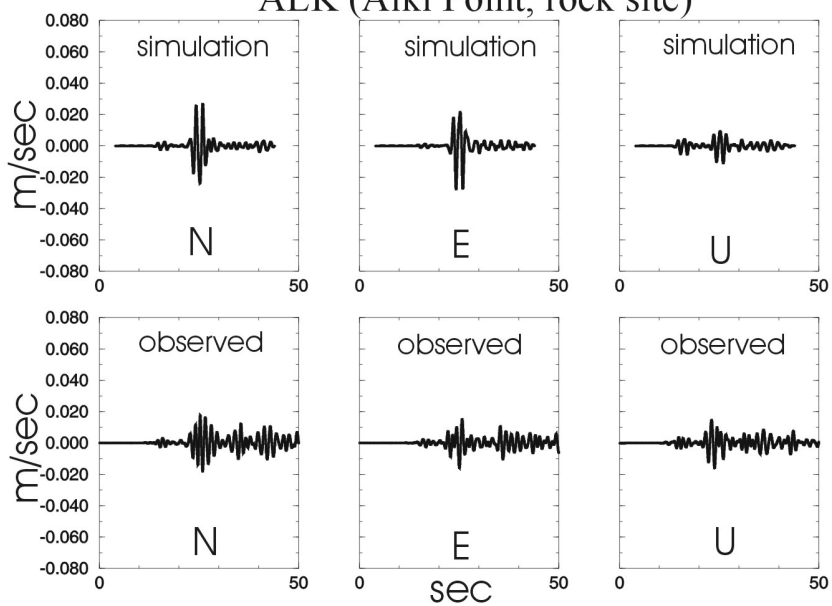

THO (Capital Hill)
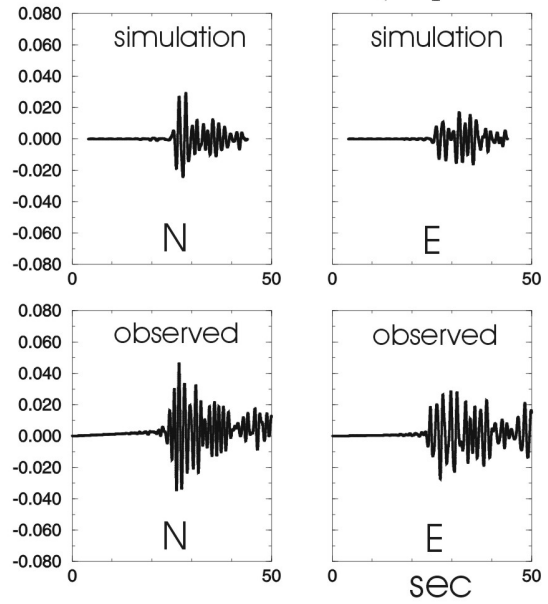

simulation

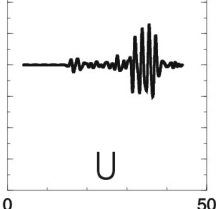

observed

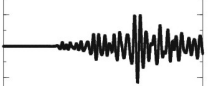

U

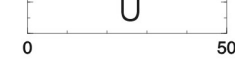

WEK (West Seattle)
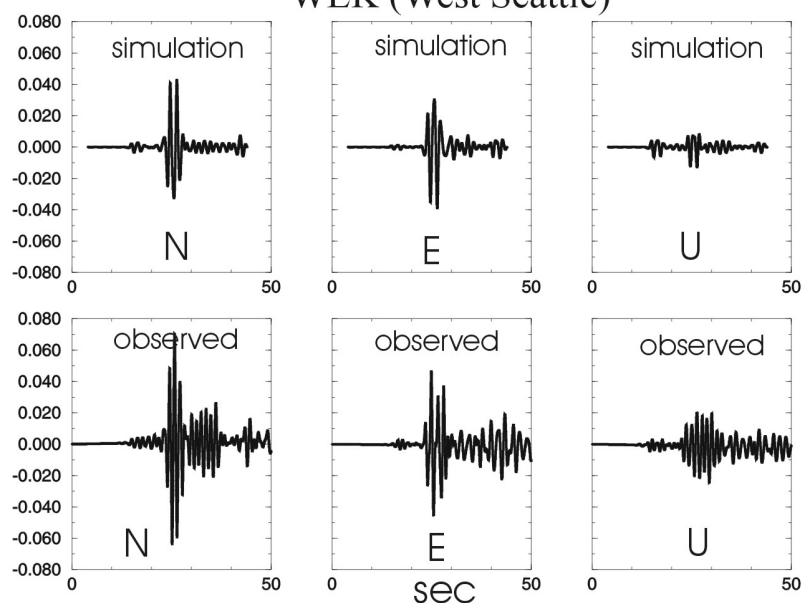

Figure 8. Synthetic and observed velocity waveforms (filtered between 0.5 and $1.0 \mathrm{~Hz}$ ), for the 2001 M6.8 Nisqually earthquake. 


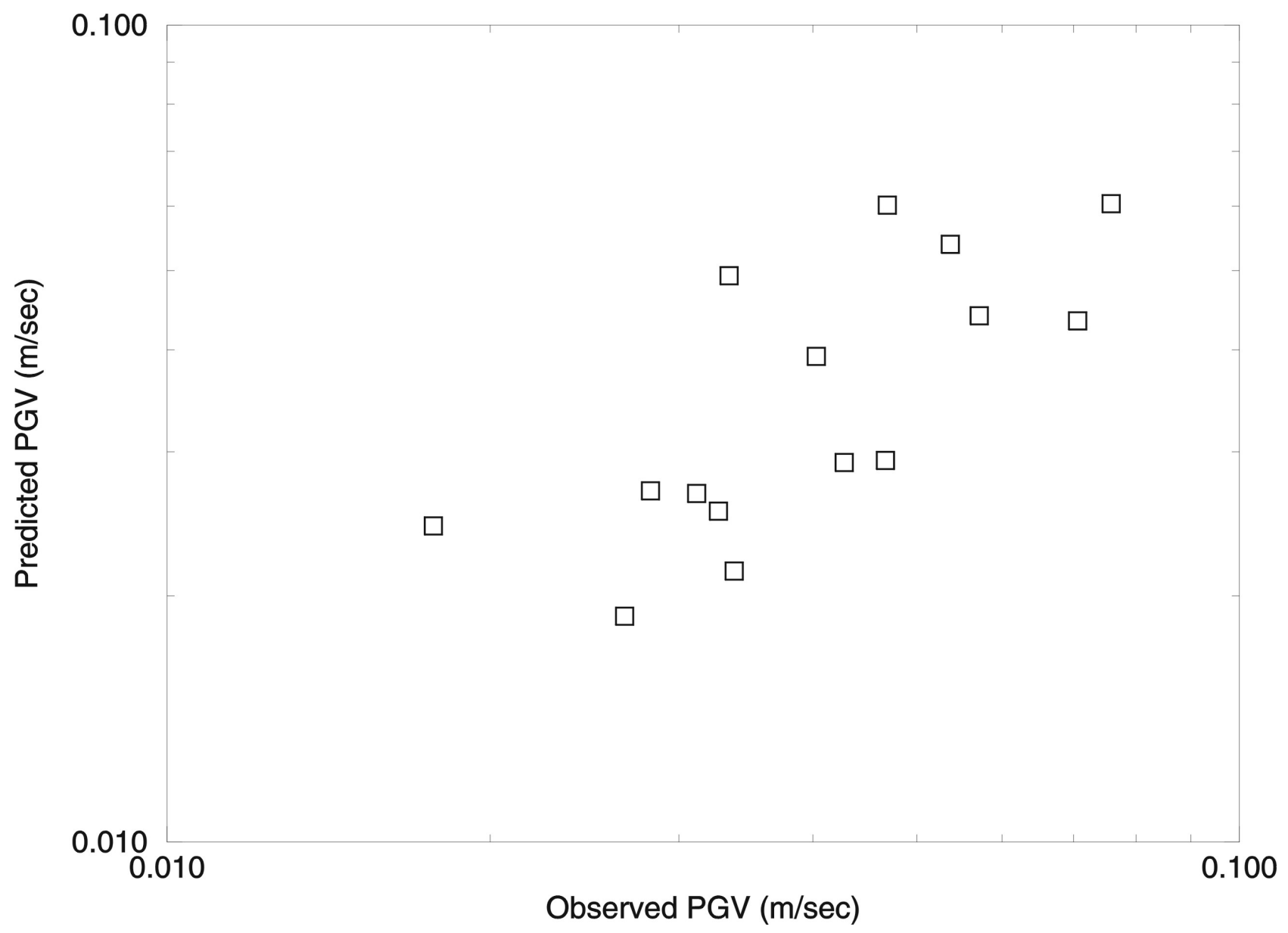

Figure 9. Comparison between the predicted peak ground velocity (PGV in $\mathrm{m} / \mathrm{sec}$ ) at 14 stations for the Nisqually earthquake using the 3D simulation and the observed PGV's. These are all stiff soil or rock sites. The observed and predicted seismograms are filtered between 0.5 and $1.0 \mathrm{~Hz}$. 


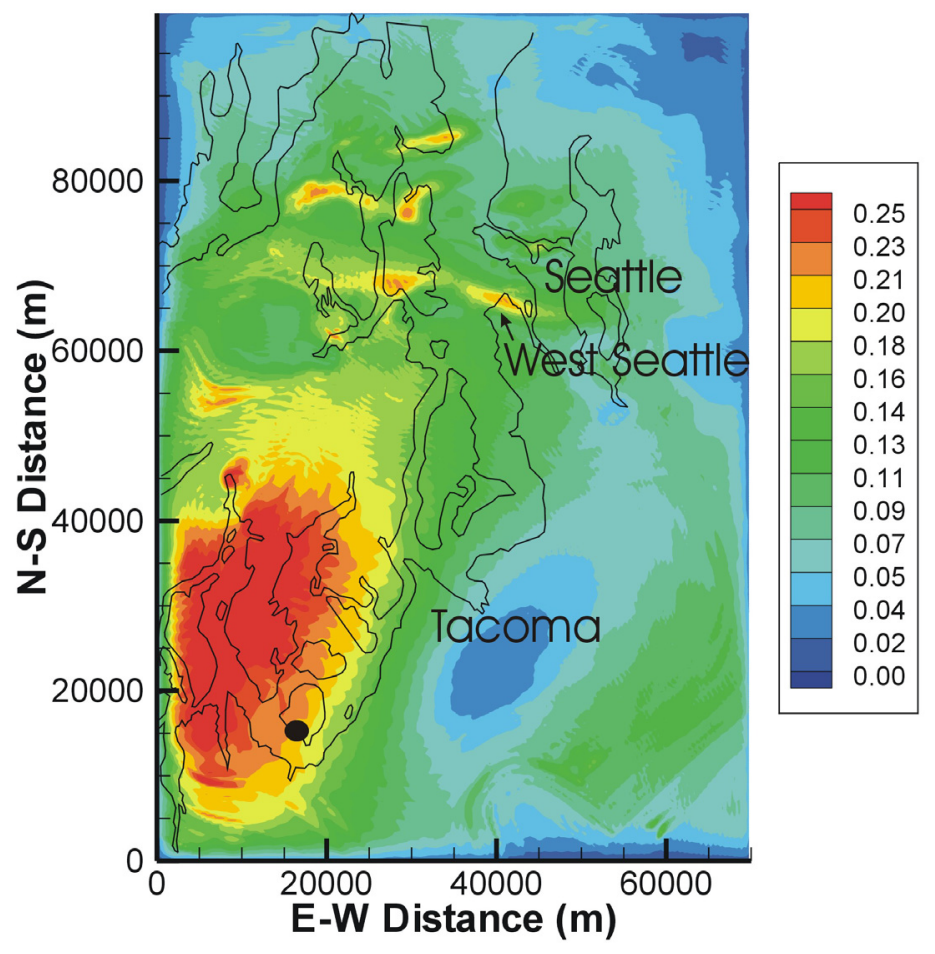

Figure 10. Puget Sound region showing the peak values of the root mean square ground velocity $(\mathrm{m} / \mathrm{s})$ of the two horizontal components from the 3D simulation of the 2001 Nisqually earthquake (see p. 9-10 of text). The highest velocities are to the northwest of the epicenter (black dot). The simulation produces a band of high amplitude along the southern edge of the Seattle basin, just north of the Seattle fault. This predicted band of high amplitudes in West Seattle corresponds to an area of concentrated damage to chimneys caused by the Nisqually earthquake (see p. 10 of text). Note also the predicted lower ground motions near Tacoma, which is correlated with the relatively low ground motions observed in that area from the Nisqually earthquake (see p. 10 of text). 


\section{Predicted and Observed Spectral Ratios wrt Rock Sites Stiff-soil sites}

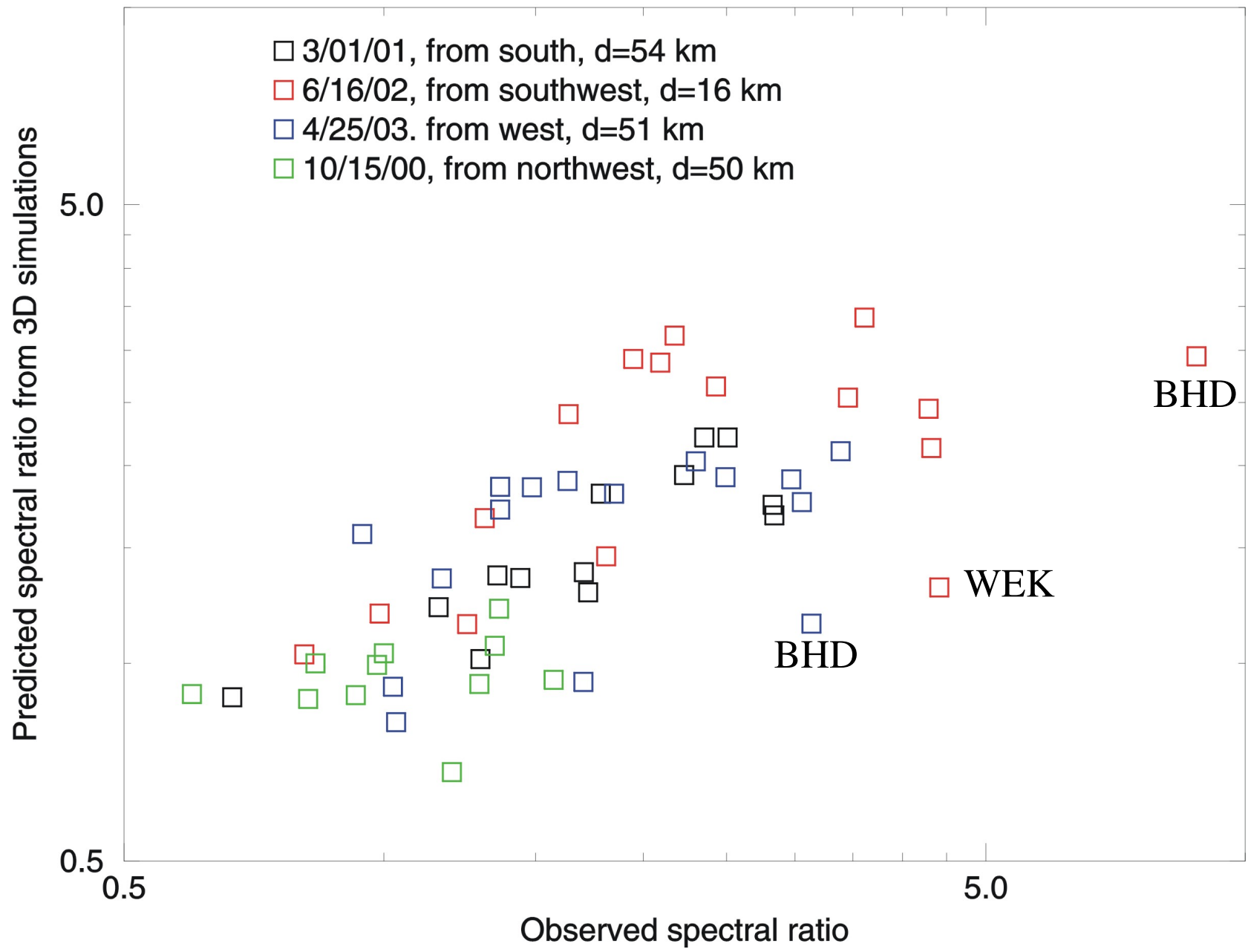

Figure 11. Predicted Fourier spectral ratios from the 3D simulations plotted against the observed spectral ratios, for four earthquakes (events 2-5 in Table 1). The three labeled outliers represent stations (BHD and WEK) near the southern edge of the Seattle basin. 


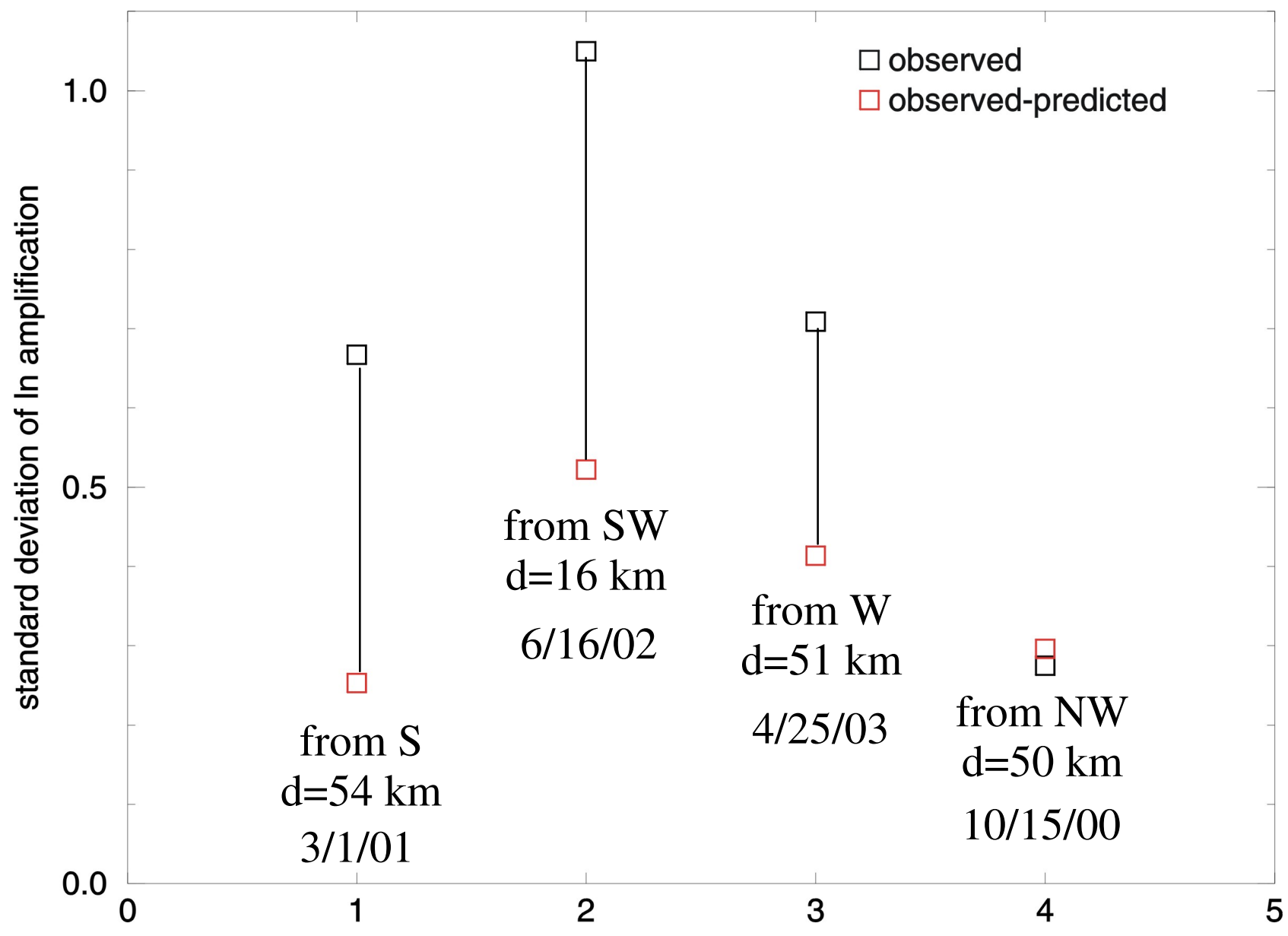

Figure 12. Standard deviations of the natural logarithm (In) of the spectral amplification for the four smaller earthquakes that were modeled (event numbers given on horizontal axis; table 1). Black squares represent the original standard deviation of the amplification form the observations. Red squares indicate the standard deviation of the amplification after correcting the observed values by the amplification derived from the 3D simulations. Note how using the predicted amplifications from the 3D simulations substantially reduce the observed variability, for the three events with the strongest observed variability. This indicates that the $3 \mathrm{D}$ model explains much of the observed variations in amplitude. 

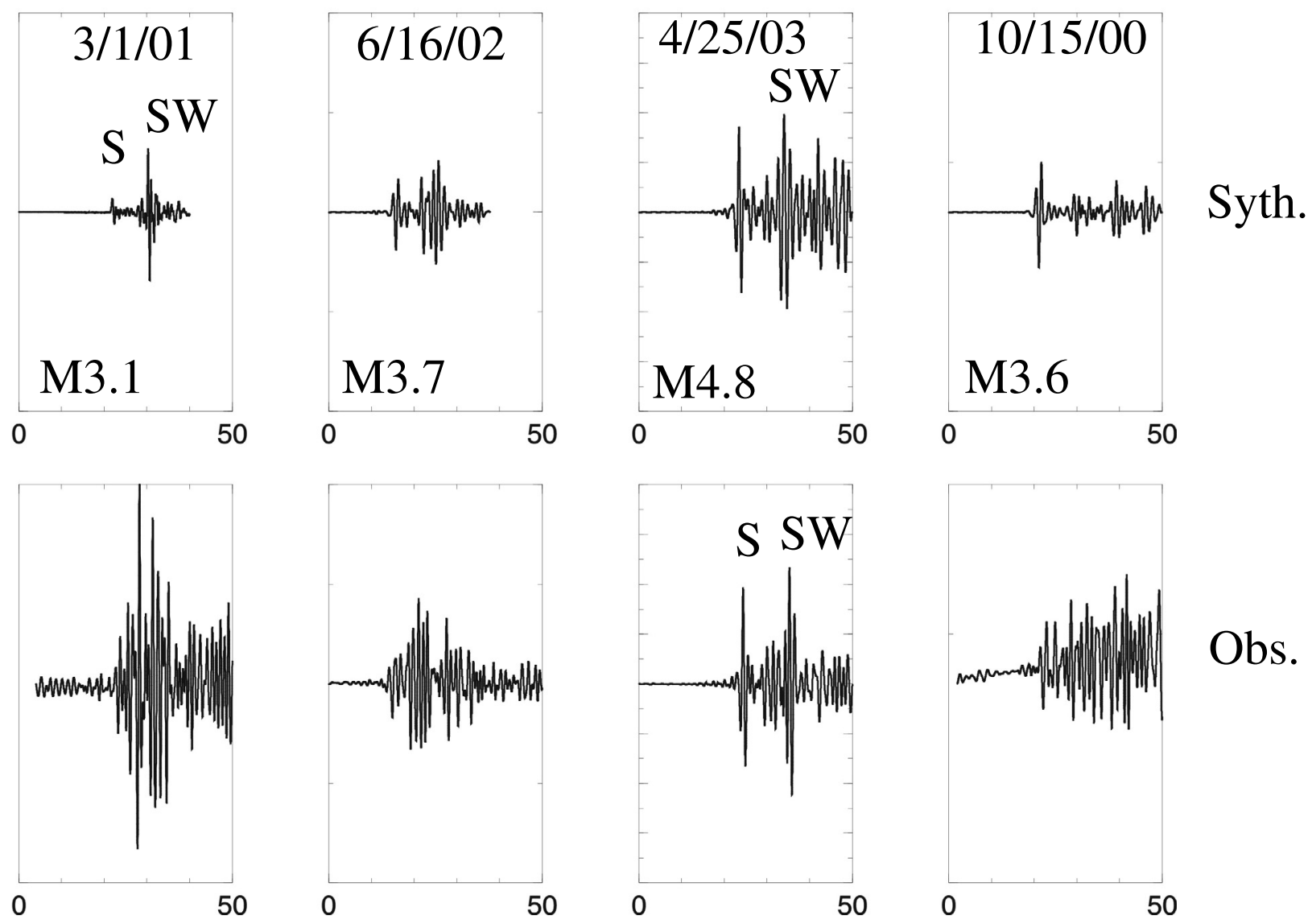

Figure 13. Synthetic (Synth.) and observed (Obs.) velocity seismograms at station LAP (E-W component) for four earthquakes that were modeled (given in month, day and year; table 1). The seismograms are all bandpass-filtered between 0.5 and $1.0 \mathrm{~Hz}$. The vertical scales are the same for the synthetic and observed seismograms for each earthquake. For the April 25, 2003 event, the Swave (S) and basin surface wave (SW) are indicated. Horizontal axes are in $\mathbf{S .}$ 


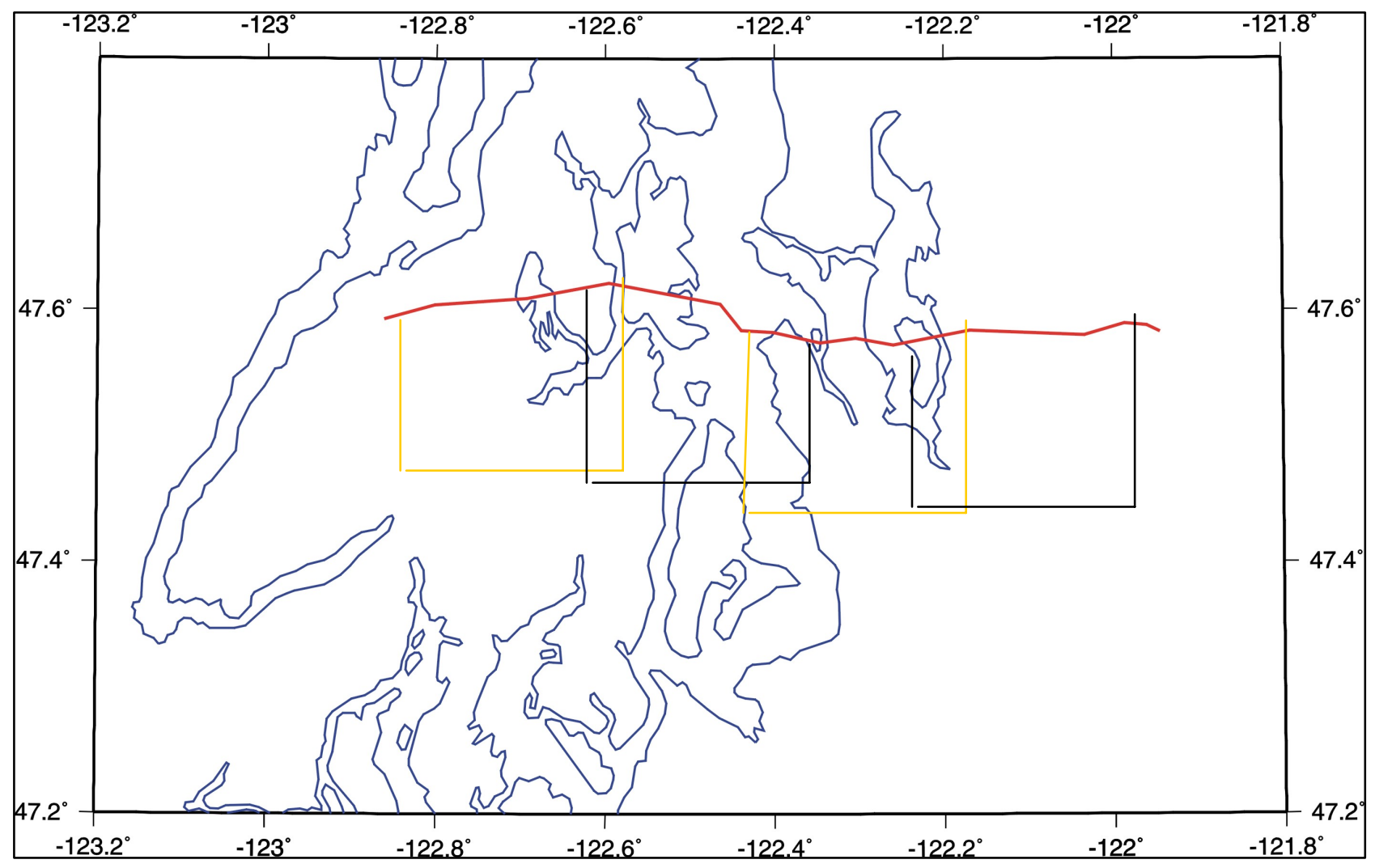

Figure 14. Map showing schematically how earthquake rupture zones (black and yellow lines) were floated along the northern strand of the Seattle fault for the seismic hazard assessment. 

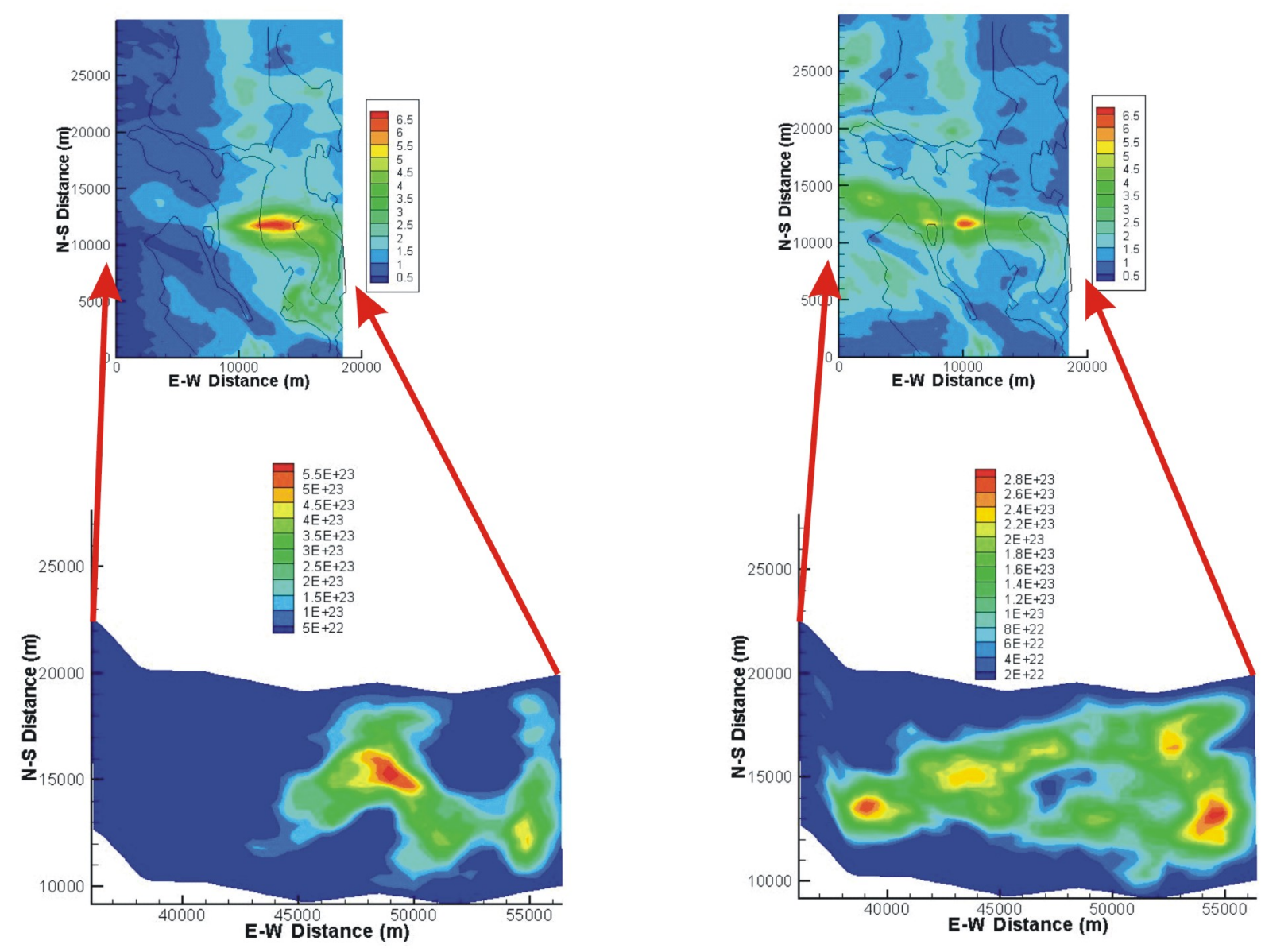

Figure 15. Bottom: Two realizations of slip (or moment release per cell in dyne-cm) for one of the rupture scenarios used in the 3D simulations. Top: The patterns of ground motion amplifications (relative to 3 rock sites) determined from the 3D simulation that used each slip distribution. The mapped area corresponds to the box in figure 1 . Note that the slip distribution plots have a different scale than the amplification maps. Red arrows indicate the approximate locations of the top corners of the rupture surfaces on the amplification maps. 

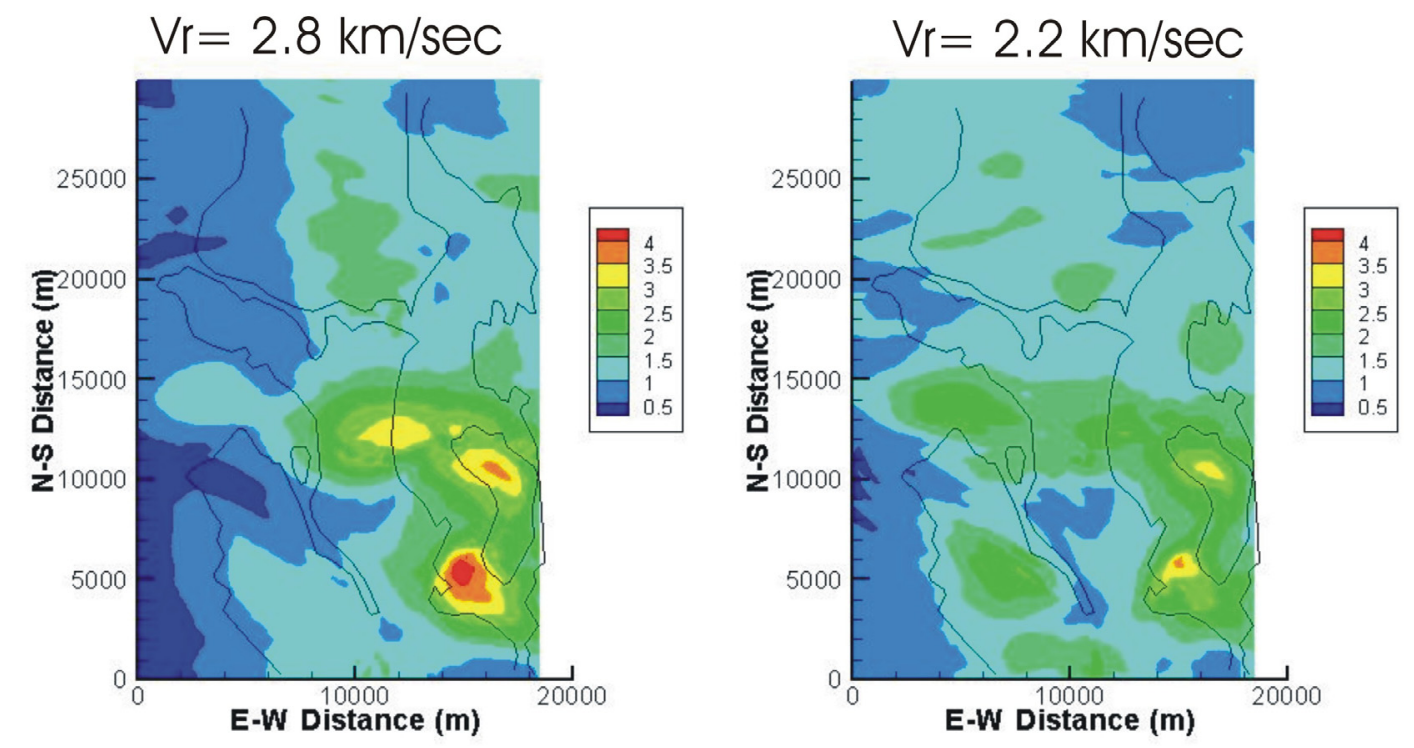

Figure 16. Comparison of amplification maps derived from simulations of Seattle fault earthquakes with two different rupture velocities $V_{r^{\prime}}$ but identical fault surfaces, slip distributions, and hypocenters. The mapped area corresponds to the box in figure 1.
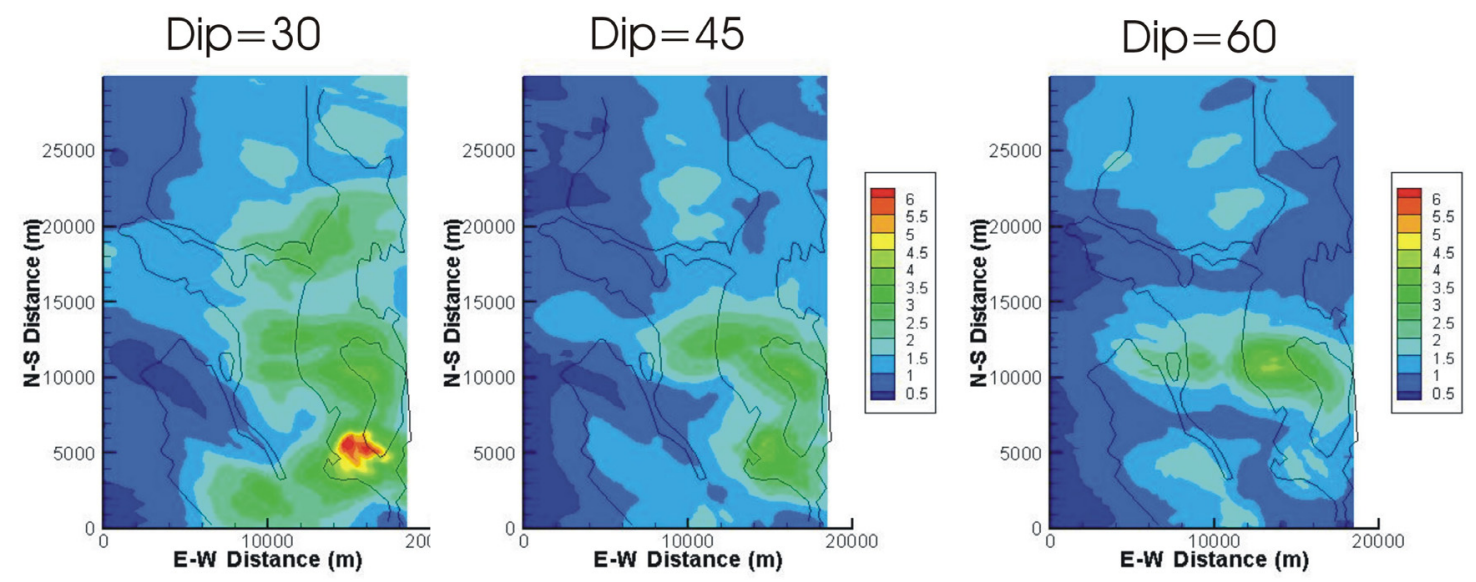

Figure 17. Comparison of amplification maps from simulations for Seattle fault earthquakes, for three different dips for the frontal strand of the Seattle fault. The mapped area corresponds to the box in figure 1. 
a

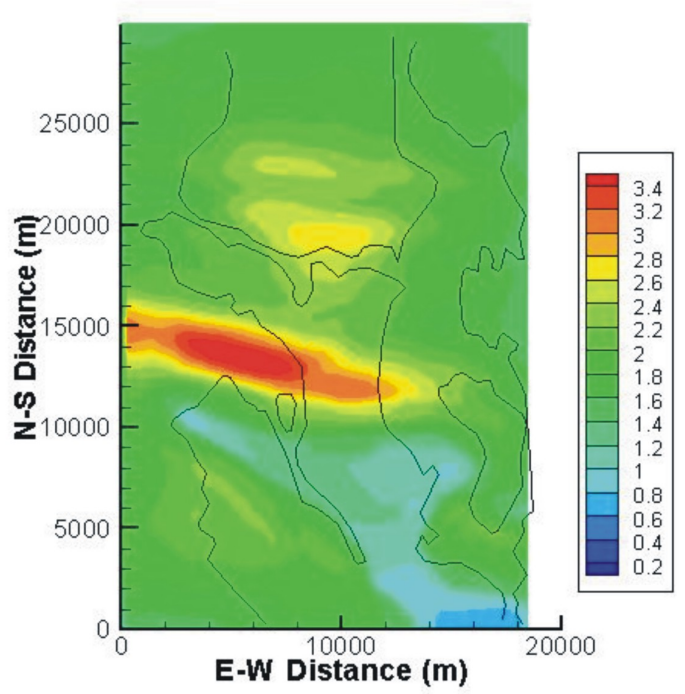

C

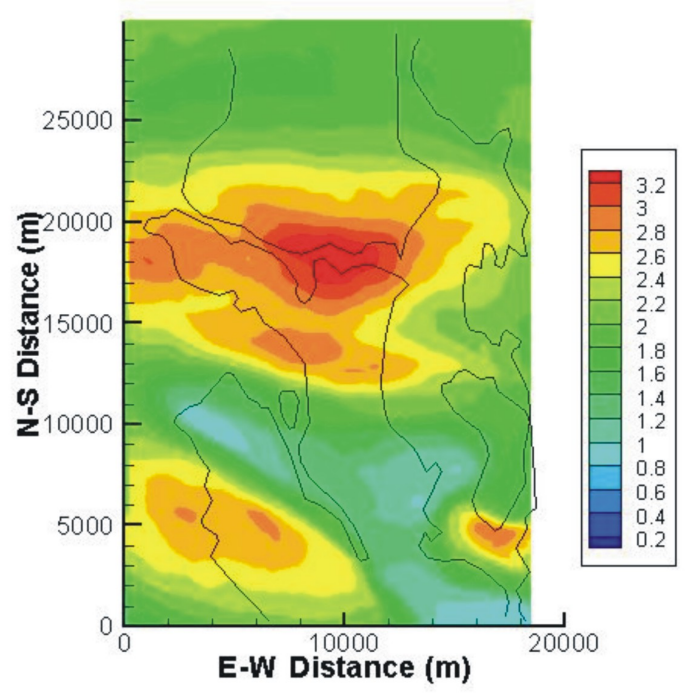

b

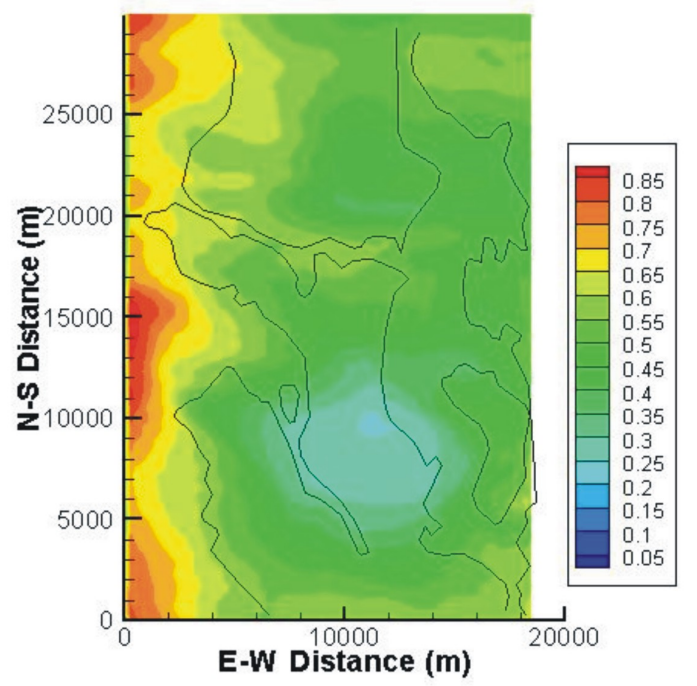

d

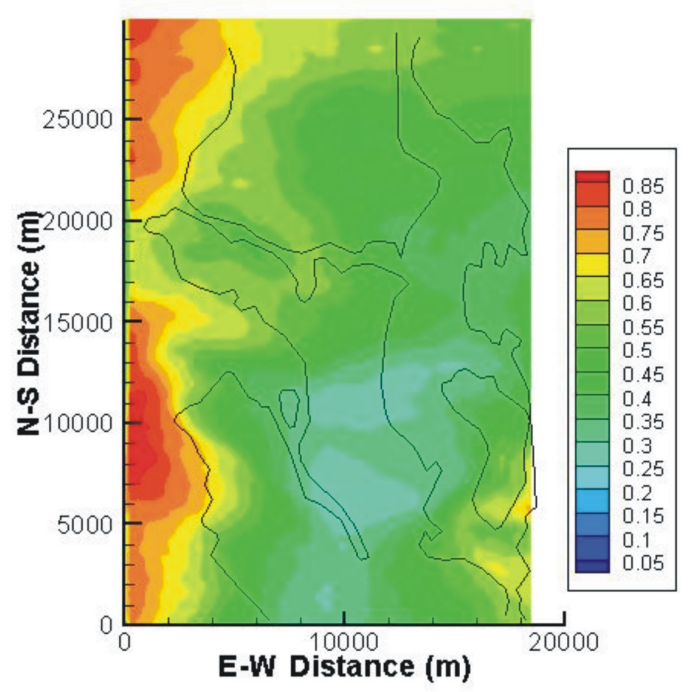

Figure 18. A) Geometrical average of the amplifications derived from 315 simulations of Seattle fault earthquakes, for the 45 degree dipping case. $B$ ) Standard deviation in natural $\log (\ln )$ units of these amplifications. C) Geometrical average of amplifications from the 135 simulations for a 30 degree dipping frontal strand of the Seattle fault. $D$ ) Standard deviation for the 30 degree dipping case. The increased standard deviation along the west side of the station grid in $(B)$ and $(D)$ is not an edge effect, since the velocity model used in the simulations extends well to the west of the station grid shown here. The mapped area corresponds to the box in figure 1. 


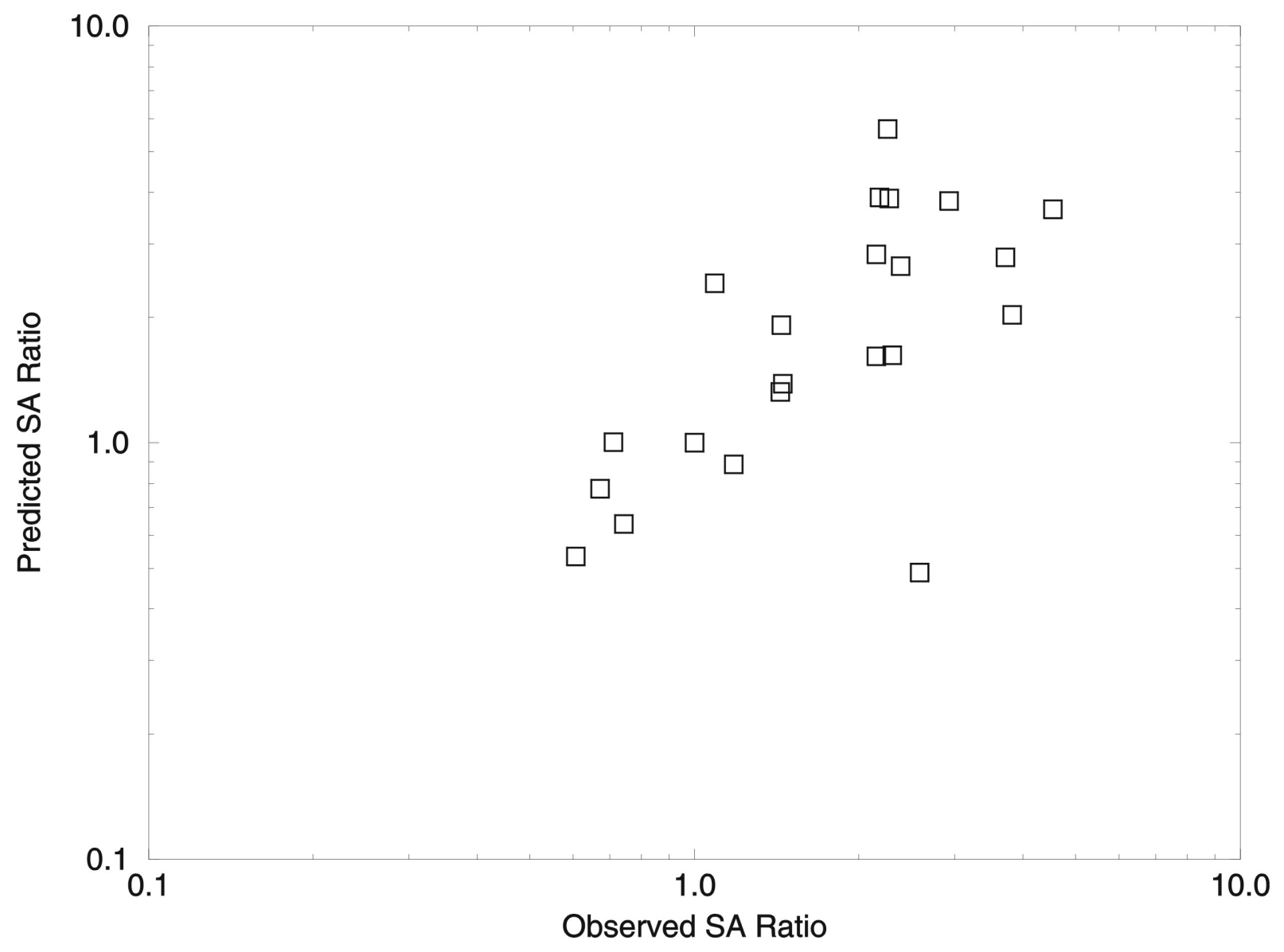

Figure 19. Predicted $1.2 \mathrm{sec}(0.833 \mathrm{~Hz})$ response spectral amplitude $(\mathrm{SA})$ ratios (referenced to the Arleta station) from the 3D simulation of the Northridge, California earthquake plotted against the observed spectra amplitude ratios, also referenced to Arleta. 


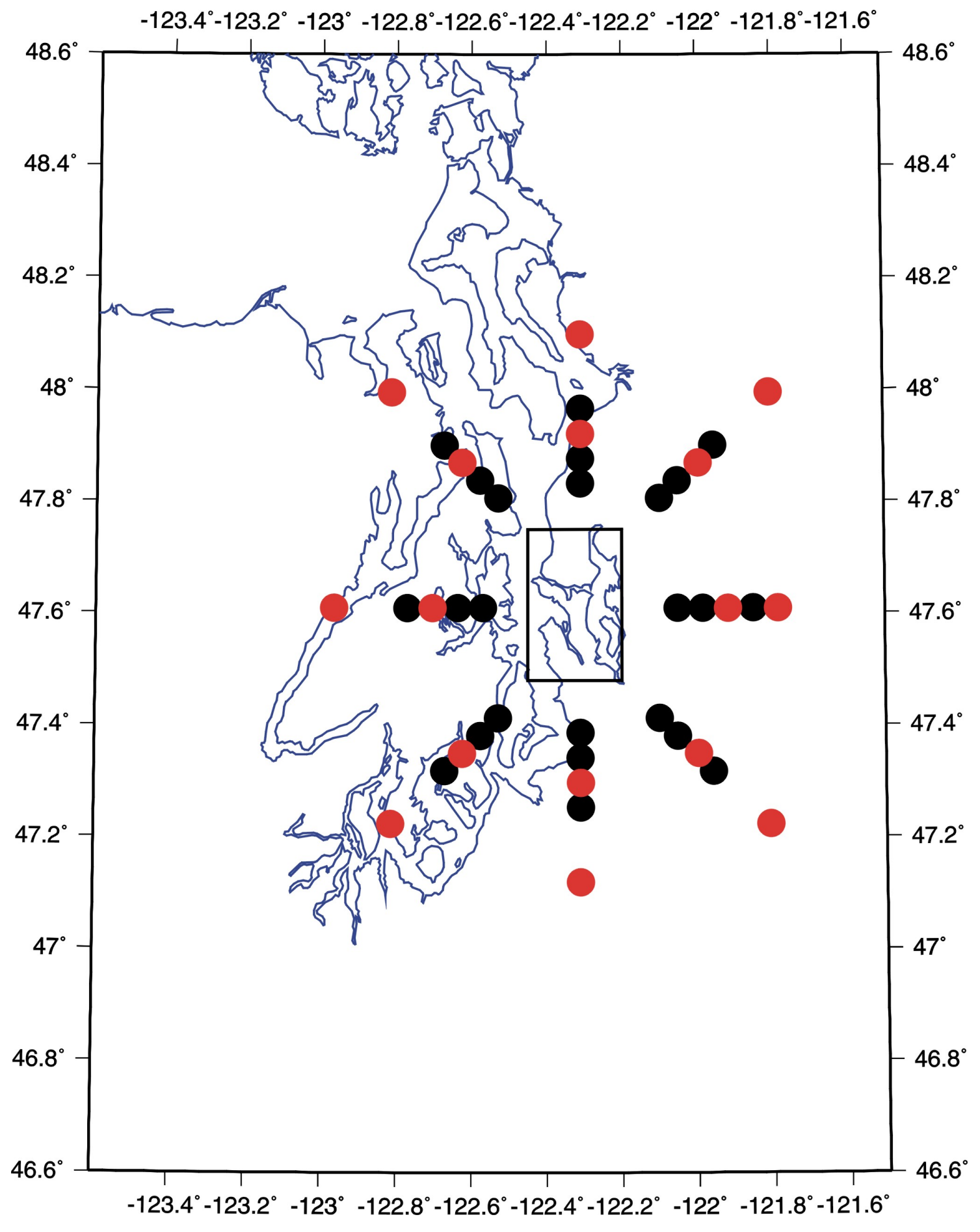

Figure 20. Black dots indicate the epicenters of shallow earthquakes (depth= 10 and $15 \mathrm{~km}$ ) used in the 3D simulations to assess the hazard from the background seismicity. Red dots denote the epicenters used for simulations of deep (depth $=50 \mathrm{~km}$ ) earthquakes. Black box is area of the Seattle urban seismic hazard maps. 
From North

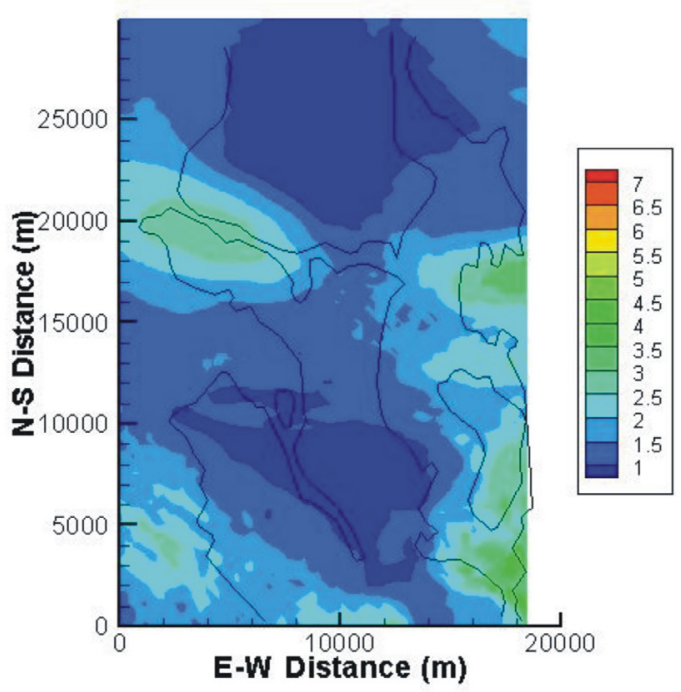

From South

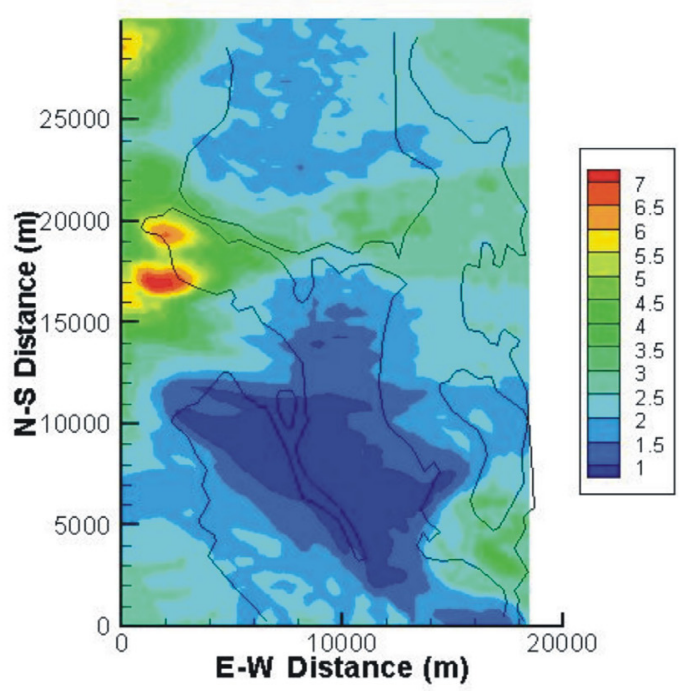

From East

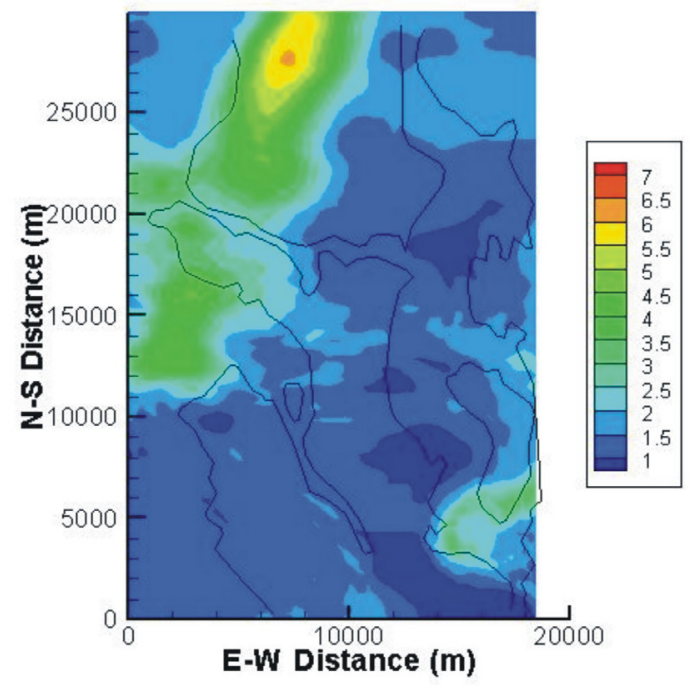

From West

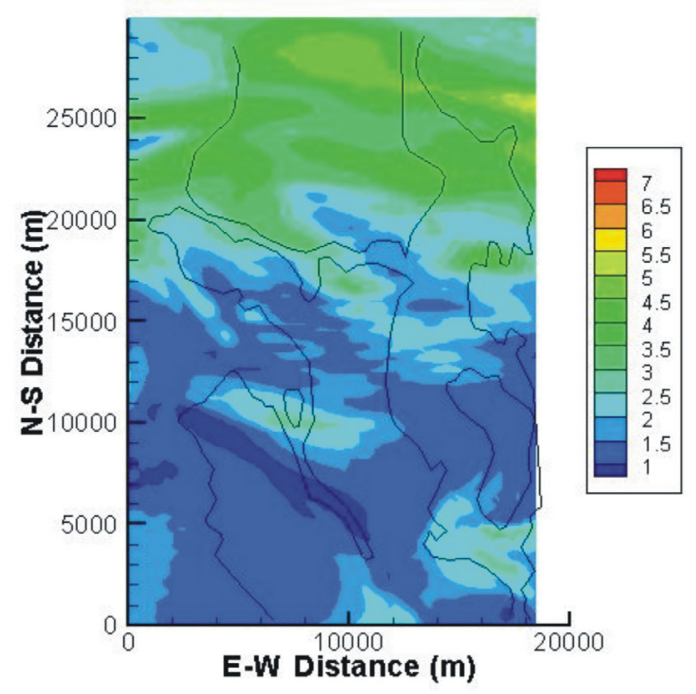

Figure 21. Amplification maps from the 3D simulations for shallow earthquakes at four azimuths (see text). The earthquakes are $20 \mathrm{~km}$ from the nearest point in the site grid. The mapped area corresponds to the box in figure 1. 

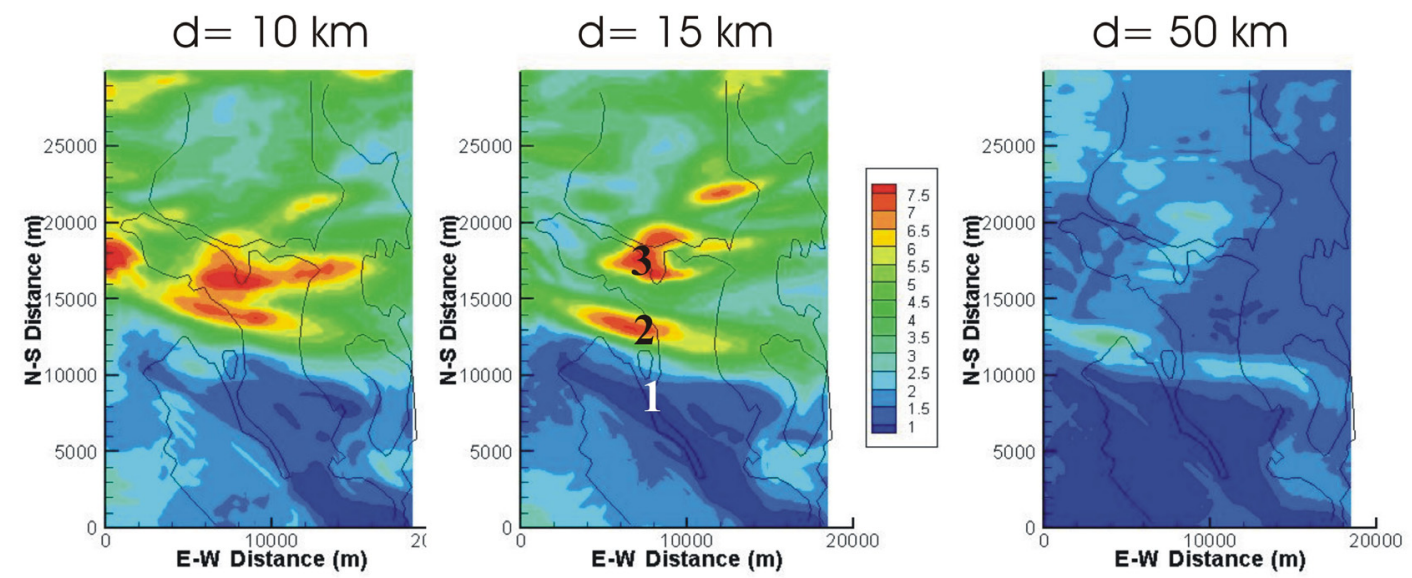

Figure 22. Amplification maps from the simulations of three earthquakes to the southwest of Seattle located at different depths (d). The epicentral distance of the $10 \mathrm{~km}$ and $15 \mathrm{~km}$ deep events was 20 $\mathrm{km}$ from the southwest corner of the map, whereas the deep event epicenter was $40 \mathrm{~km}$ from the southwest corner of the map. Numbers indicate locations of stations for seismograms shown in figure 23. The mapped area corresponds to the box in figure 1. 


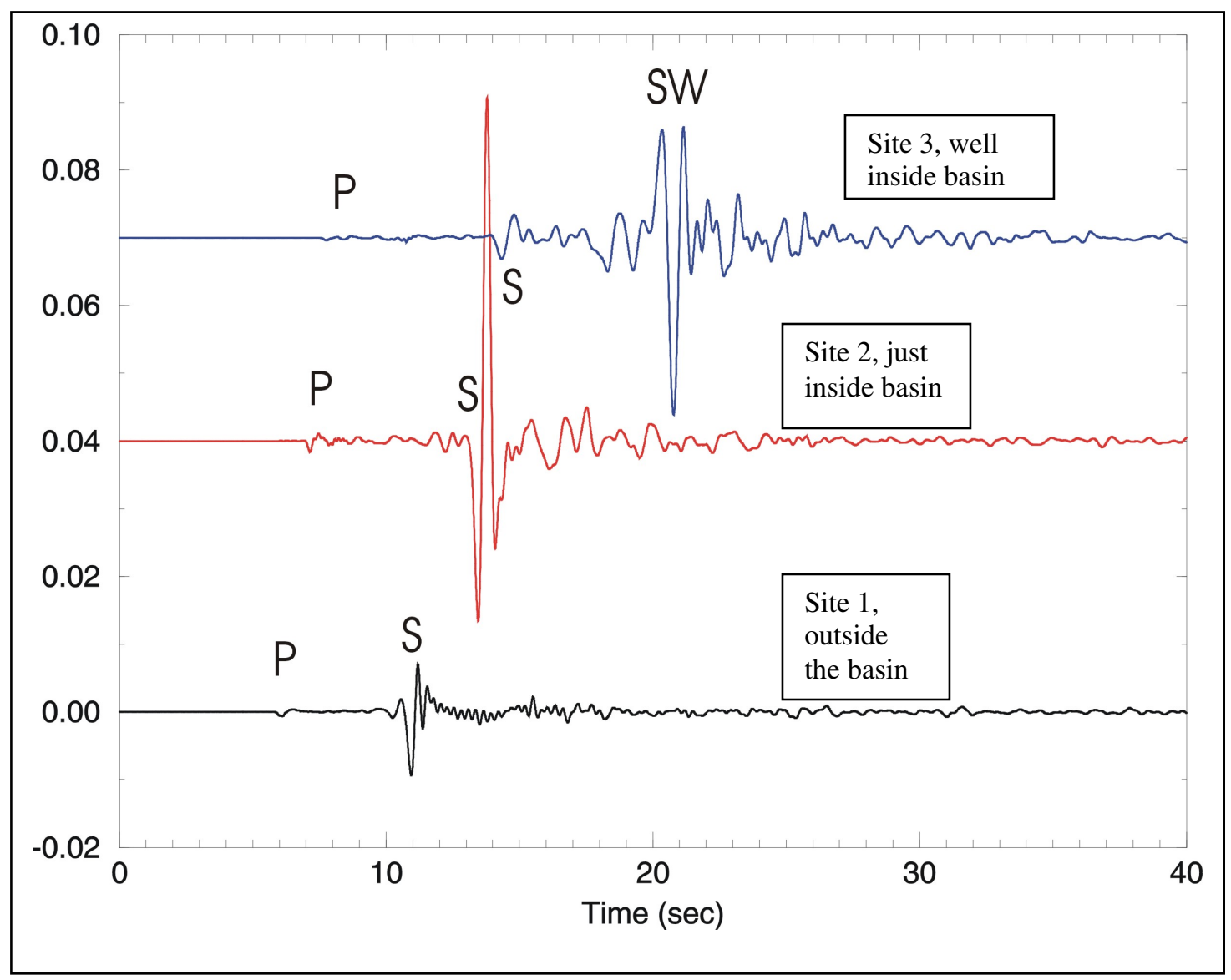

Figure 23. East-west velocity seismograms from the 3D simulation shown in Figure 22 center. Numbers correspond to locations shown in figure 22. Note the amplification of the S-wave for the site located just inside the Seattle basin (site 2) and the large basin surface wave (SW) for the stations well within the basin (site 3). 


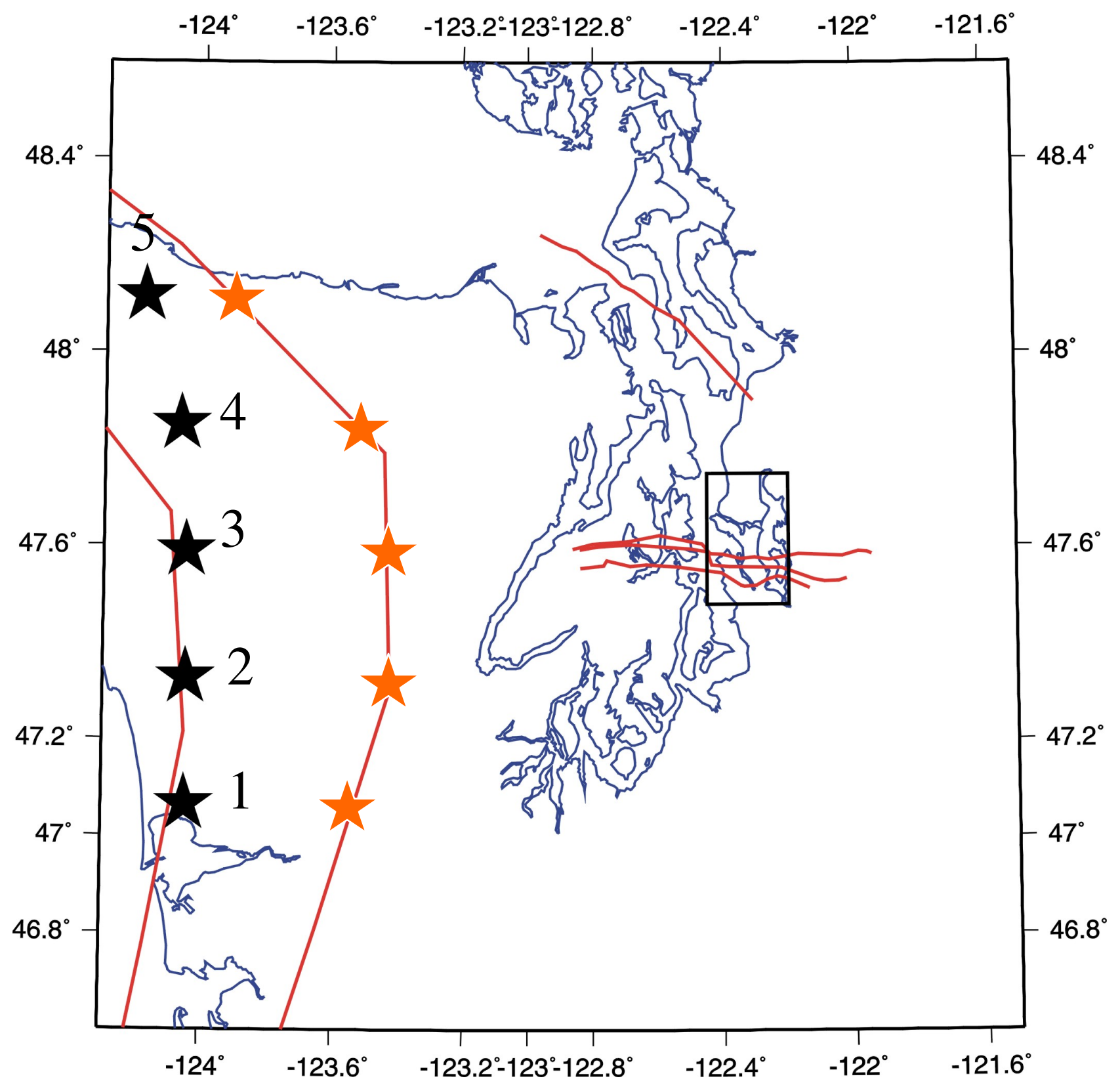

Figure 24. Locations of the 10 point sources along the Cascadia subduction zone used to estimate the amplification from great Cascadia subduction zone earthquakes. The two red lines (left to right) indicate 1) midpoint of the bases of the elastic and transition zones from Flueck and others (1997) and 2) the base of the transition zone from Flueck and others (1997). Black box is area of Seattle urban seismic hazard maps. Traces of the South Whidbey Island and Seattle faults are shown as irregular red lines (see figure 1). 

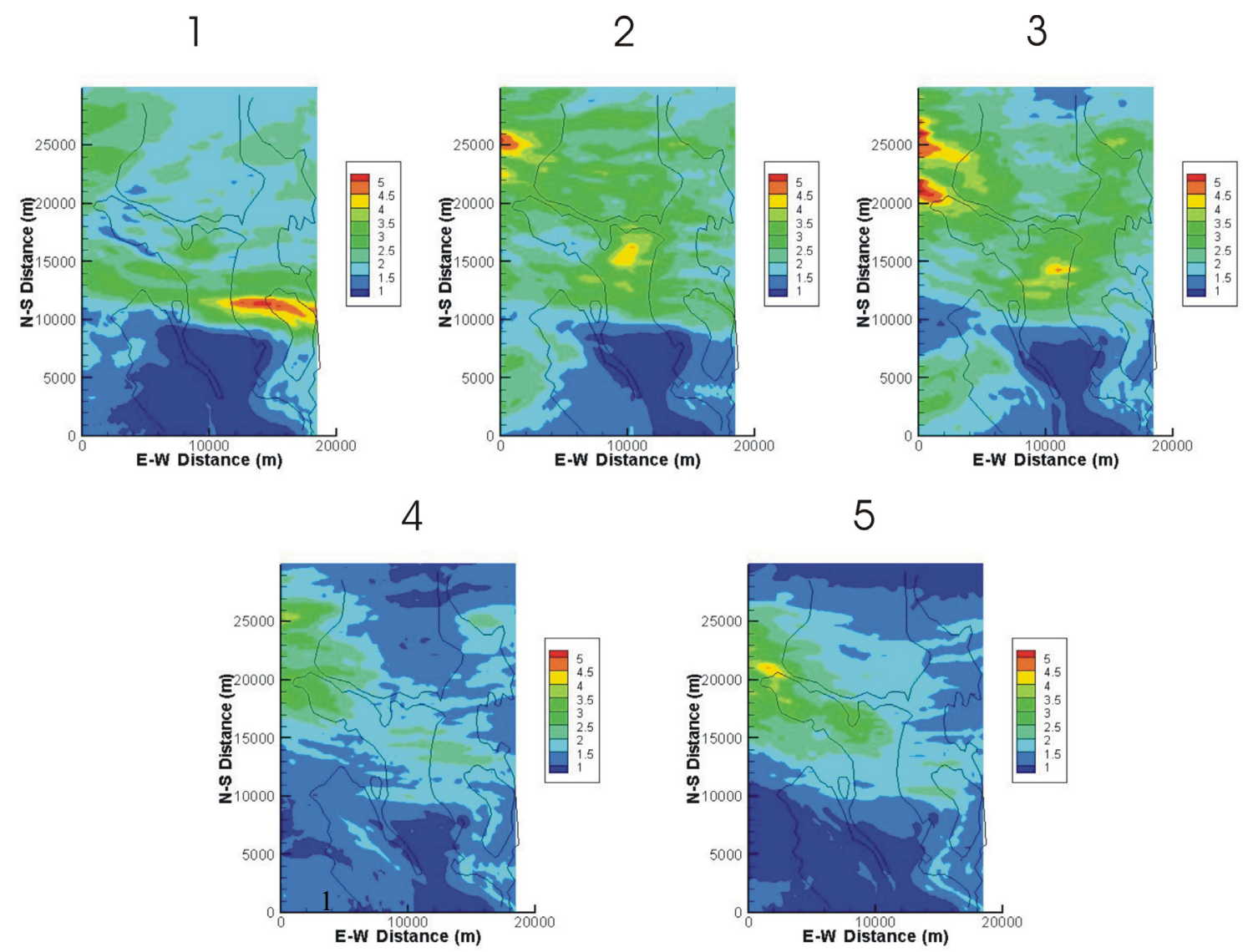

Figure 25. Amplification maps for five Cascadia point sources (see Figure 23 for locations), derived from the 3D simulations. Map area corresponds to box in figure 1. 


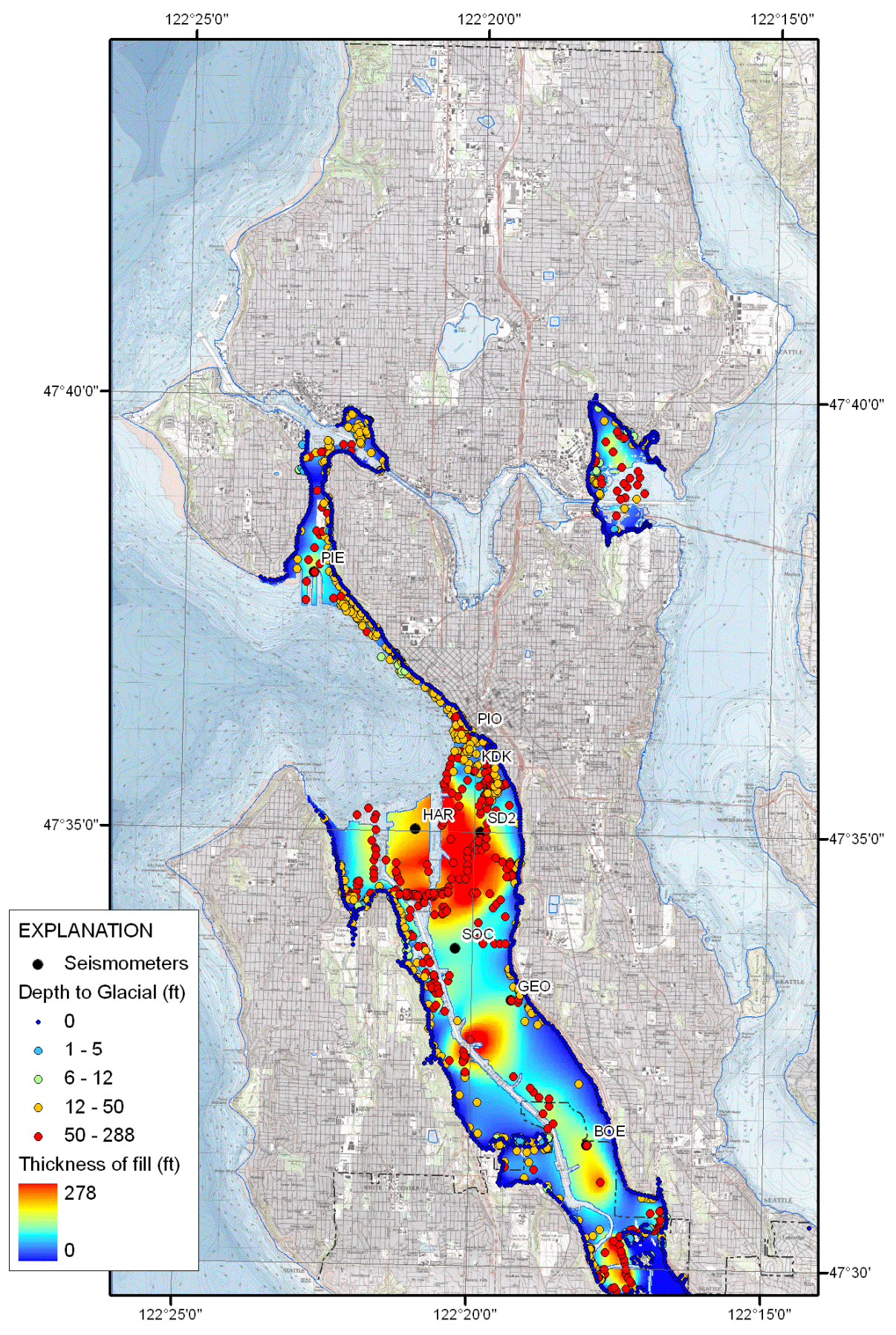

Figure 26. Thickness of fill and Holocene alluvium (in feet), derived from borehole data (dots) compiled by Pacific Northwest Center for Geologic Mapping Studies (2005). Circles indicate locations of boreholes with depth determinations, with colors keyed to depth to base of fill/alluvium, relative to the surface. Black circles are locations of seismometers on fill/alluvium. 


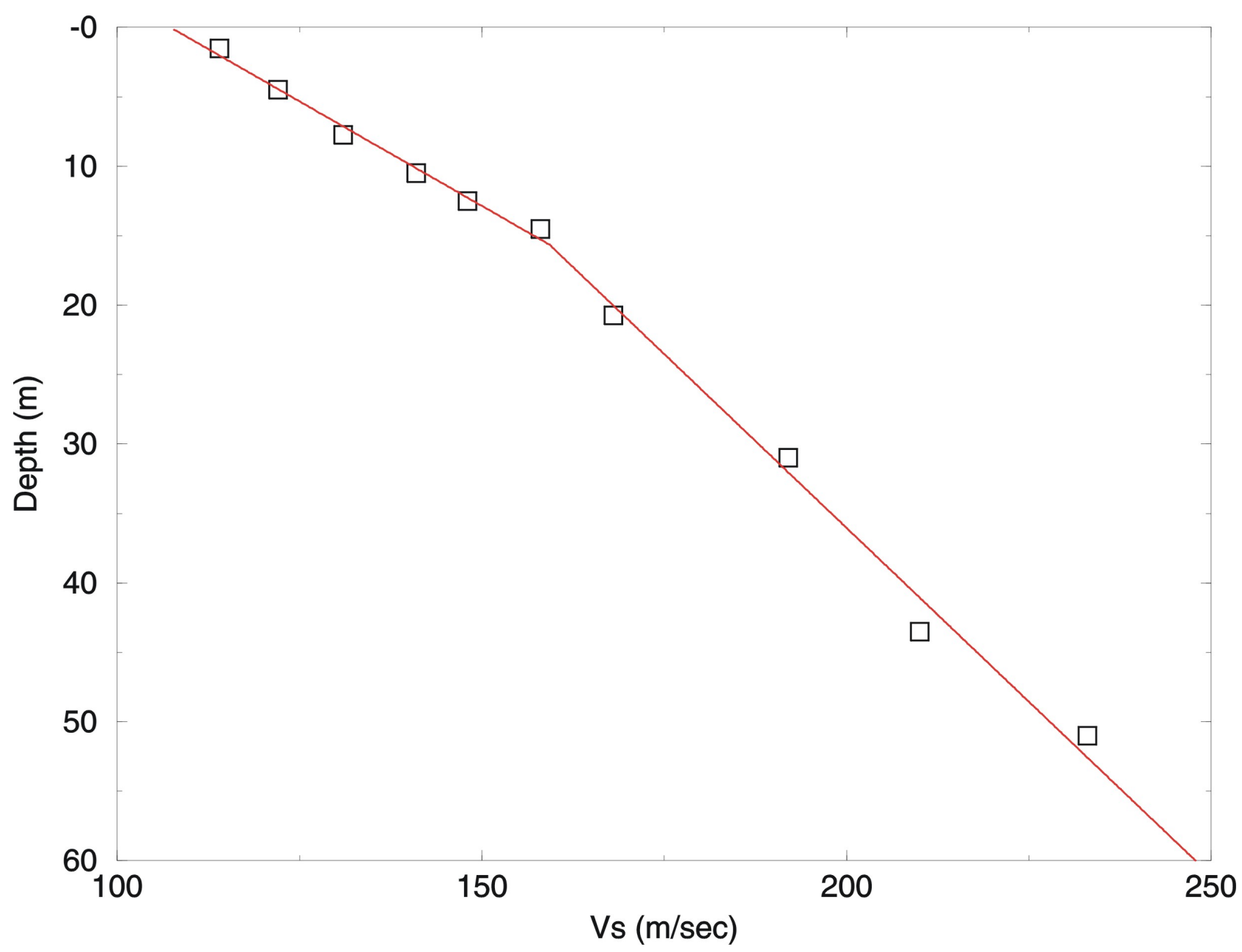

Figure 27. Average shear wave velocity (Vs) with depth for fill/alluvium sites (black boxes). Red line is a bilinear fit to the data. Points at depths above $40 \mathrm{~m}$ are derived from seismic reflection/refraction data, points at depths below $40 \mathrm{~m}$ are from borehole measurements. 


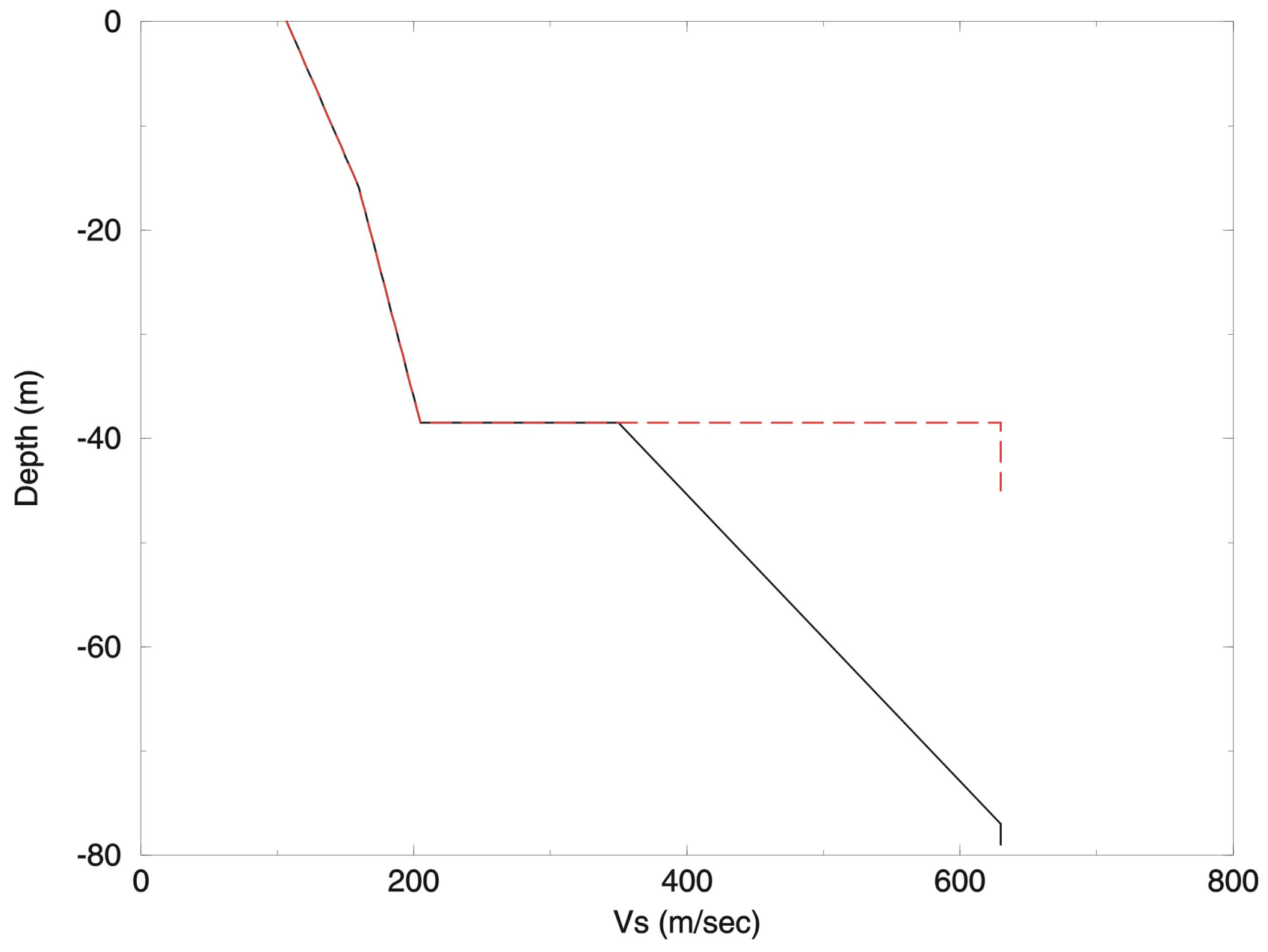

Figure 28. Examples of shear-wave velocity profiles used for SHAKE for a site near station HAR at $47.581 \mathrm{~N}, 122.357 \mathrm{~W}$. The fill/alluvium has an estimated thickness of $38.5 \mathrm{~m}$. Black line indicates the velocity profile assuming a gradient in the stiff soils beneath the interface between the fill/alluvium and the underlying stiff soil at $38.5 \mathrm{~m}$. The dashed red line shows the velocity profile which uses a step in velocity at the base of the fill/alluvium. These two profiles yield very similar amplifications from SHAKE (see text and table 4). 


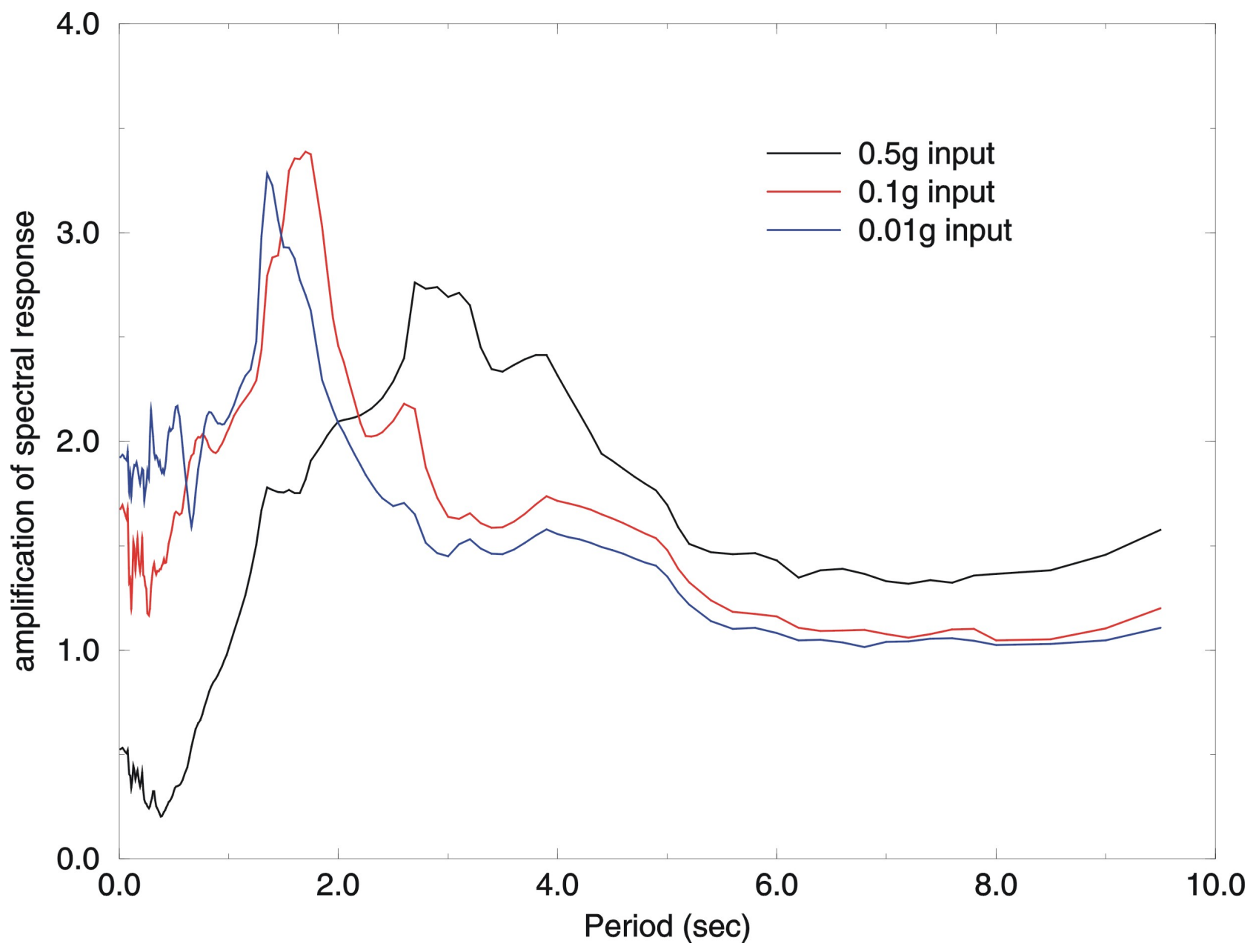

Figure 29. Response spectra amplification predicted for station HAR from SHAKE runs with different input accelerations, where $\mathrm{g}$ is the acceleration of gravity. 


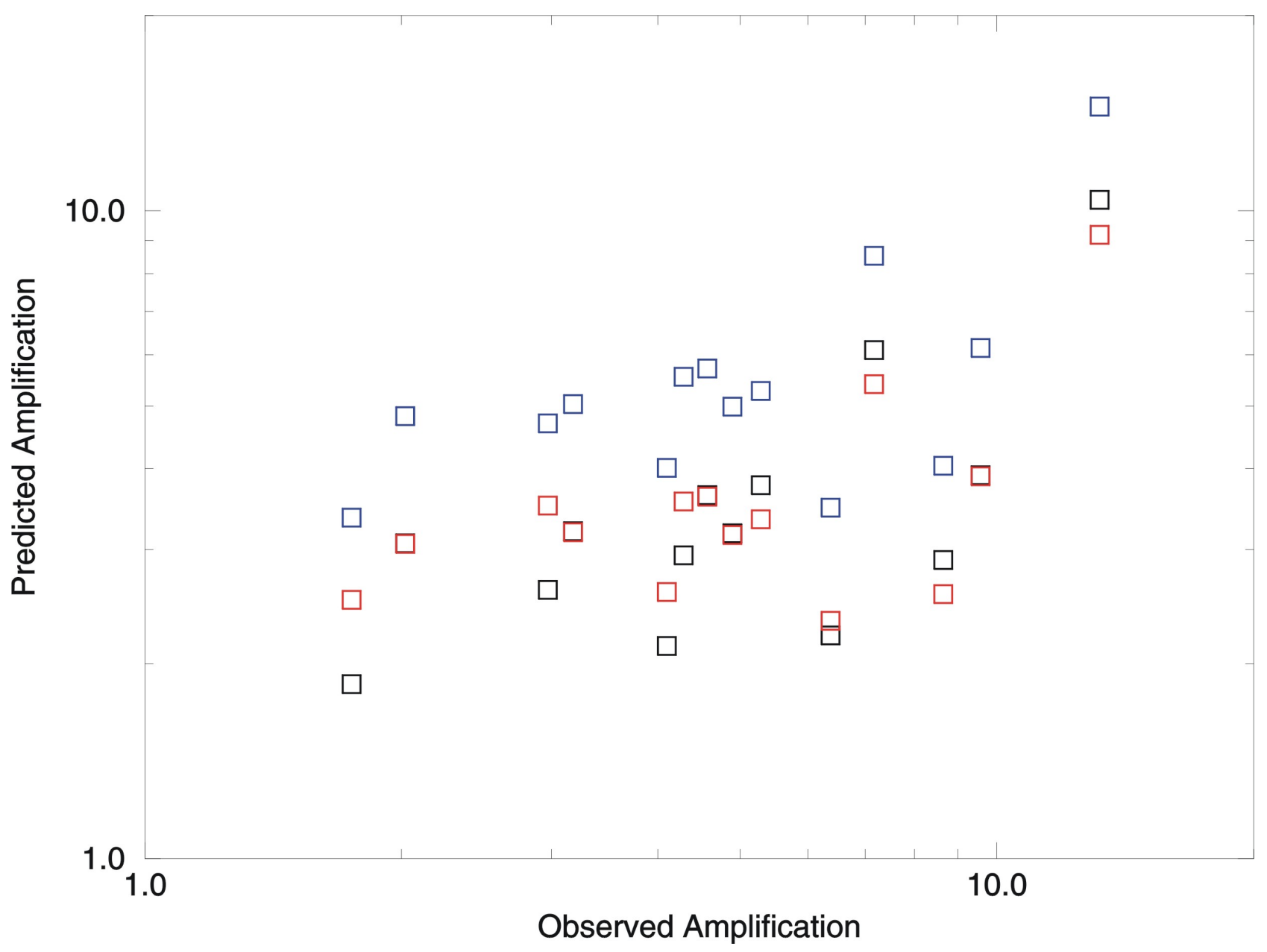

Figure 30. Predicted versus observed amplifications at soft-soil sites, for the four smaller earthquakes in table 1 (events 1-4). The predicted amplifications are derived from the product of the amplifications from the 3D simulation multiplied by the amplification from SHAKE (black squares), NEHRP factors (red squares) and Choi and Stewart (2005); blue squares. 

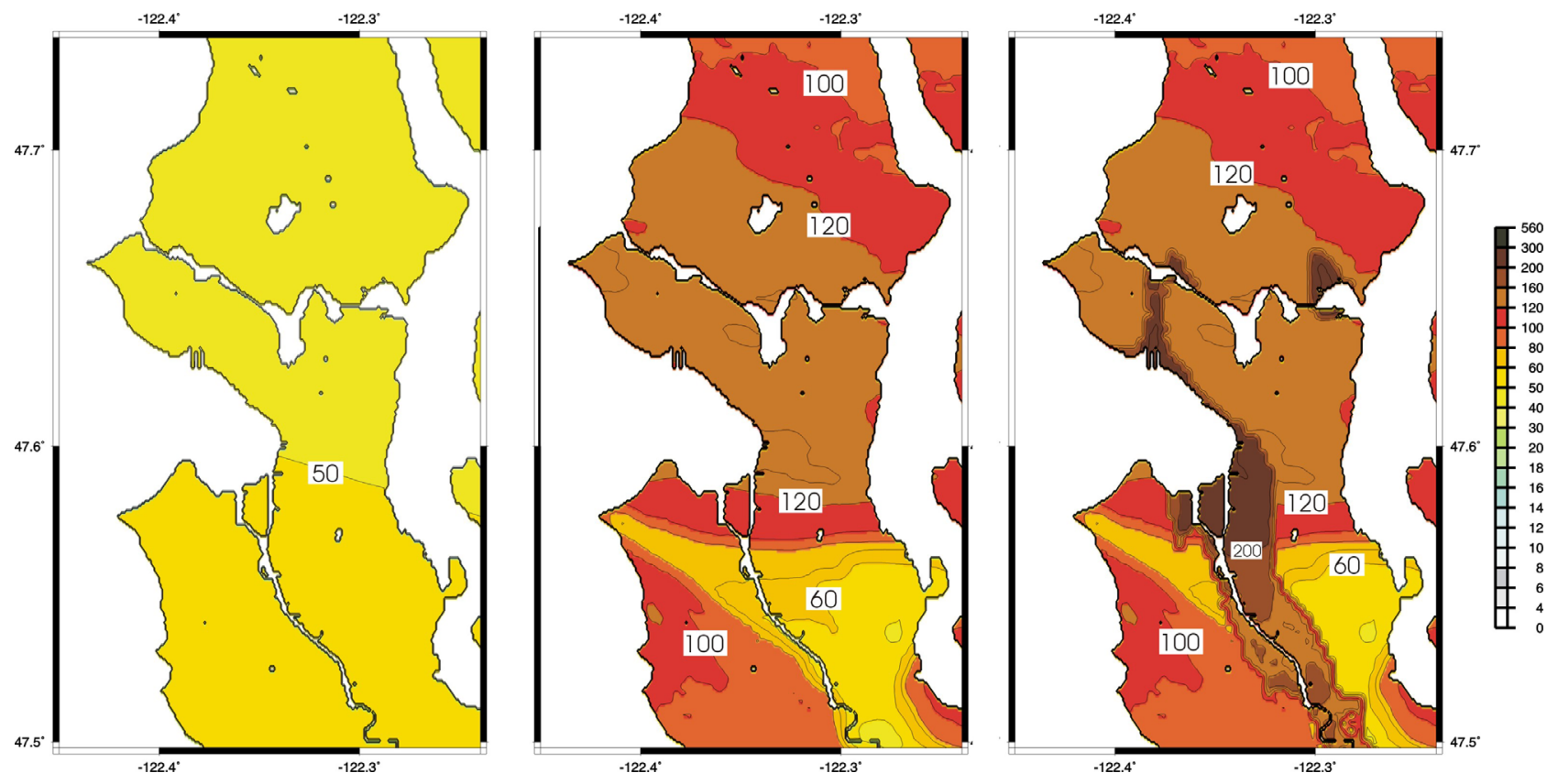

Figure 31. Seismic hazard maps for Seattle showing $1 \mathrm{~Hz}$. S.A. $(\% \mathrm{~g})$ with $2 \%$ probability of exceedance in $50 \mathrm{yr}$. (left) Map for a firm-rock site condition (B-C boundary) from the 2002 national seismic hazard maps. (middle) Map from this study using the amplifications from the 3D simulations. (right) Map developed from this study using 3D simulations and nonlinear amplification for soft-soil sites determined from the Choi and Stewart (2005) amplification factors. 

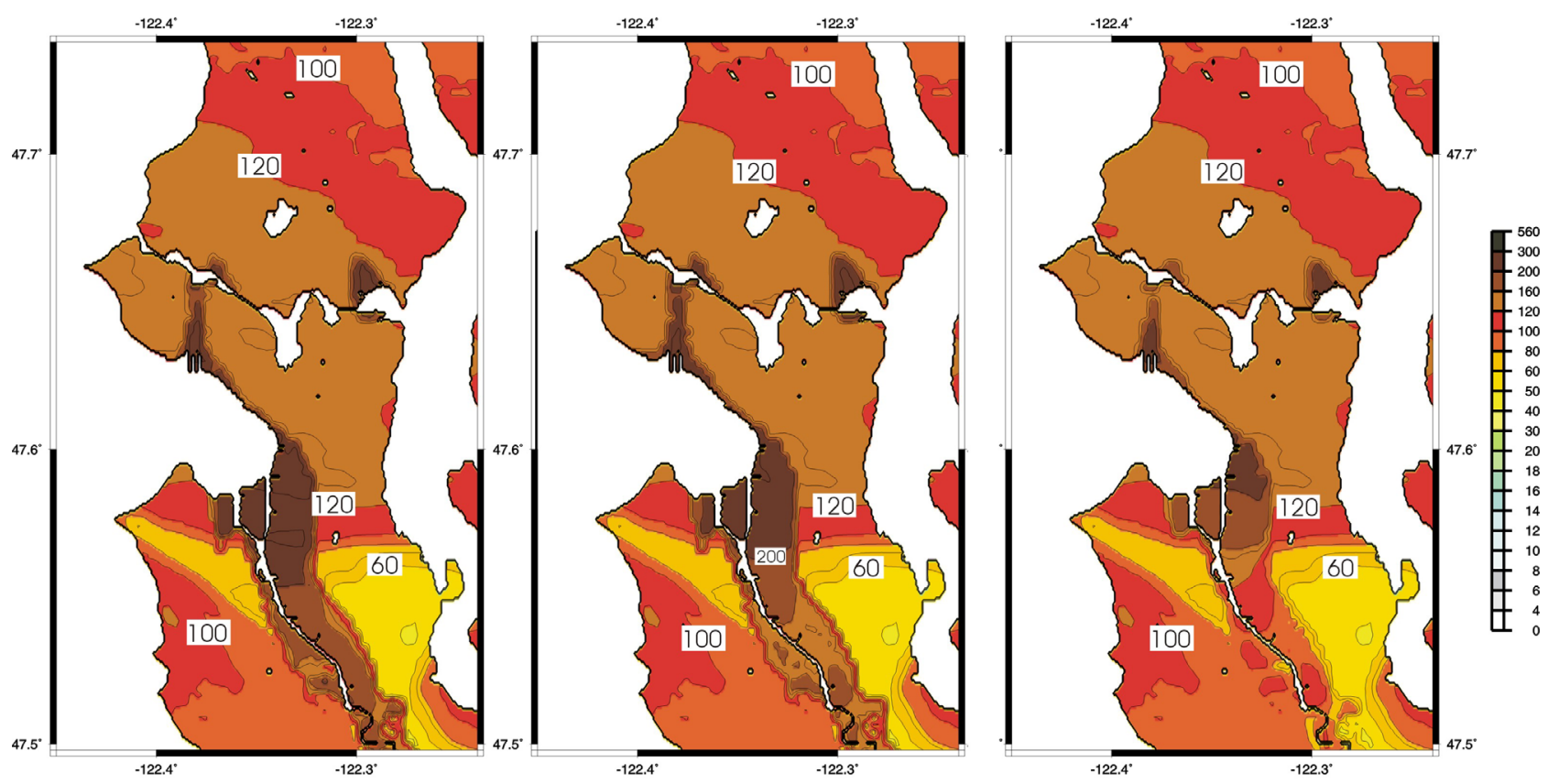

Figure 32. Seismic hazard maps for Seattle $(1 \mathrm{~Hz}$ S.A. in \%g with $2 \%$ probability of exceedance in 50 yr). Amplification for soft-soil sites based on (left) NEHRP factors, (middle) Choi and Stewart (2005) factors, and (right) SHAKE runs.
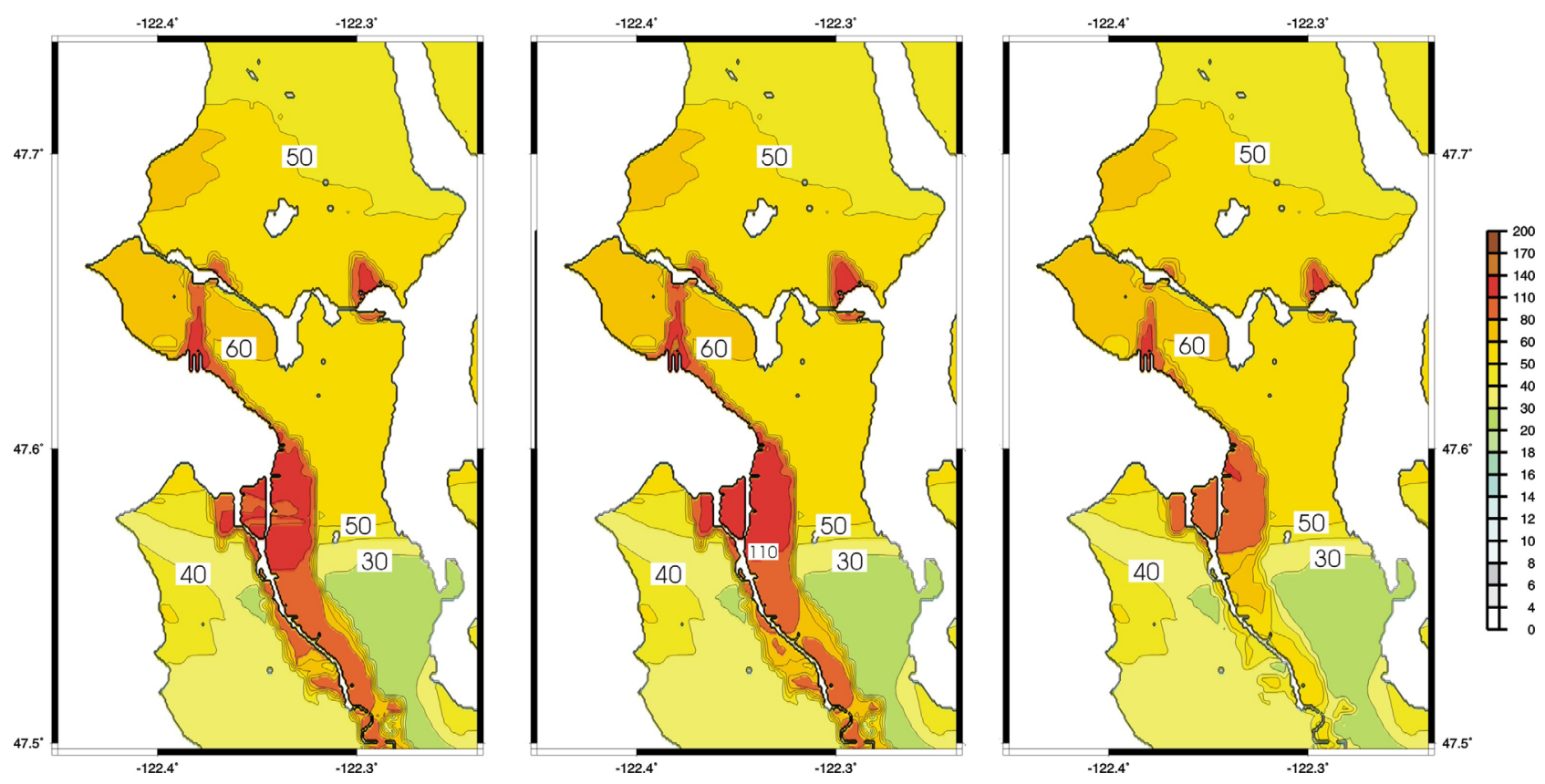

Figure 33. Seismic hazard maps for Seattle $11 \mathrm{~Hz}$ S.A. in \%g with $10 \%$ probability of exceedance in $50 \mathrm{yr}$ ). Amplification for soft-soil sites based on (left) NEHRP factors, (middle) Choi and Stewart (2005) factors, and (right) SHAKE runs. 


\section{Table 1: Earthquakes modeled using 3D simulations*}

\begin{tabular}{|c|c|c|c|c|c|c|}
\hline $\begin{array}{c}\text { Event \# or } \\
\text { description }\end{array}$ & $\begin{array}{c}\text { Date } \\
\text { (yr,mo,day) }\end{array}$ & $\begin{array}{c}\text { Time } \\
\text { (UTC in } \\
\mathrm{hr}, \text { min })\end{array}$ & Latitude & Longitude & $\begin{array}{c}\text { Depth } \\
(\mathrm{km})\end{array}$ & Magnitude \\
\hline $\begin{array}{c}\text { Nisqually } \\
\text { mainshock }\end{array}$ & $2001 / 02 / 28$ & $18: 54$ & 47.15 & -122.73 & 51.9 & 6.8 \\
\hline 1 & $2001 / 03 / 01$ & $9: 10$ & 47.20 & -122.71 & 54.3 & 3.4 \\
\hline 2 & $2002 / 06 / 16$ & $17: 11$ & 47.47 & -122.83 & 16.1 & 3.7 \\
\hline 3 & $2003 / 04 / 25$ & $10: 02$ & 47.67 & -123.25 & 51.3 & 4.8 \\
\hline 4 & $2000 / 10 / 15$ & $14: 30$ & 47.84 & -123.03 & 50.0 & 3.6 \\
\hline
\end{tabular}

*information from the Pacific Northwest Seismic Network 


\section{Table 2: Locations of Stations Used in Study}

\begin{tabular}{|c|c|c|c|}
\hline Station Name & Network & Latitude $\left({ }^{\circ} \mathrm{N}\right)$ & Longitude $\left({ }^{\circ} \mathrm{E}\right)$ \\
\hline ALO & SUSA & 47.6272 & -122.3136 \\
\hline AL3, ALK & SUSA & 47.5751 & -122.4176 \\
\hline BHD & SUSA & 47.5864 & -122.3158 \\
\hline BOE & SUSA & 47.5235 & -122.2998 \\
\hline BOW & SUSA & 47.5677 & -122.3089 \\
\hline BRI & SUSA & 47.5483 & -122.2828 \\
\hline C43 & SUSA & 47.6243 & -122.2850 \\
\hline CTR & SUSA & 47.6207 & -122.3514 \\
\hline EVA & SUSA & 47.6557 & -122.3509 \\
\hline GEO & SUSA & 47.5512 & -122.3220 \\
\hline HAL & SUSA & 47.6418 & -122.3616 \\
\hline HAR & SUSA & 47.5837 & -122.3501 \\
\hline HIG & SUSA & 47.6292 & -122.3641 \\
\hline ICR & SUSA & 47.5492 & -122.2227 \\
\hline KDK & SUSA & 47.5951 & -122.3336 \\
\hline LAP & SUSA & 47.6393 & -122.3505 \\
\hline MAR & SUSA & 47.6046 & -122.3336 \\
\hline MCG & SUSA & 47.6395 & -122.2803 \\
\hline NOR & SUSA & 47.6007 & -122.3320 \\
\hline PIE & SUSA & 47.6327 & -122.3803 \\
\hline PIO & SUSA & 47.6023 & -122.3350 \\
\hline SD2 & SUSA & 47.5833 & -122.3315 \\
\hline SEU & SUSA & 47.6078 & -122.3178 \\
\hline SEW & SUSA & 47.5497 & -122.2504 \\
\hline SOC & SUSA & 47.5610 & -122.3382 \\
\hline THO & SUSA & 47.6205 & -122.3190 \\
\hline UNK & SUSA & 47.6100 & -122.3341 \\
\hline WEK & SUSA & 47.5745 & -122.3841 \\
\hline WHI & SUSA & 47.5166 & -122.3574 \\
\hline QAW & PNSN & 47.6317 & -122.3543 \\
\hline SP2 & PNSN & 47.5565 & -122.2480 \\
\hline TKCO & PNSN & 47.5369 & -122.3004 \\
\hline HOLY & PNSN & 47.5654 & -122.3836 \\
\hline LAWT & PNSN & 47.6565 & -122.3894 \\
\hline SEA & PNSN & 47.6544 & -122.3081 \\
\hline NOWS & PNSN & 47.6867 & -122.2559 \\
\hline KIMB & PNSN & 47.5748 & -122.3028 \\
\hline SUSA= Seattle Urban Seismic Array (USGS) \\
PNSN= Pacific Northwest Seismic Network $($ University of Washington) \\
\hline
\end{tabular}




\section{Table 3: Rock-site attenuation relations used for various earthquake sources, with weights in parentheses (based on 2002 national seismic hazard maps)}

\begin{tabular}{|c|c|c|}
\hline $\begin{array}{c}\text { Earthquakes on Seattle Fault, South } \\
\text { Whidbey Island Fault, and } \\
\text { other shallow earthquakes } \\
\text { (depth }<35 \mathrm{~km})\end{array}$ & Cascadia subduction zone & $\begin{array}{c}\text { Deep earthquakes on Benioff } \\
\text { zone } \\
(\text { depth } \bullet 35 \mathrm{~km})\end{array}$ \\
\hline Abrahamson and Silva (1997) $(0.25)$ & $\begin{array}{c}\text { Youngs and others }(1997) \\
\left(\begin{array}{c}0.5 \text { for distances }<60 \mathrm{~km} ; \\
1.0 \text { for distance } \bullet 60 \mathrm{~km})\end{array}\right.\end{array}$ & $\begin{array}{c}\text { Atkinson and Boore }(2003) \\
\text { Global case }(0.25) \\
\text { Cascadia case }(0.25)\end{array}$ \\
\hline Boore and others, (1997) $(0.25)$ & $\begin{array}{c}\text { Sadigh and others }(1997) \\
(0.5 \text { for distances }<60 \mathrm{~km} ; \\
0 \text { for distances } \bullet 60 \mathrm{~km})\end{array}$ & $\begin{array}{c}\text { Youngs and others, }(1997) \\
(0.5)\end{array}$ \\
\hline Campbell and Bozorgnia $(0.25)$ & & \\
\hline Sadigh and others $(1997)(0.25)$ & & \\
\hline
\end{tabular}

\section{Table 4: Amplification factors used for site at $47.581^{\circ} \mathrm{N}, 122.357^{\circ} \mathrm{W}$, near station HAR, with respect to the top of the 3D velocity model}

\begin{tabular}{|c|l|l|l|l|l|l|l|l|l|l|l|l|}
\hline $\begin{array}{c}\text { Rock-site } \\
\text { PGA or 1 Hz } \\
\begin{array}{c}\text { S.A. (for } \\
\text { NEHRP } \\
\text { amps) }\end{array}\end{array}$ & $0.01 \mathrm{~g}$ & $0.05 \mathrm{~g}$ & $0.1 \mathrm{~g}$ & $0.2 \mathrm{~g}$ & $0.3 \mathrm{~g}$ & $0.4 \mathrm{~g}$ & $0.5 \mathrm{~g}$ & $0.6 \mathrm{~g}$ & $0.7 \mathrm{~g}$ & $0.8 \mathrm{~g}$ & $0.9 \mathrm{~g}$ & $1.0 \mathrm{~g}$ \\
\hline $\begin{array}{c}\text { Shake with } \\
\text { velocity } \\
\text { gradient }\end{array}$ & 2.37 & --- & 2.33 & 1.99 & 1.68 & 1.31 & 1.10 & 0.951 & 0.842 & 0.748 & 0.668 & 0.621 \\
\hline $\begin{array}{c}\text { Shake with } \\
\text { step in } \\
\text { velocity }\end{array}$ & 2.43 & --- & 2.37 & 2.02 & 1.71 & 1.32 & 1.11 & 0.965 & 0.851 & 0.746 & 0.677 & 0.638 \\
\hline $\begin{array}{c}\text { NEHRP } \\
\text { amplification } \\
\text { factors }\end{array}$ & --- & --- & 2.17 & 2.09 & 1.94 & 1.77 & 1.89 & $1.89 *$ & $1.89 *$ & $1.89 *$ & $1.89^{*}$ & $1.89^{*}$ \\
\hline $\begin{array}{c}\text { Choi and } \\
\text { Stewart } \\
\text { (2005) } \\
\text { amplification } \\
\text { factors, } \\
\text { geometrical } \\
\text { average of } \\
\text { models A1, } \\
\text { A2, A3 }\end{array}$ & --- & 3.31 & 2.51 & 1.90 & 1.62 & 1.44 & 1.32 & 1.22 & 1.15 & 1.09 & $1.09 *$ & $1.09^{*}$ \\
\hline
\end{tabular}

*see text for explanation of choices of cutoffs at high accelerations 


\section{Appendix}

This appendix contains synthetic and observed velocity seismograms for five earthquakes in the Puget Sound region (table 1 and figure 1). The synthetics were derived from the 3D simulations. In fig. 10 we showed how the amplification at $1 \mathrm{~Hz}$ predicted by the simulations were similar, in general, to the observed amplifications, for events 1-4.

The seismograms in this appendix are a representative sampling; not all stations are shown. All of the stations displayed are on stiff soils. The stations are from the Seattle Urban Seismic Array operated by the USGS. All seismograms were bandpass filtered between 0.5 and $1.0 \mathrm{~Hz}$. The lower corner frequency was necessary to remove long-period noise in the observed seismograms. The higher corner frequency was needed to remove the inaccurate portions of the synthetics. Figure A1 is a map of Seattle showing the station locations.

The observed and synthetic seismograms for the Nisqually earthquake are shown in Figure A2. There is generally good agreement in the timing of the $S$-wave between the synthetics and the observed seismograms. In general, the peak velocities of the horizontal components are similar between the observed and synthetic seismograms (also see fig. 8). However, the peak velocities of the east-west component of the synthetics at stations BHD, BRI, and SEW are severely underestimated by the synthetics. This discrepancy may be due to localized bending of the rays not accounted for in the 3D model, or by near-surface scattering of the S-waves which would tend to equalize the peak amplitudes of the two horizontal components. The synthetics at many of the stations in the Seattle basin exhibit basin surface waves following the S-wave that are apparent in the observed seismograms (stations LAP, EVA, HAL). The vertical components of the synthetics often show basin surface waves that are not clearly observed in the data.

Figure A3 displays the observed and synthetic seismograms for the M3.4 aftershock (event 1 in table 1; depth $=50 \mathrm{~km}$ ) of the Nisqually earthquake. In general the peak amplitudes of the synthetics are substantially lower than those of the observed data. We attribute this mostly to using a rise time of $1 \mathrm{sec}$ in the synthetics, which is too short for such a small magnitude event. It is possible that the local magnitude determined for this event underestimates its moment magnitude. At stations EVA, LAP, and CTR the synthetics exhibit the basin surface waves following the Swave arrival that are present in the observed seismograms. The synthetics for stations outside of the Seattle basin (ALK, SEW, WEK) are much simpler than the observed seismograms.

The synthetic and observed seismograms for event 2 (table 1) are depicted in fig. A4. This is a relatively shallow (depth $=16 \mathrm{~km}$ ) earthquake that was located to the southwest of Seattle. Now stations LAP, SEU, and THO exhibit basin surface waves on the synthetics that are also seen in the data. However, the inferred surface waves in the observed seismograms arrived a few seconds before their arrival predicted in the synthetics.

Figure A5 contains the synthetics and observed seismograms for event 3 (table 1), which is a deep event to the west of Seattle. The synthetics for stations ALO, CTR, EVA, LAP, SEU, THO, and MCG display basin surface-wave arrivals after the S-waves. These surface waves are clearly present in the observed seismograms at LAP and THO, but are less distinct at the other stations. The synthetic seismograms at ICR, SEU, and SEW predicted a strong arrival near the end of the time window used for the synthetics. This late arrival is not observed in the data at these stations.

Figure A6 shows the synthetics and observed recordings for event 4 (table 1), a deep event to the northwest of Seattle. The observed seismograms at station ALK, outside the Seattle basin, contain a second arrival after the $\mathrm{S}$-wave. This arrival is not present in the synthetics. Strong arrivals after the S-wave that are observed at stations THO and UNK are not evident in the synthetics at these stations. 


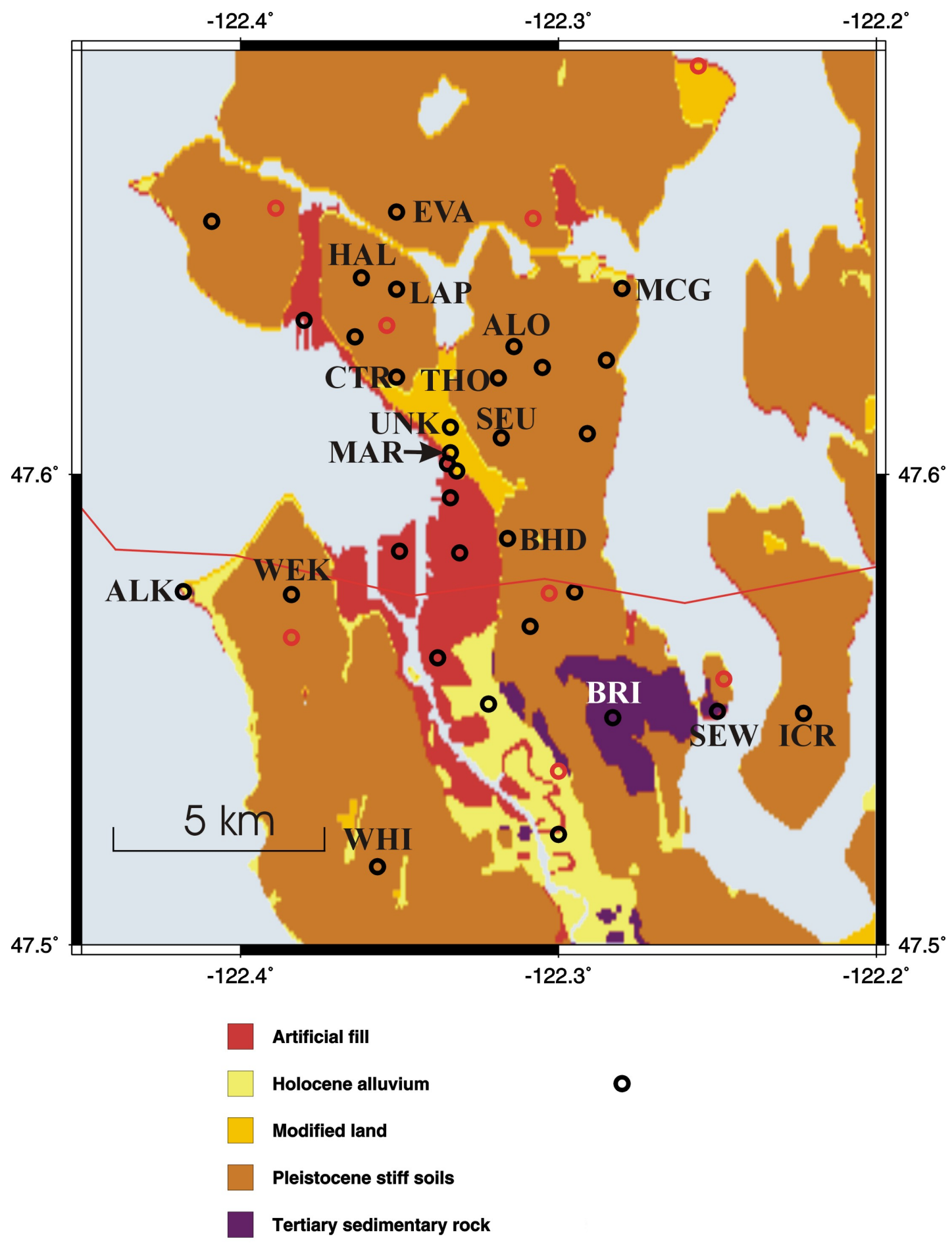

Figure A1. Stations from the Seattle Urban Seismic Array (black circles) and the Pacific Northwest Seismic Array (red circles). Stations whose seismograms are shown in the appendix are labeled. Surficial geology from Waldron and others, 1962. 
ALK
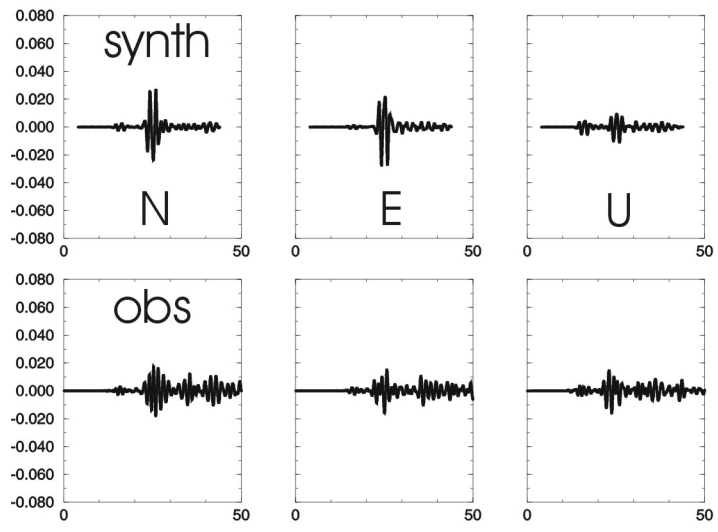

$\mathrm{BHD}$

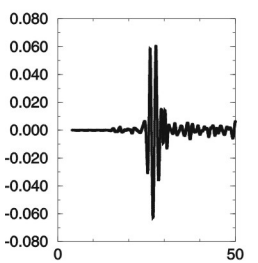

0.080
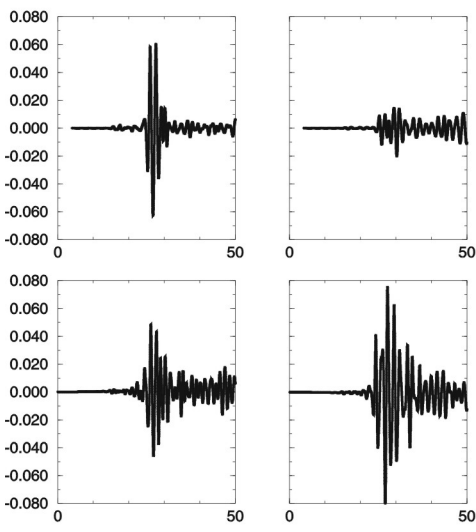

CTR

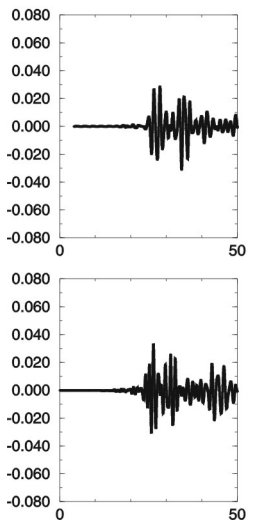

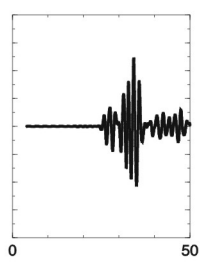

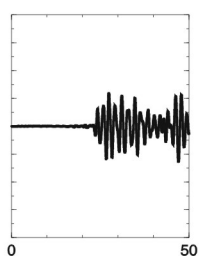

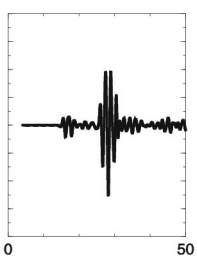
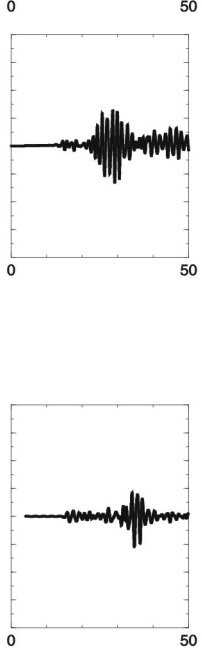
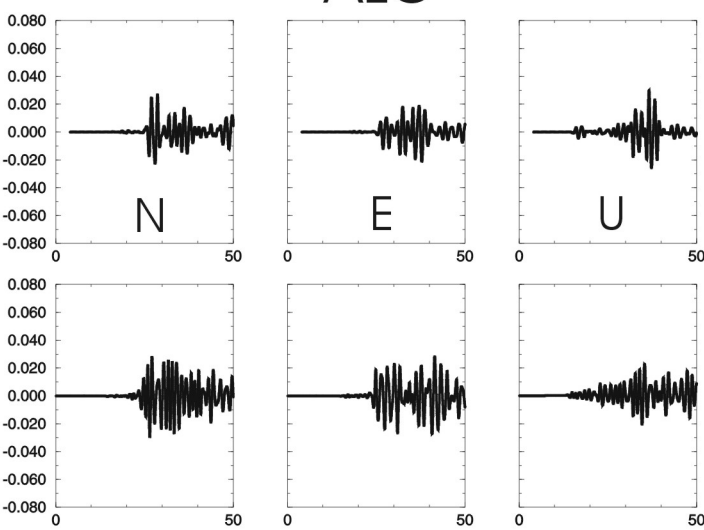

BRI
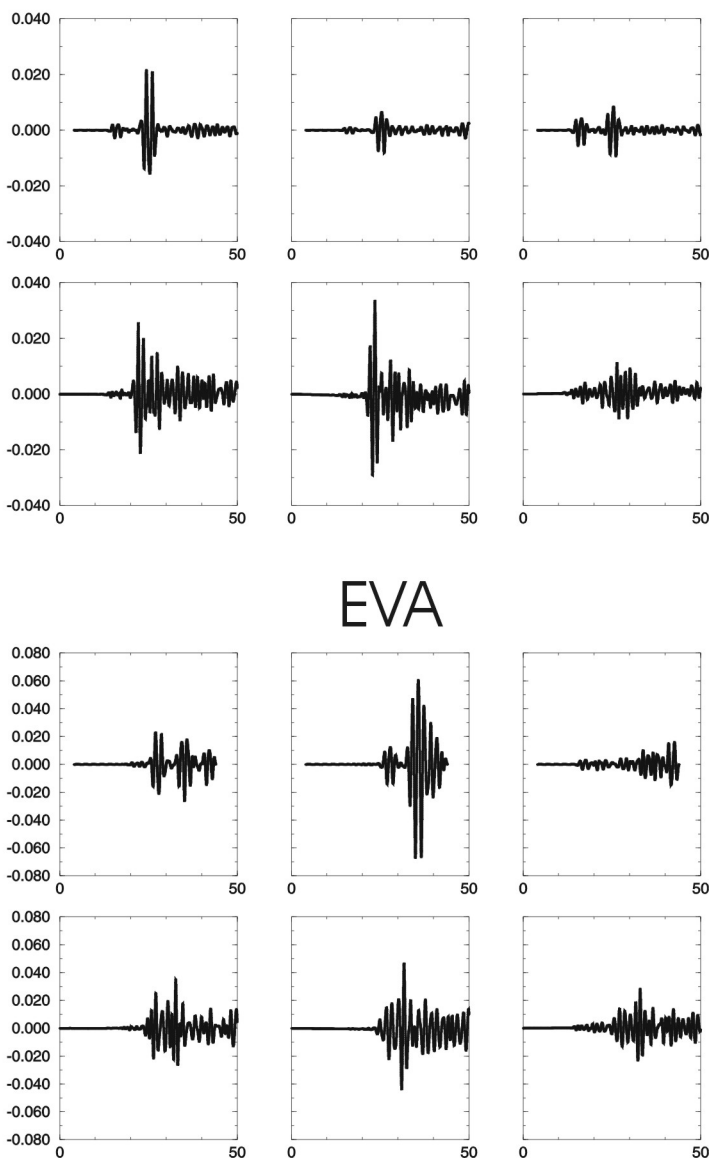

Figure A2. Synthetic (synth) and observed (obs) seismograms for the M6.8 Nisqually earthquake. For each station, the synthetics are in the top row, the observed seismograms are in the bottom row. From left to right, the components are east-west, north-south, and up-down. The time on the horizontal axis is in seconds after the origin time. The vertical axis is velocity in $\mathrm{m} / \mathrm{sec}$, with the same scale used for the synthetics and data. The data and synthetics are bandpass filtered from $0.5-1.0 \mathrm{~Hz}$. 

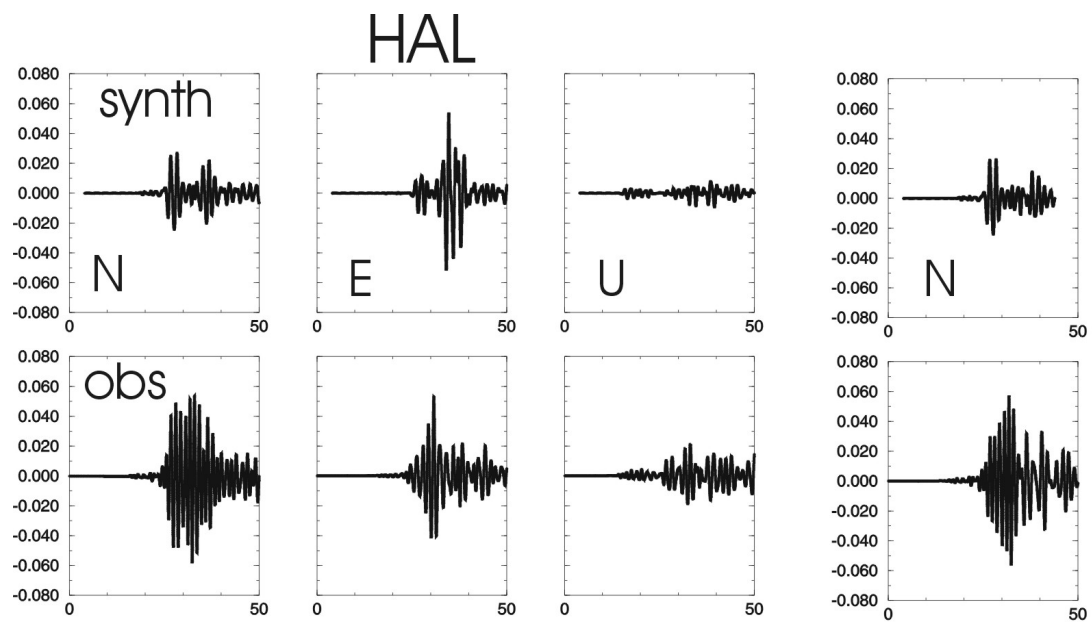

LAP
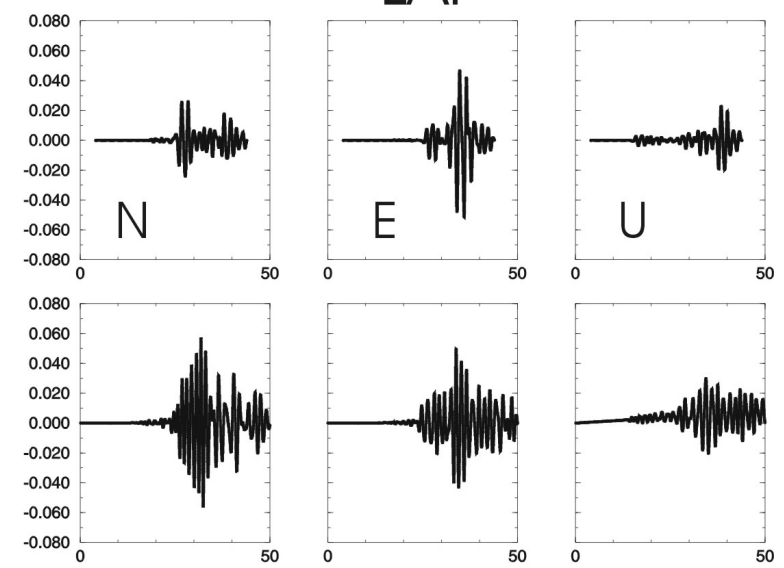

SEW
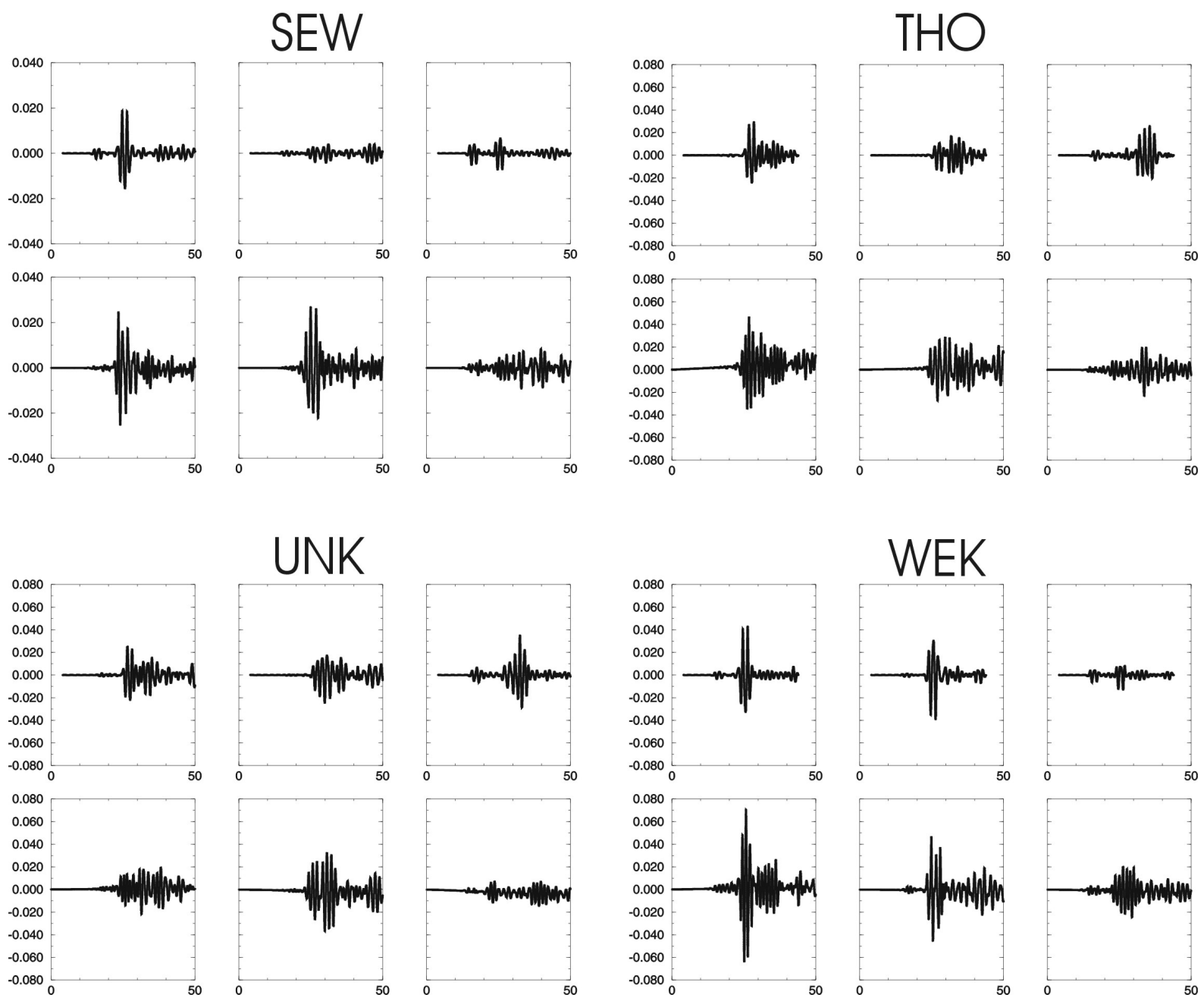

Figure A2 continued. 

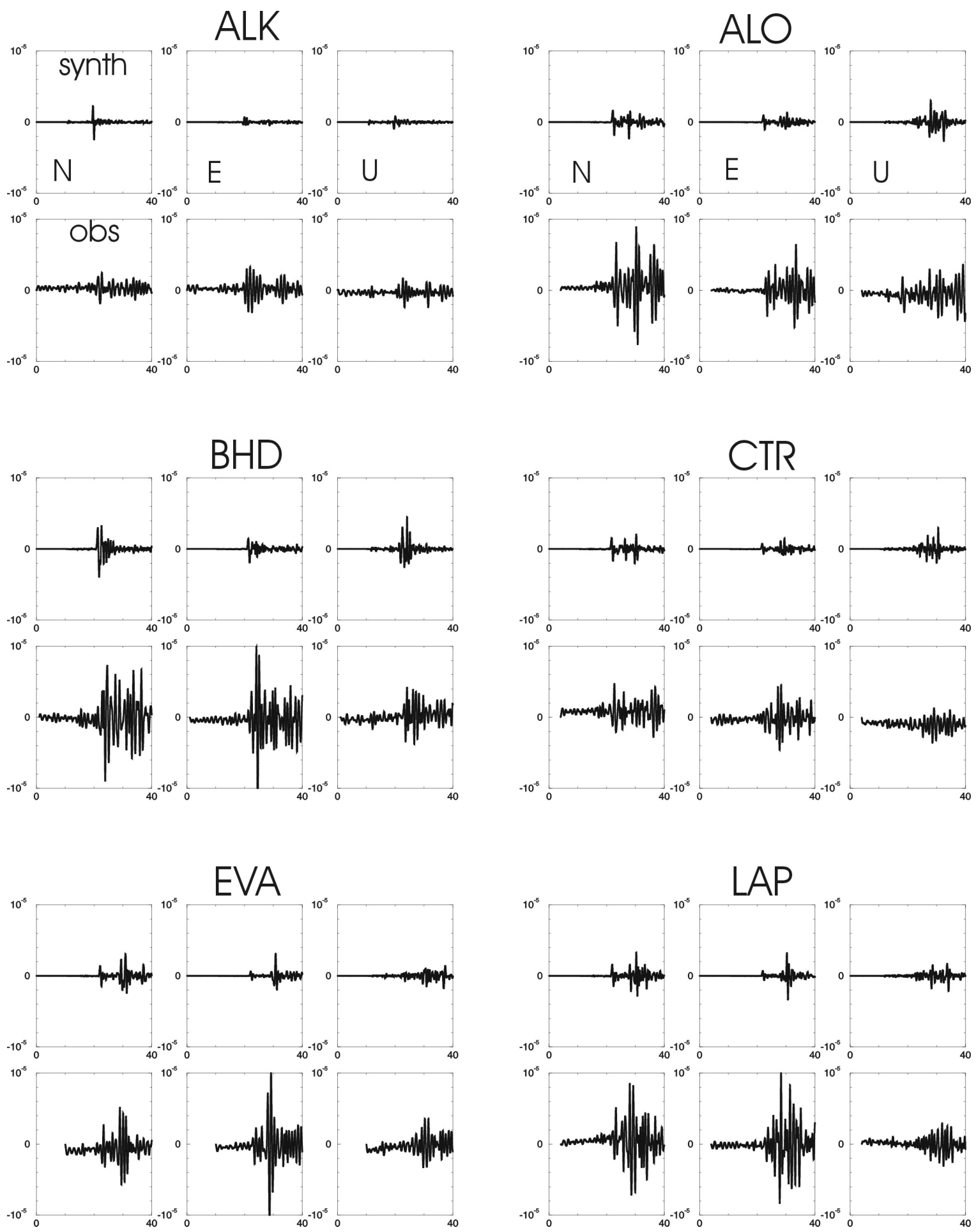

Figure A3. Synthetic (synth) and observed (obs) seismograms for event 1. 

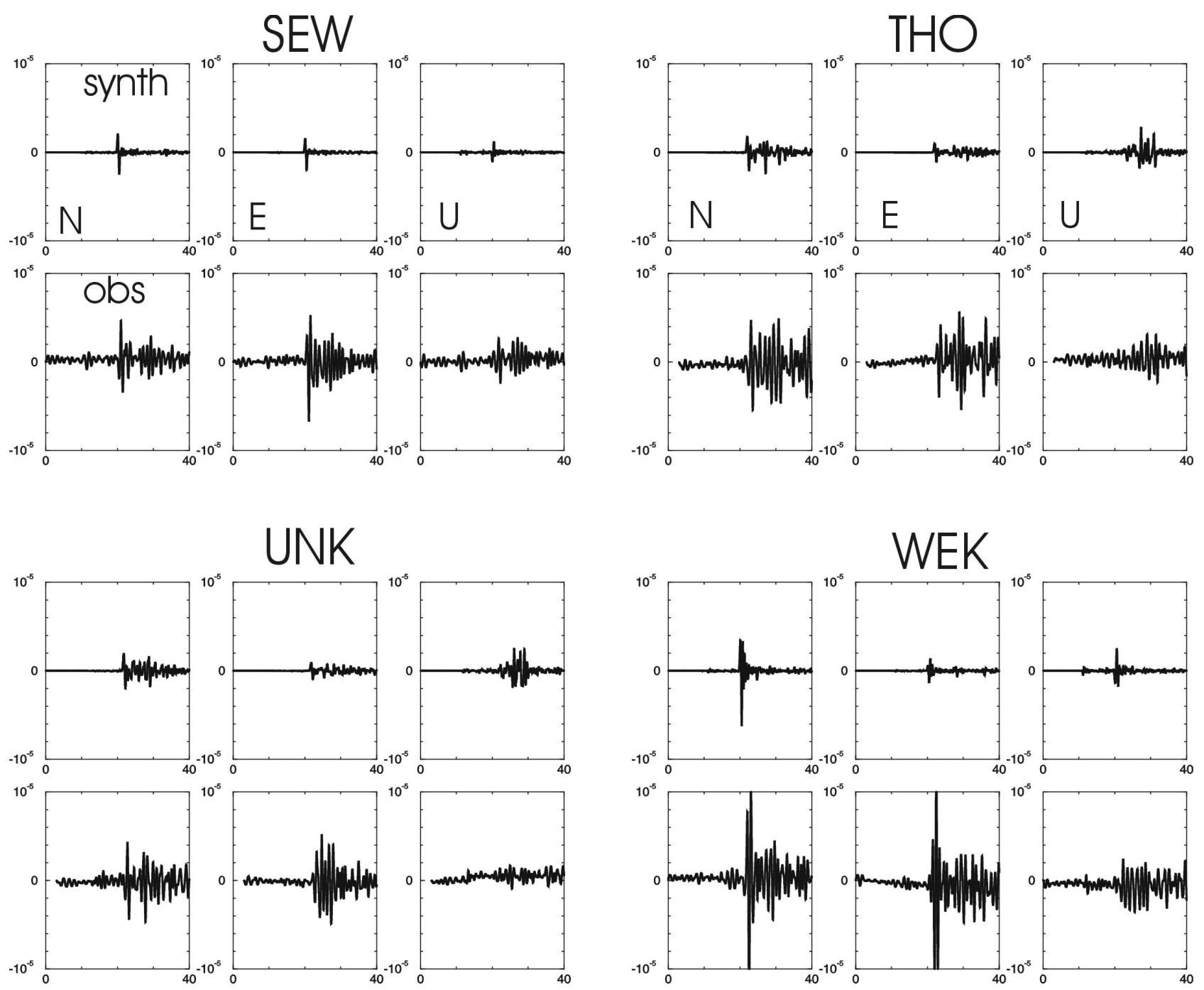

Figure $A 3$, continued. 
$\mathrm{ALO}$
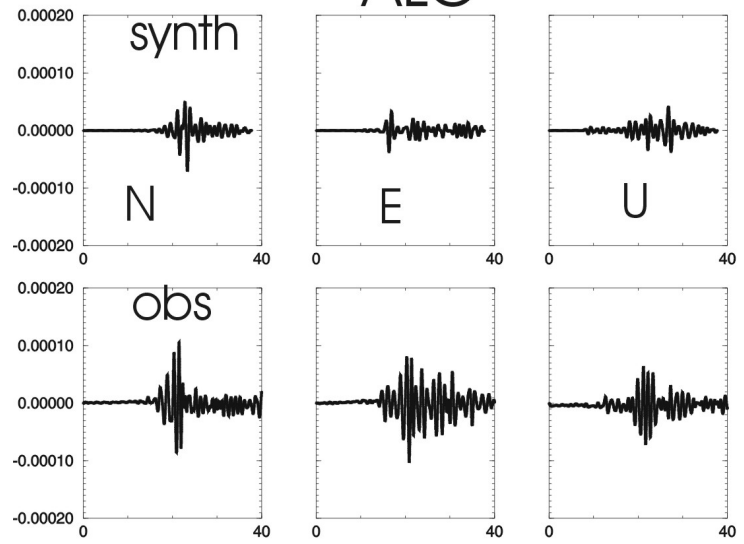

BRI
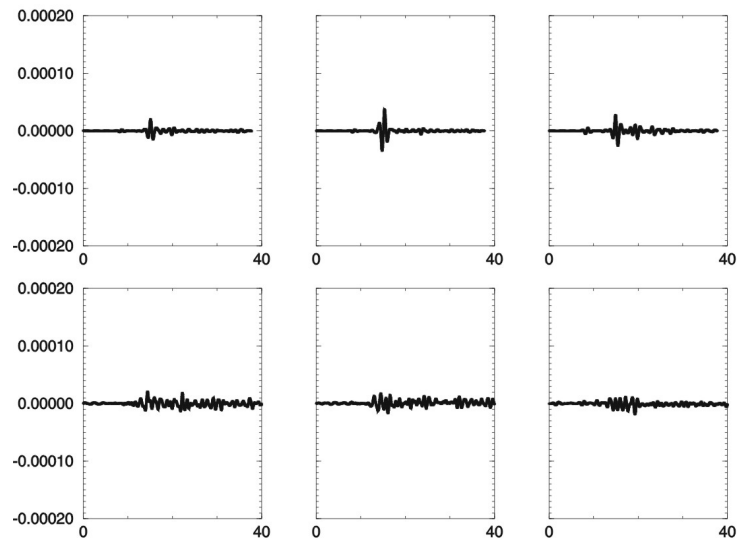

EVA
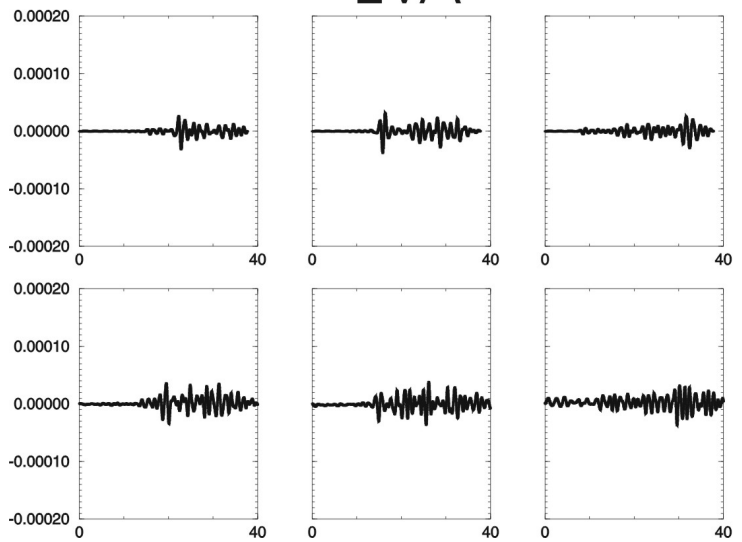

$\mathrm{BHD}$
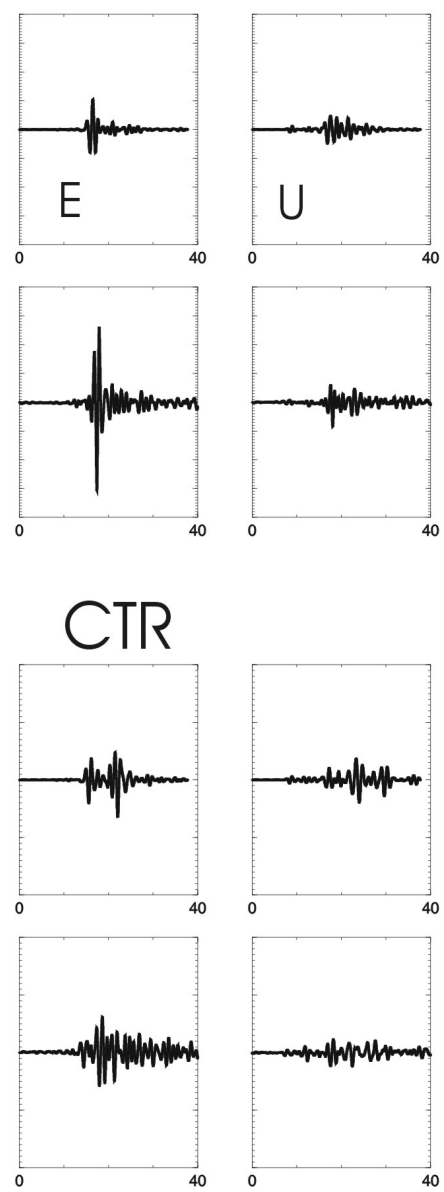

ICR
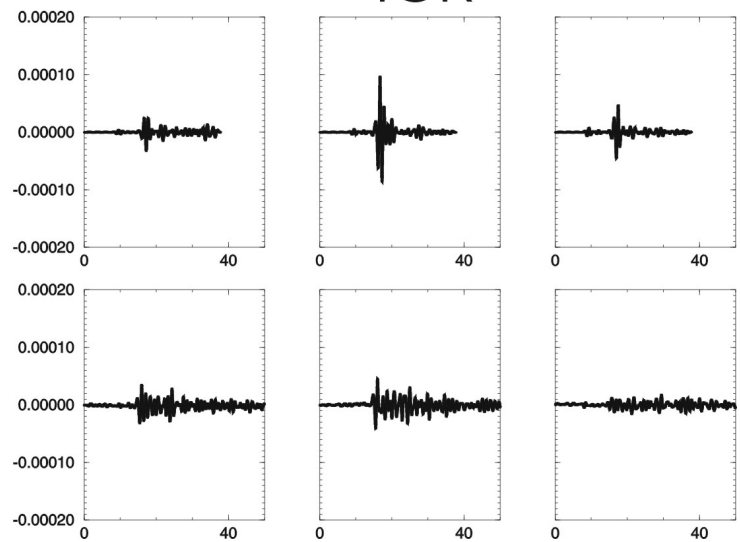

Figure A4. Synthetic (synth) and observed (obs) seismograms for event 2. 
LAP
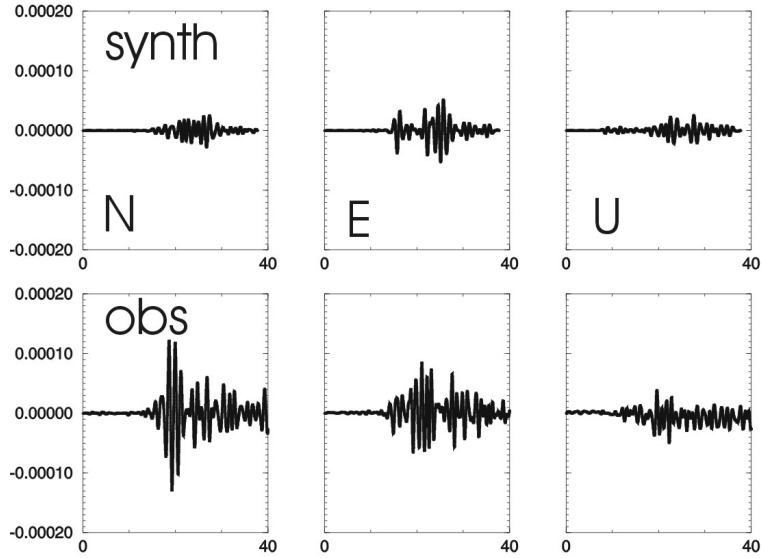

MCG
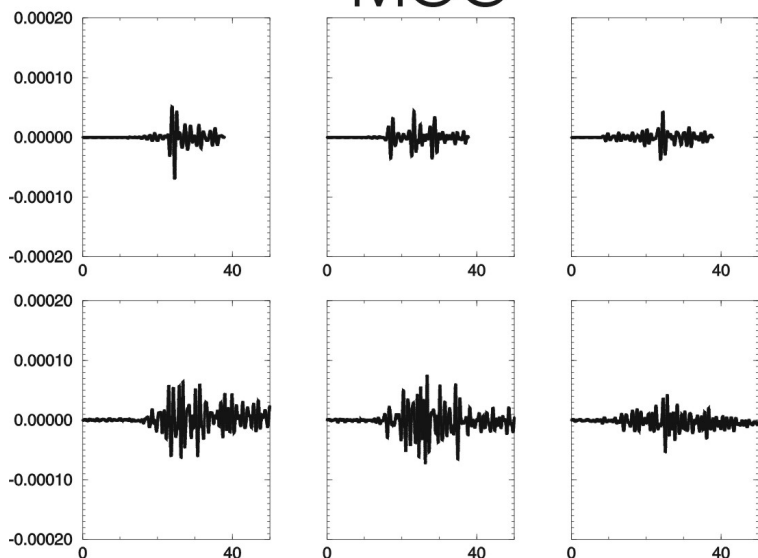

SEW

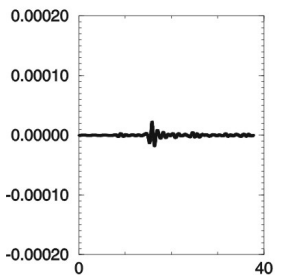

0.00020

0.00010

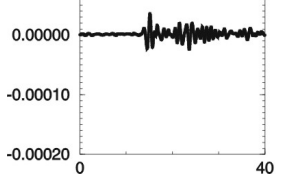

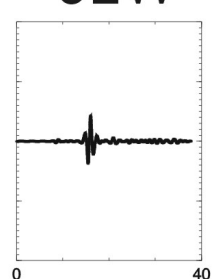

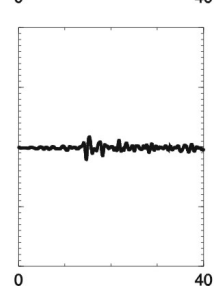

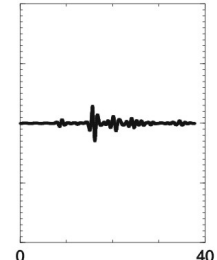

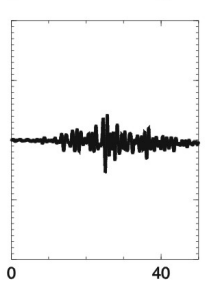

40

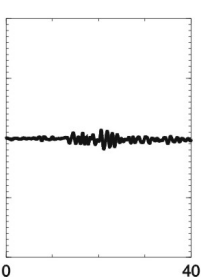

MAR
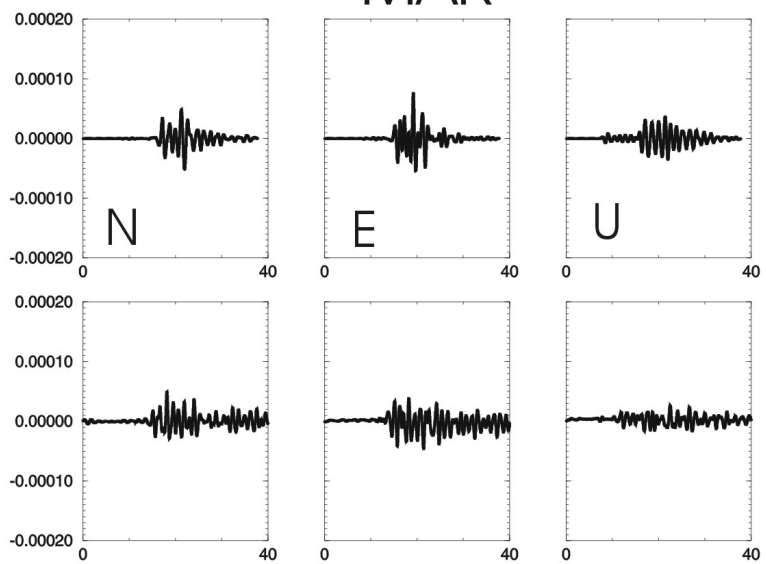

SEU
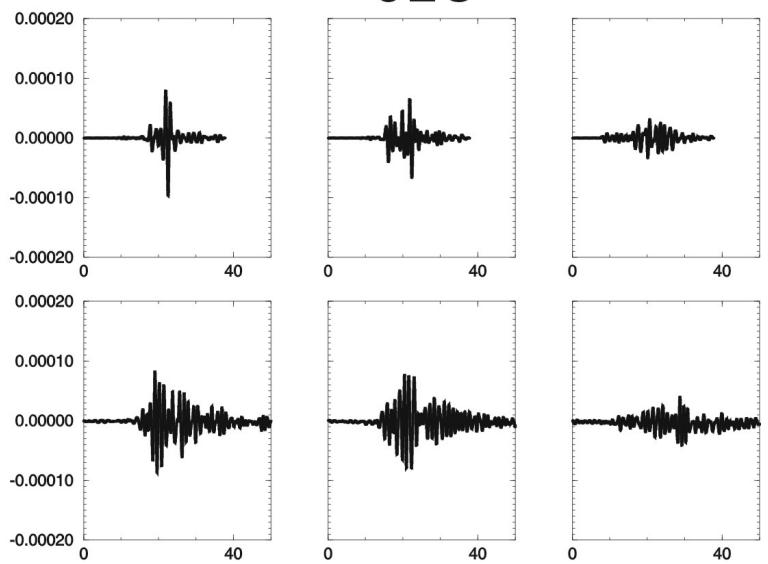

\section{$\mathrm{THO}$}
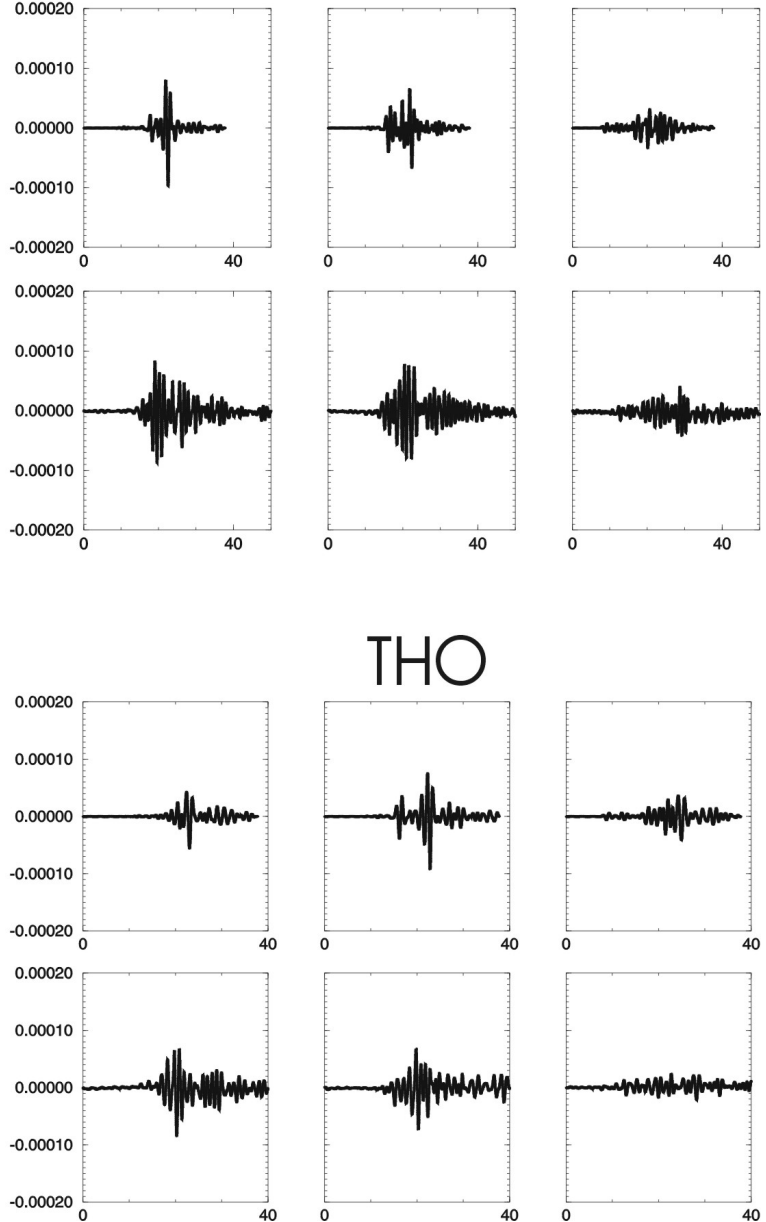

40

Figure A4, continued. 

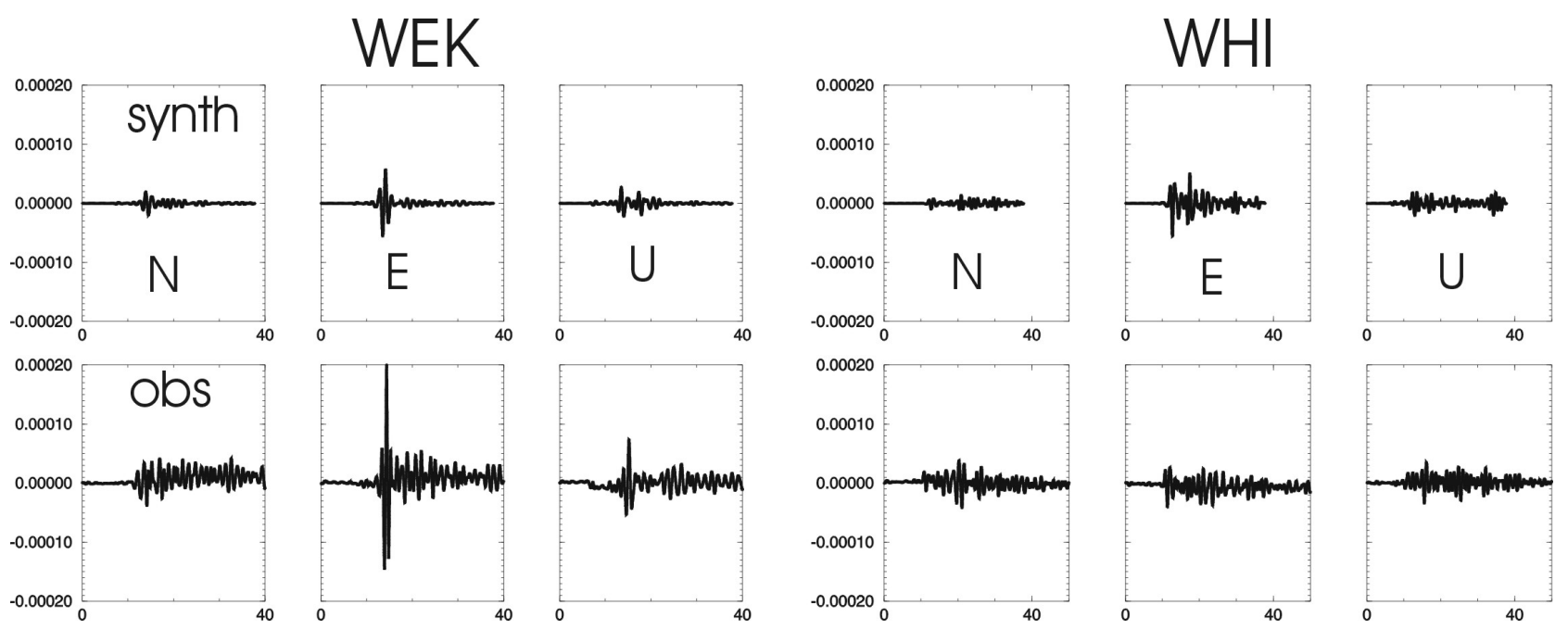

Figure A4, continued. 

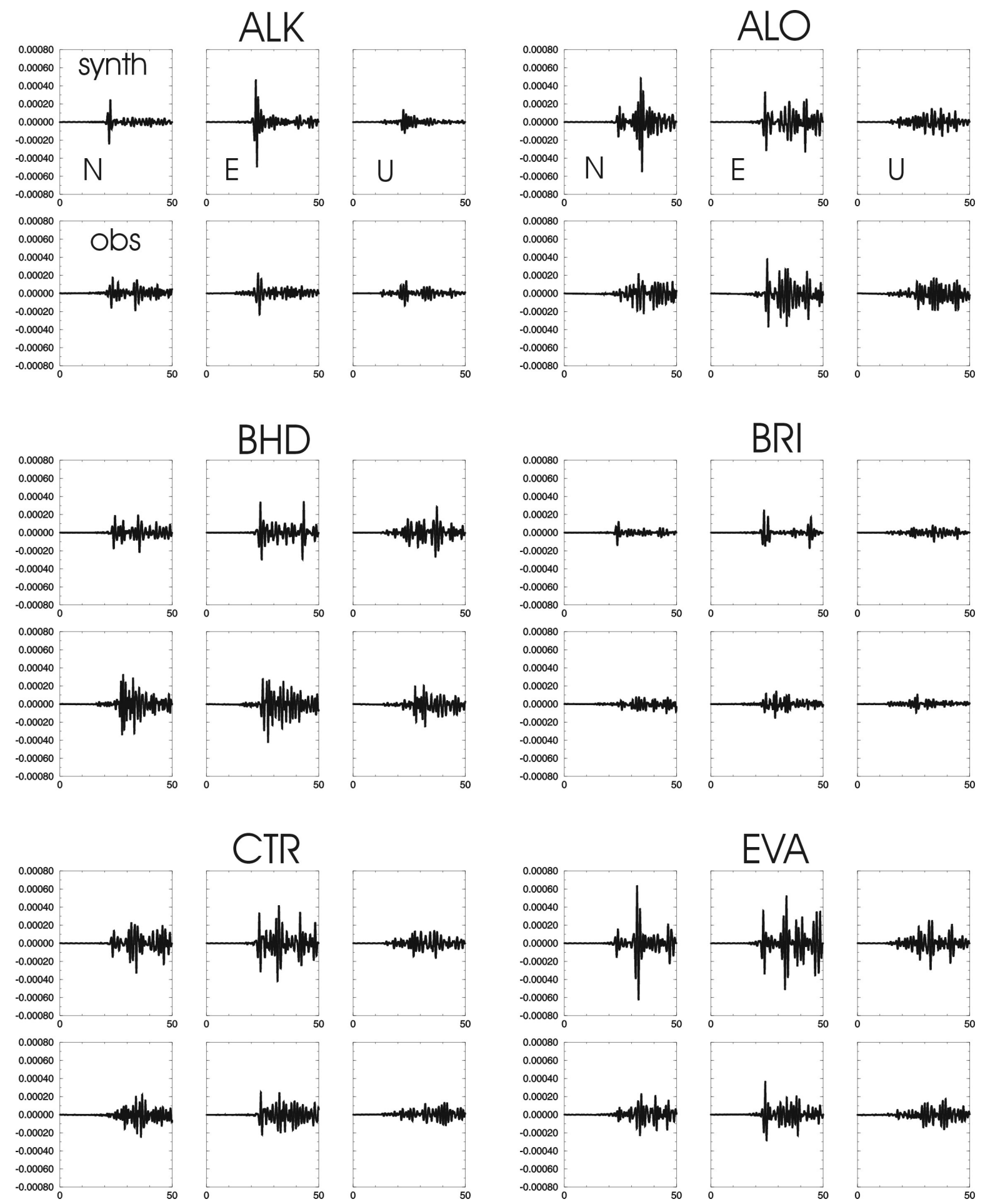

Figure A5. Synthetic (synth) and observed (obs) seismograms for event \#3. 

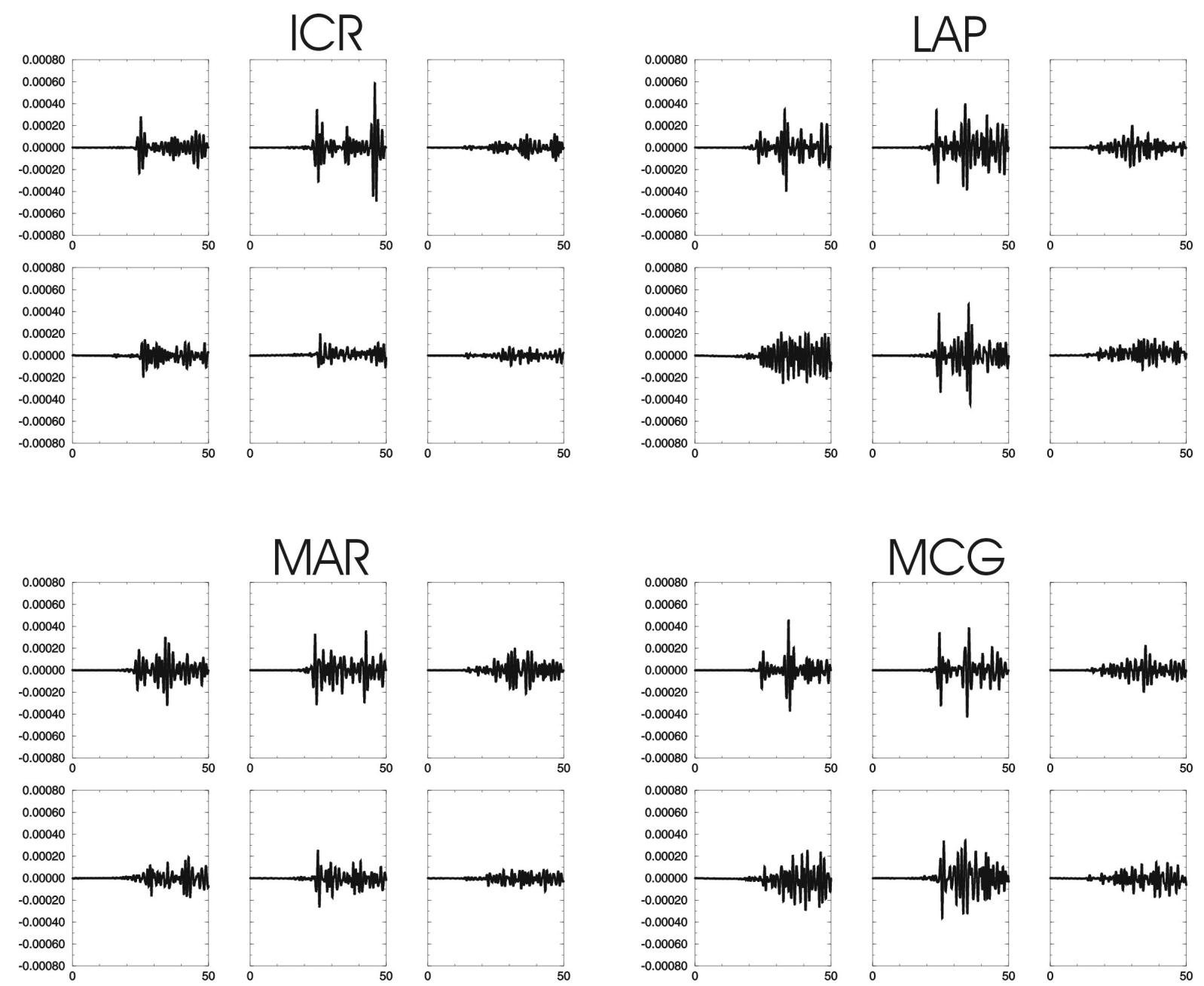

SEU
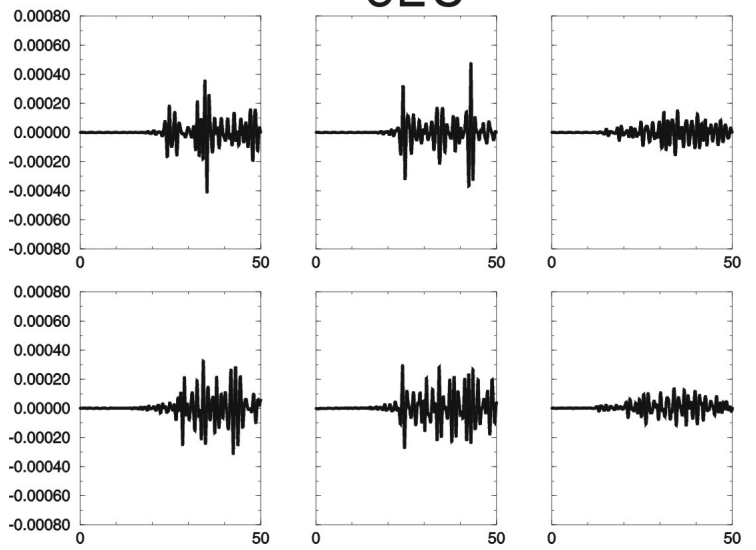
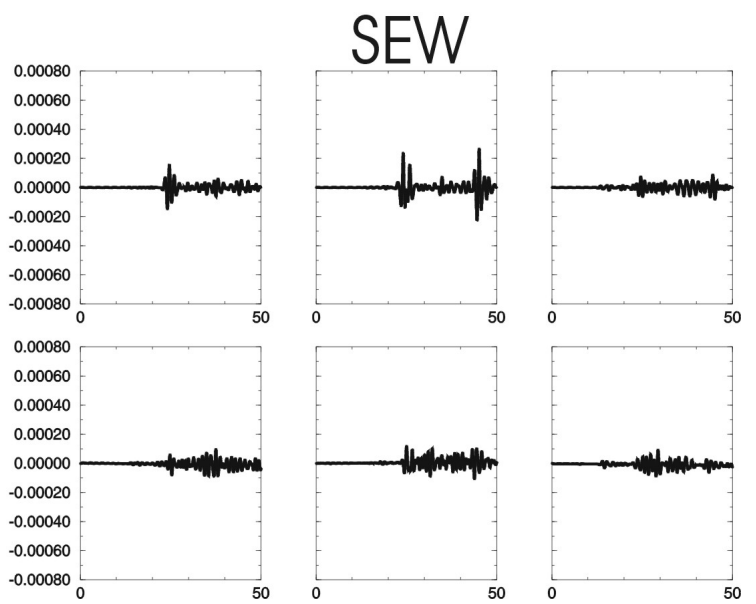

Figure A5, continued. 

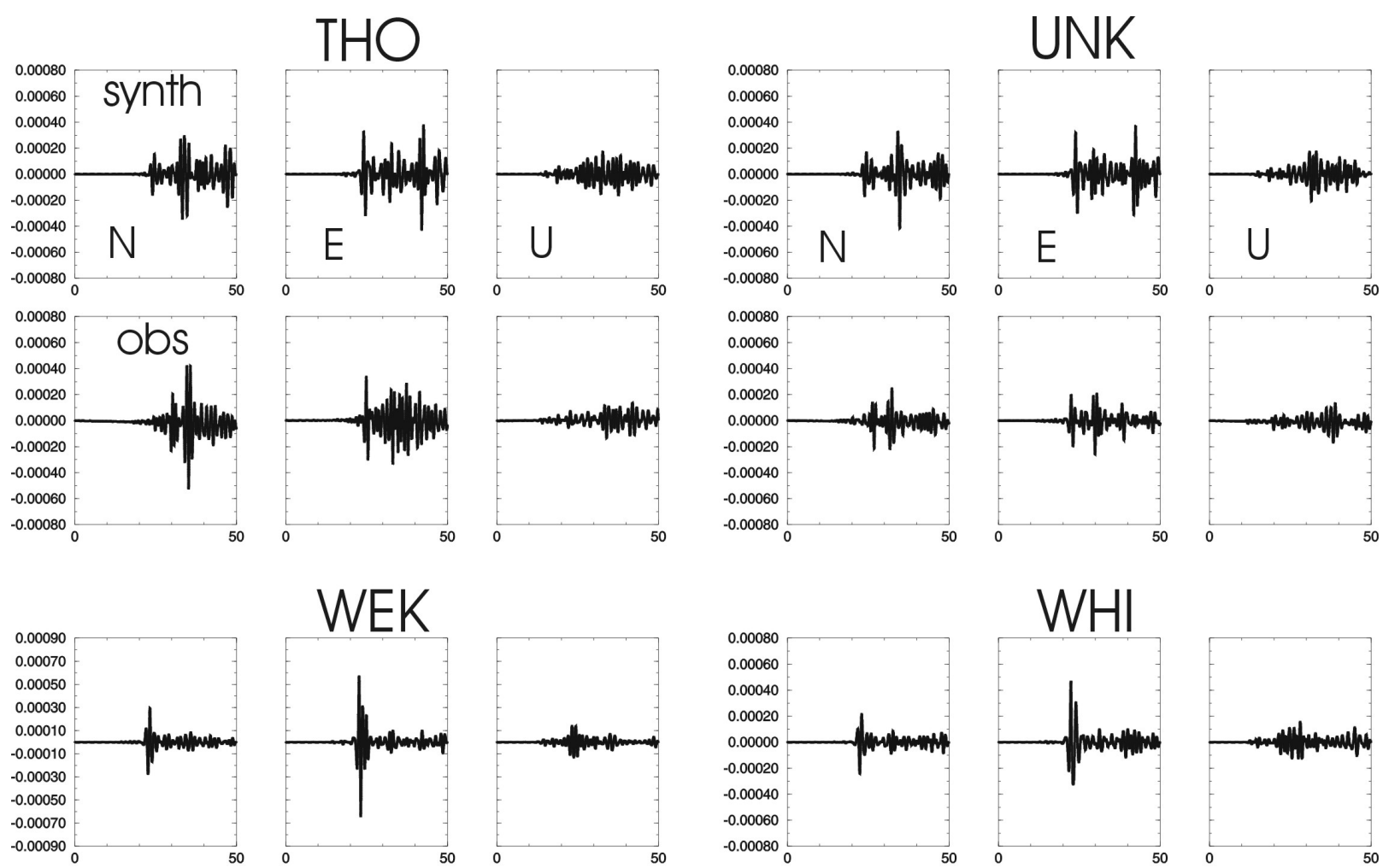

0.00070

0.00050

0.00030 -

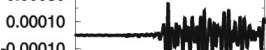

$-0.00030$

$-0.00050$

$-0.00070$
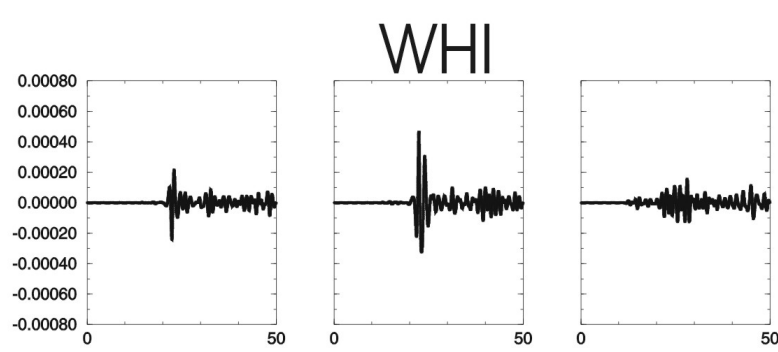

$-0.00090$
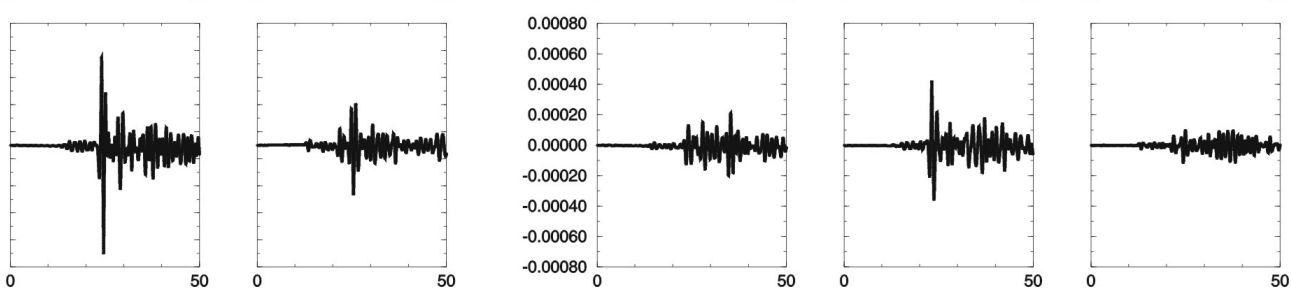

Figure $\mathrm{A} 5$, continued. 


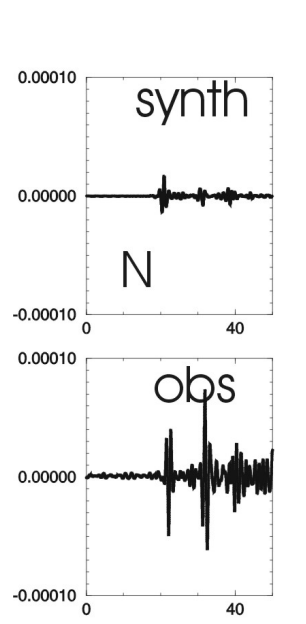

ALK
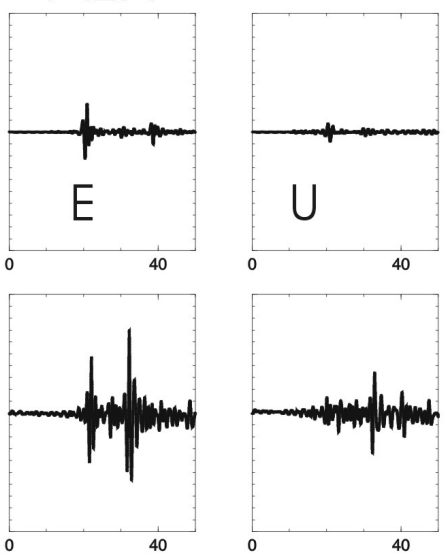

EVA

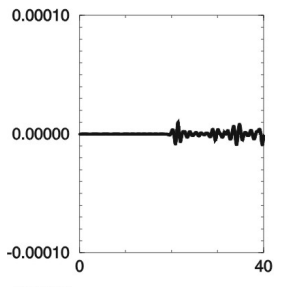

0.00010

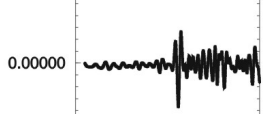

$-0.00010$
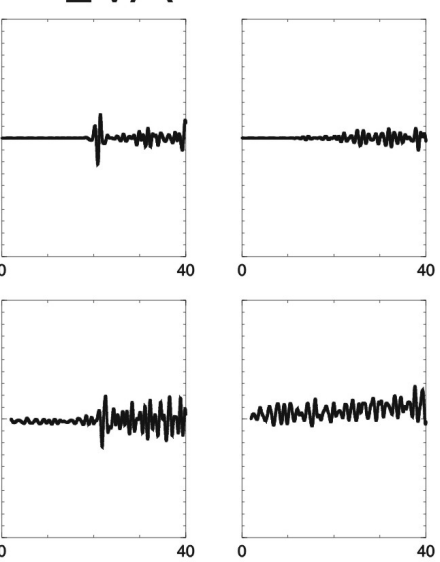

SEW
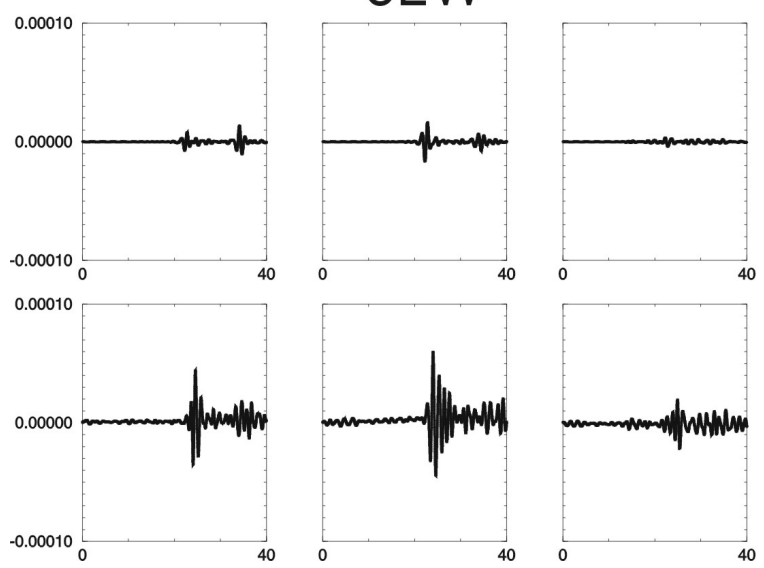
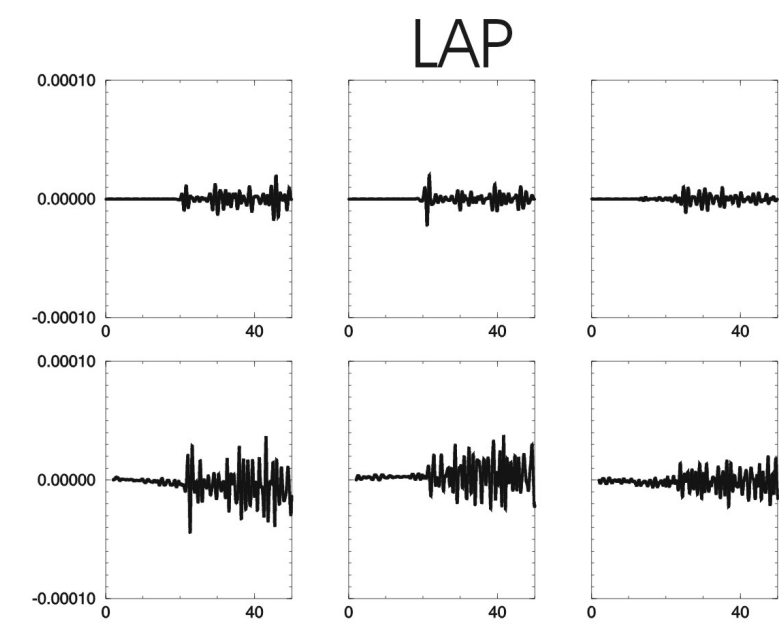

$\mathrm{BHD}$

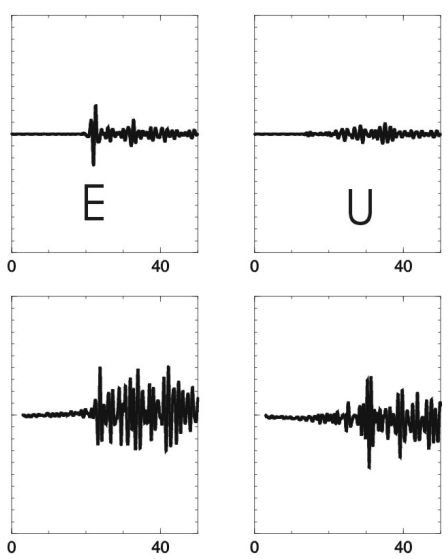

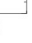
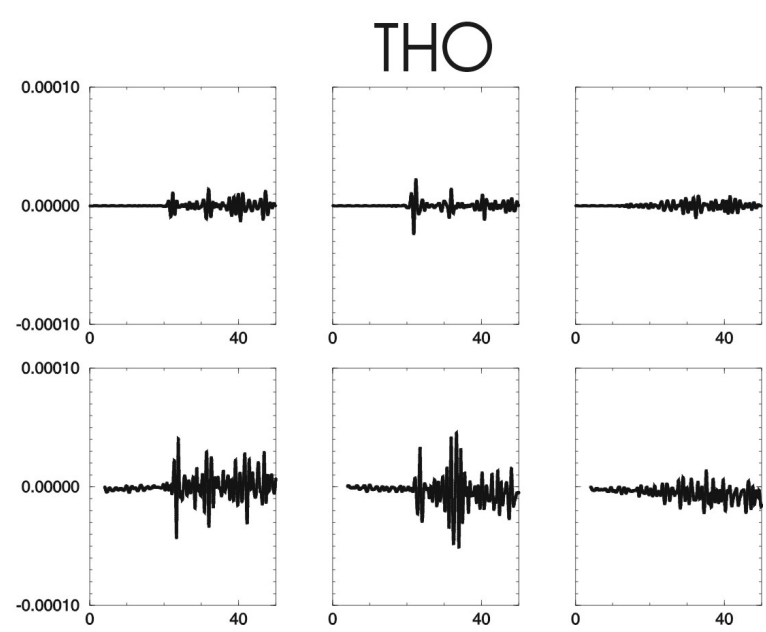

Figure A6. Synthetic (synth) and observed (obs) seismograms for event 4. 

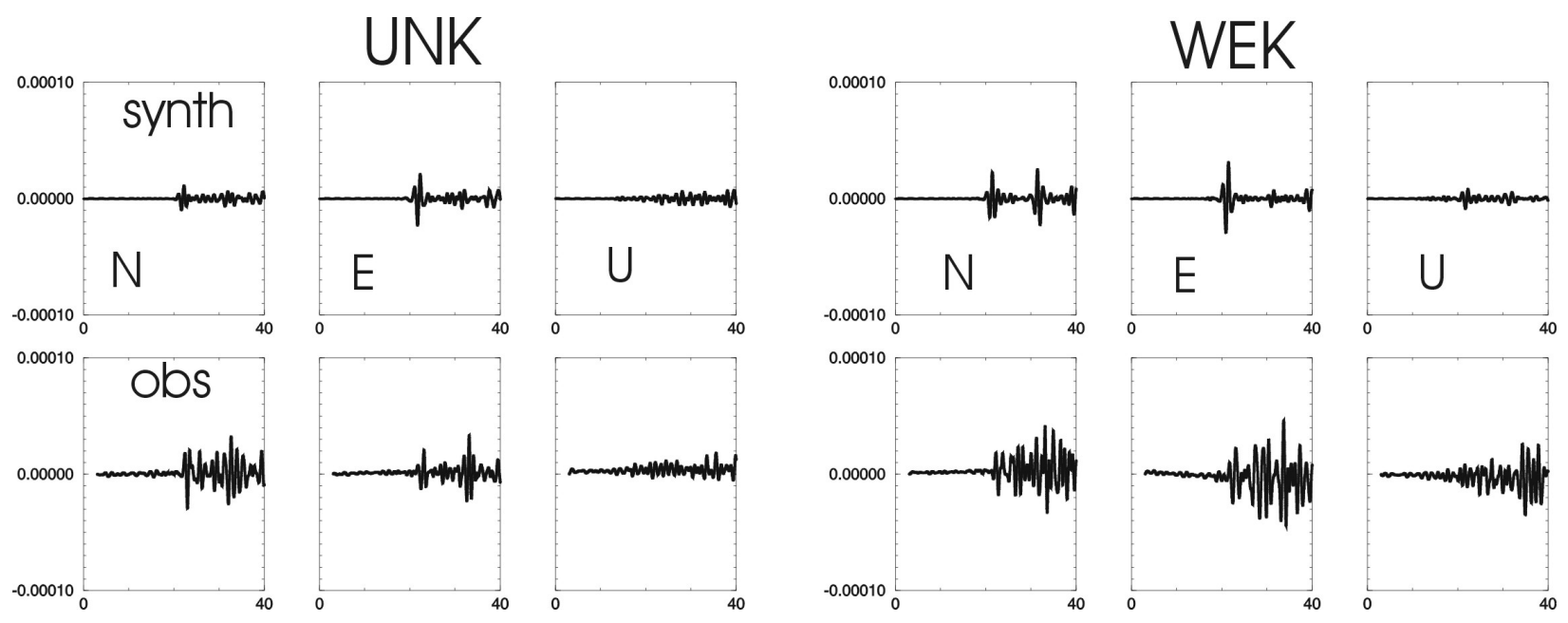

Figure $\mathrm{A6}$, continued. 